\title{
Forensic, Archaeological and Related Application of Inductively Coupled Plasma Mass Spectrometry
}

Xinya Zhang

West Virginia University

Follow this and additional works at: https://researchrepository.wvu.edu/etd

\section{Recommended Citation}

Zhang, Xinya, "Forensic, Archaeological and Related Application of Inductively Coupled Plasma Mass Spectrometry" (2012). Graduate Theses, Dissertations, and Problem Reports. 4944.

https://researchrepository.wvu.edu/etd/4944

This Dissertation is protected by copyright and/or related rights. It has been brought to you by the The Research Repository @ WVU with permission from the rights-holder(s). You are free to use this Dissertation in any way that is permitted by the copyright and related rights legislation that applies to your use. For other uses you must obtain permission from the rights-holder(s) directly, unless additional rights are indicated by a Creative Commons license in the record and/ or on the work itself. This Dissertation has been accepted for inclusion in WVU Graduate Theses, Dissertations, and Problem Reports collection by an authorized administrator of The Research Repository @ WVU.

For more information, please contact researchrepository@mail.wvu.edu. 


\title{
Forensic, Archaeological and Related Application of Inductively Coupled Plasma Mass Spectrometry
}

\author{
Xinya Zhang
}

\author{
Dissertation Submitted to the \\ C. Eugene Bennett Department of Chemistry \\ at West Virginia University \\ in partial fulfillment of the requirements \\ for the degree of
}
Doctor of Philosophy
in
Chemistry

\author{
Suzanne C. Bell, Ph.D., Chair \\ Patrick S. Callery, Ph.D. \\ Harry O. Finklea, Ph.D. \\ Amy J. Hirshman, Ph.D. \\ Keith B. Morris, Ph.D. \\ Department of Chemistry
}
Morgantown, West Virginia
2012

Keywords: ICP-MS, Chemometrics, Archaeological Pottery, Provenience, Gunshot Residue, Isotope Ratio, Hair

Copyright 2012 Xinya Zhang 


\title{
Abstract \\ Forensic, Archaeological and Related Application of Inductively Coupled Plasma Mass Spectrometry
}

\author{
Xinya Zhang
}

Inductively coupled plasma spectrometry (ICP-MS) is a powerful analytical instrument that can be applied to multiple disciplines for trace elements detection. In the first stage of this research, ICP-MS was used to group archaeological pottery sherds based on the compositional information obtained. Provenience of the pottery was evaluated using multivariate analysis. Results were compared with those obtained on the same data set using neutron activation analysis (NAA). It was found that the groups generated in this study were comparable to the previous ones, and more details within groups were observed. In the second stage of this research, ICP-MS was applied to a current forensic problem, the characterization of gunshot residue (GSR). The technique was found to be useful in comparison between shooters and non-shooters using inorganic GSR, mainly antimony, barium, and lead. Not only is the concentration on shooter's hand higher, but also the dominant element is different from nonshooters. Lead isotope ratio can be determined by ICP-MS and assist in the differentiation of handguns and ammunitions. Two handguns and four ammunitions used in this study were differentiated by the biplot of mean of lead isotope ratio 208/206 against lead concentration. In the final stage of this research, ICP-MS was used to determine the concentration of inorganic elements in hair collected from mining and control areas. This work was done in concert with the Department of Community Medicine at the WVU Health Sciences Center. A unique aspect of this work was the extremely small sample size available for analysis. The results showed a depletion of chromium, manganese and iron, and an enrichment of aluminum, zinc, and arsenic in samples from mining area. Similar patterns of elemental concentration were also found in mining versus control areas and cancer versus non-cancer groups. 


\section{Dedication}

To my parents (Daoli Zhang and Junlan Ding), my husband (Zhongyuan Zha), and to all who have helped me along the way. 


\section{Acknowledgments}

I would like to acknowledge:

Dr. Suzanne Bell, for her help, advice, mentorship, support, and friendship

Dr. Amy Hirshman, for her help, support, and samples (Chapter 2)

Dr. Michael Hendryx, for his support and samples (Chapter 4)

Mr. Michael Bell, for his help and advice on the ICP-MS

Mr. Akash Munshi from Detection Limits, for his training on the ICP-MS

members of my committee, Dr. Suzanne Bell, Dr. Patrick Callery, Dr. Harry Finklea, Dr. Amy Hirshman, and Dr. Keith Morris for taking the time to review this work

members of the Bell research group, Rona Nishikawa, Jordan Moran, and Holly McCall, for reading this work and all the help along the way; Lucy Oldfield, Jim Arndt, Stephanie Martindale, Corey Nida, Lee Greenawald as well as undergraduate members, Stephen Raso, and Brittany Yeager for their assistance and support

and past members of the Bell research group, Amy Aylor, Melissa Ely, Josh Gunn, Jennifer Mercer, and Heidi Nawrocki for their support.

This material is based upon work supported by the WVU ARTS Program and the US Department of Defense, Battlefield Forensics Program, \#HQ0034-11-C-0038, as well as Department of Community Medicine at WVU. 


\section{Table of Contents}

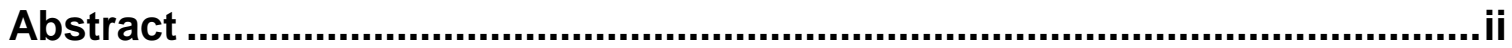

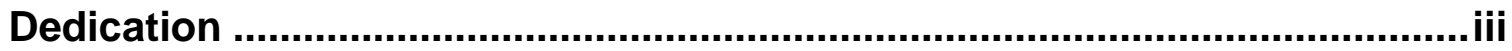

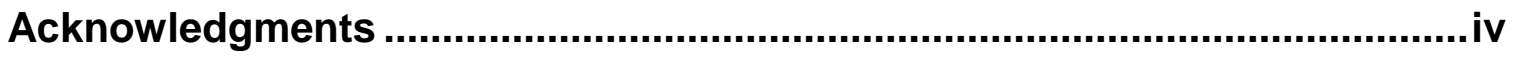

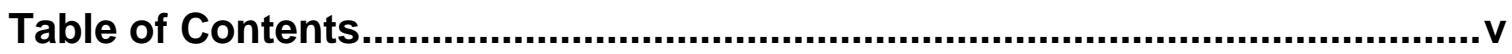

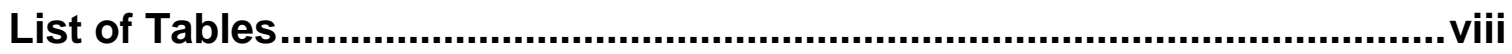

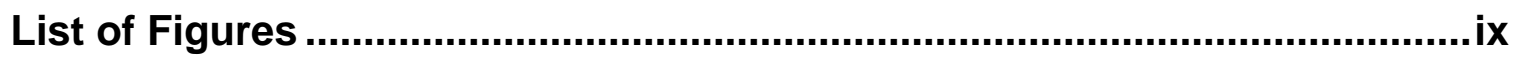

List of Abbreviations, Symbols/Nomenclature................................................

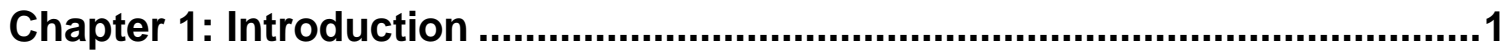

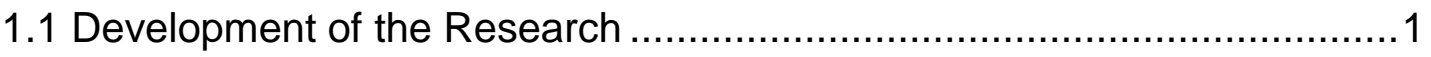

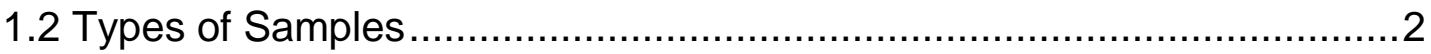

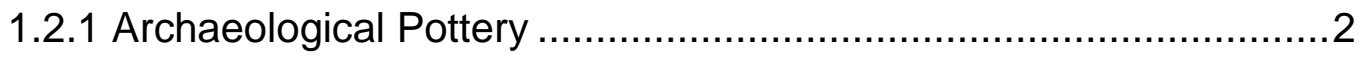

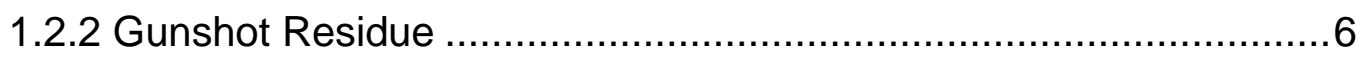

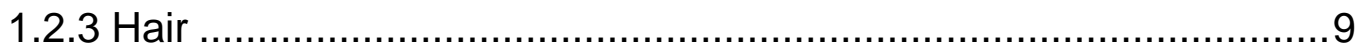

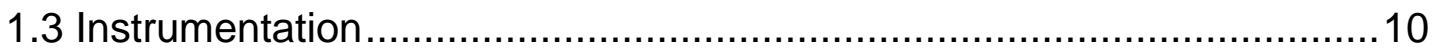

Chapter 2: Application of ICP-MS for Characterization of Archaeological

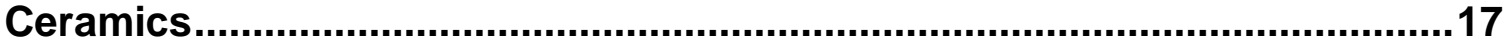

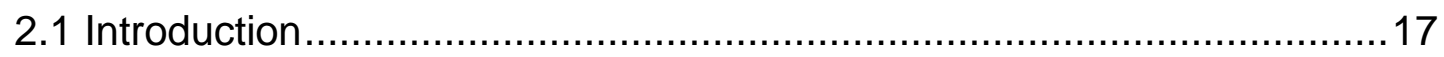

2.1.1 Analytical Consideration....................................................... 17

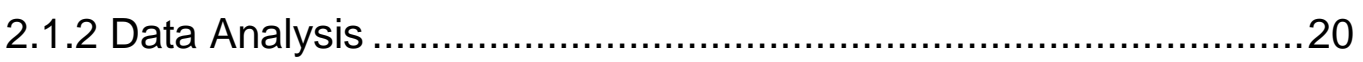

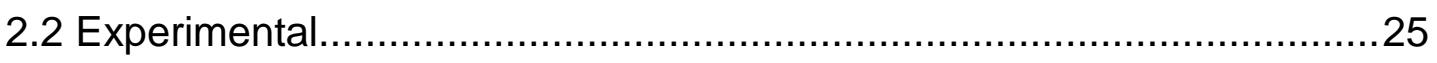

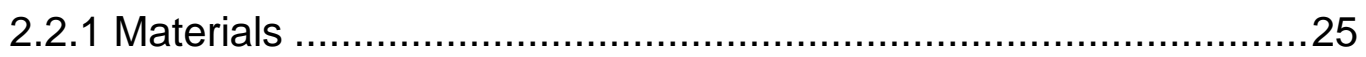

2.2.2 Sample Preparation ..........................................................26

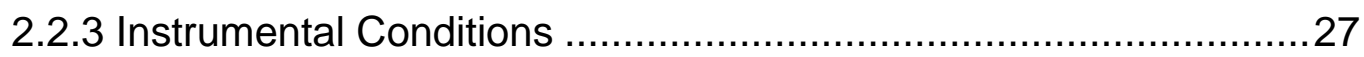

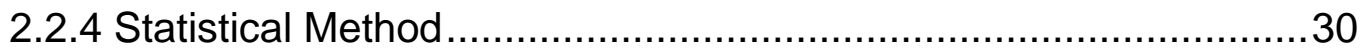

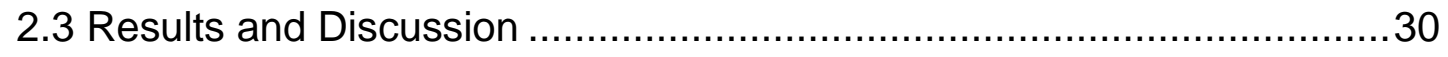




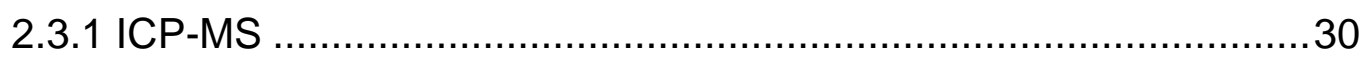

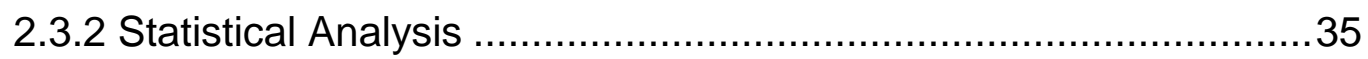

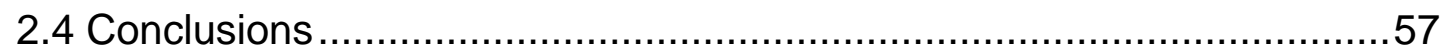

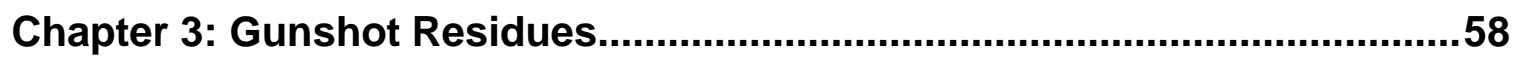

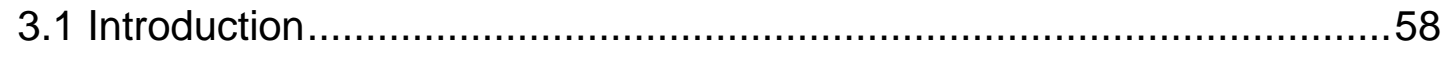

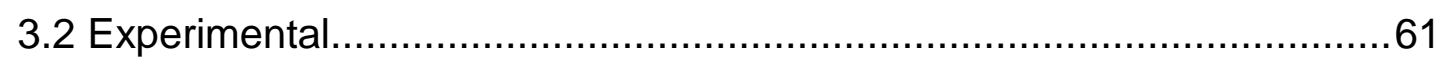

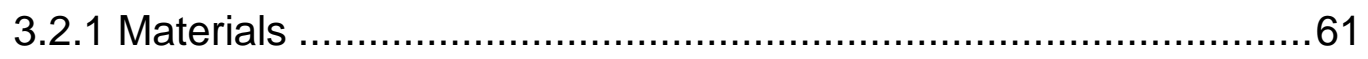

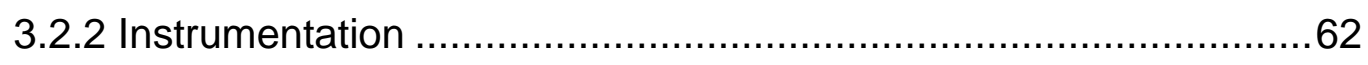

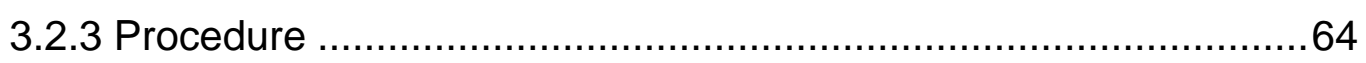

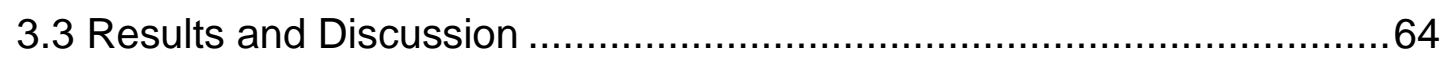

3.3.1 Comparison between Shooter and Non-shooter's Hand Based on

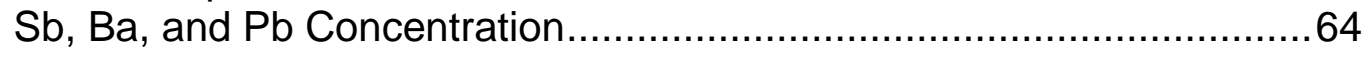

3.3.2 Lead Isotope Study on GSR Samples......................................78

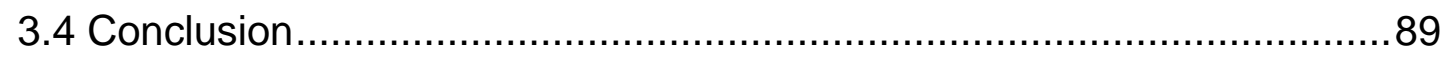

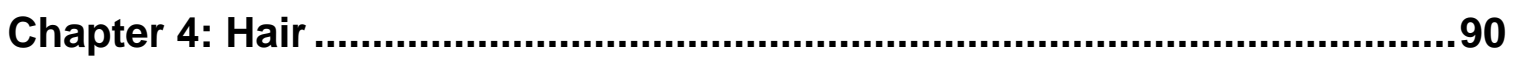

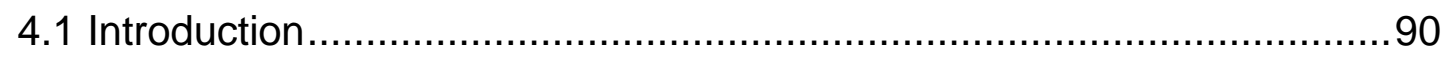

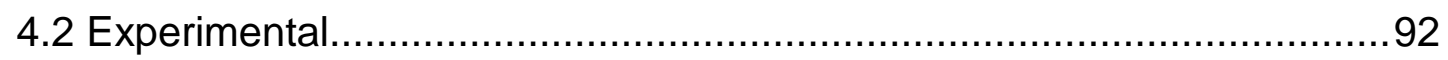

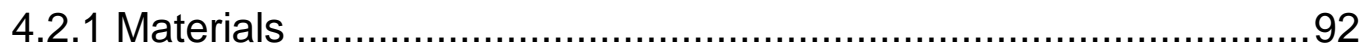

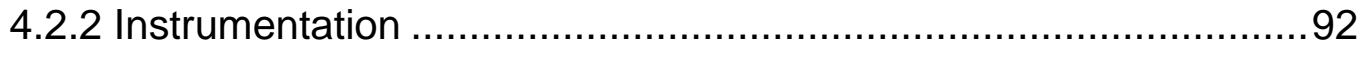

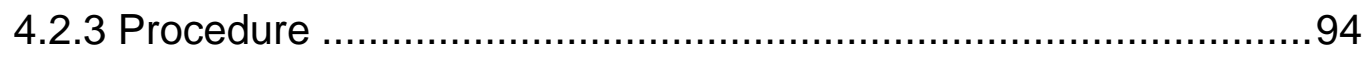

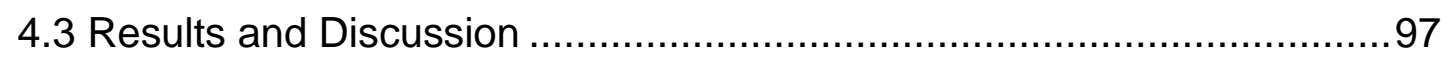

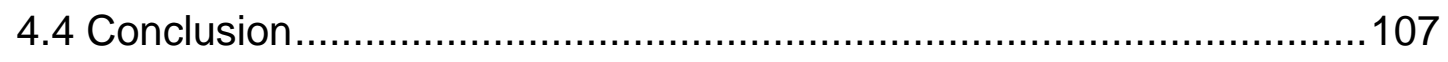

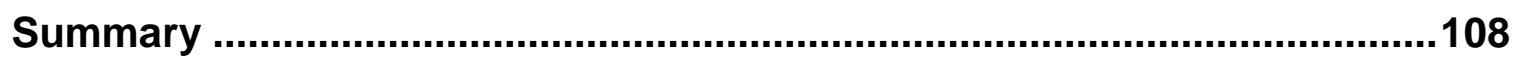

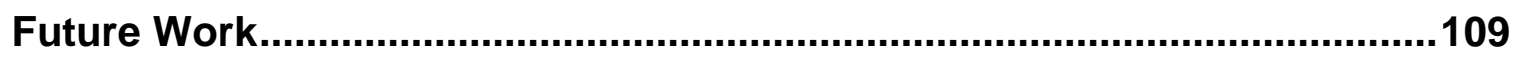

Appendix A: Scree plots of cluster analyses ....... Error! Bookmark not defined. Appendix B: Mahalanobis Distances ................... Error! Bookmark not defined. 
Appendix C: Mean plots of elemental concentration by group ................Error! Bookmark not defined.

Appendix D: Standard Operation Procedure for Hair Analysis ................Error! Bookmark not defined.

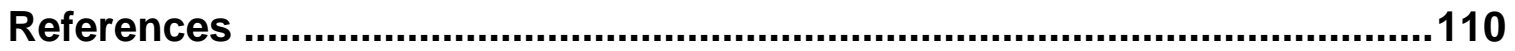




\section{List of Tables}

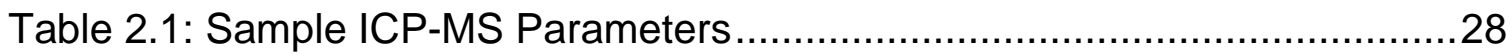

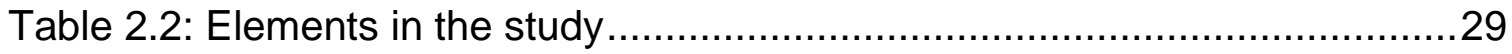

Table 2.4: SRM 2711 (Soil) 10 replicates (intra and inter day) ..........................33

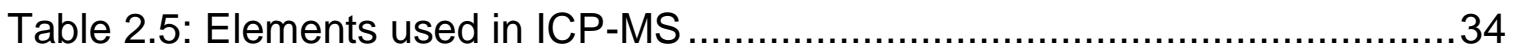

Table 2.6: The complete dataset............................................................. 42

Table 2.7: Squared Mahalanobis distances between groups ............................54

Table 2.8: Selected squared Mahalanobis distances......................................54

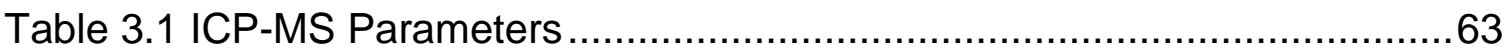

Table 3.2: Comparison between sample introduction methods $(n=10) \ldots \ldots \ldots \ldots . . .80$

Table 3.3: Effect of integration time on \%RSD ............................................ 80

Table 4.1: ICP-MS Conditions and Parameters ..............................................93

Table 4.2: Calibration standard concentration (all in ppb) ...............................96

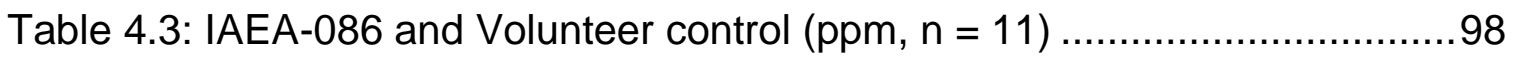

Table 4.4: Correlation coefficient, LOD and LOQ of elements (ppb) ..................99

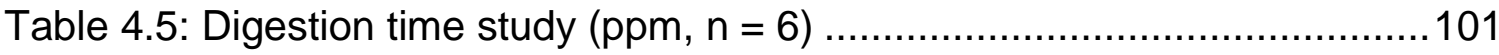

Table 4.6: Sample size study (ppm) ......................................................103

Table 4.7: Mean concentration of different groups (ppm) ..............................106 


\section{List of Figures}

Figure 1.1: Example pottery sherd (Tz-441) …….................................... 4

Figure 1.2: Government statistics of types of firearm used in homicide in the

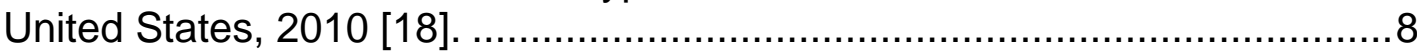

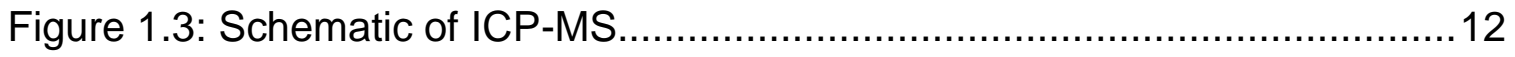

Figure 1.4: Space charge effect. ............................................................. 16

Figure 2.1: Pottery samples biplot of $\mathrm{Y}$ against $\mathrm{Hf}$ (concentration data,

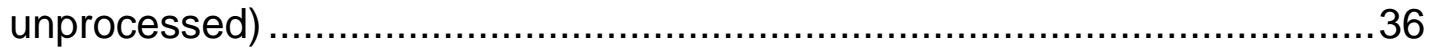

Figure 2.2: Pottery samples biplot of $\mathrm{Zn}$ against $\mathrm{Rb}$ (concentration data, unprocessed).

Figure 2.3: Pottery samples scatterplot of $\mathrm{Ga}$ against $\mathrm{Ba}$ (concentration data, unprocessed)

Figure 2.4: Tree diagram of PC 1-5 of pottery in separately standardized dataset

Figure 2.5: Mean plots of Ti, Mn, Ga, Sr, and Ba of the groups A, B, C, and D. .47

Figure 2.6: Mean plots of Eu, Gd, Dy, Er, and Yb of the groups A, B, C, and D. 48

Figure 2.7: Tree diagram of PC 1-5 of pottery in standardized whole dataset. ...51

Figure 2.8: Plot of PC1 and PC2 of all samples .........................................56

Figure 3.1: Comparison of sample media. .................................................66

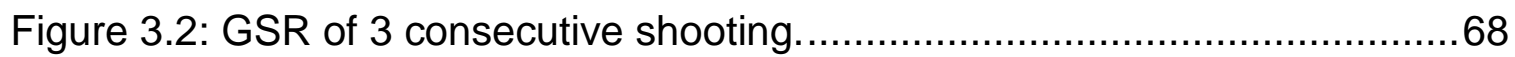

Figure 3.3: Persistence study by cotton square ............................................69

Figure 3.4: All samples mean plot of $\mathrm{Sb}, \mathrm{Ba}$, and $\mathrm{Pb}$ grouped by sample area. .72

Figure 3.5: Hand blanks and GSR samples grouped by sample area (re-scaled).

Figure 3.6: Mean plot of $\mathrm{Sb}, \mathrm{Ba}$, and $\mathrm{Pb}$ comparison of shooters and nonshooters.

Figure 3.7: GSR samples mean plot of $\mathrm{Sb}, \mathrm{Ba}$, and $\mathrm{Pb}$ grouped by handgun. ...77

Figure 3.8: Effect of concentration on isotope ratio. 
Figure 3.9: Lead isotope ratios grouped by handgun.................................... 83

Figure 3.10: 208/206 grouped by ammunition. .......................................... 84

Figure 3.11: Comparison between ammunitions by $206 / 204$ against $208 / 206 \ldots . .87$

Figure 3.12: Comparison between ammunitions by 208/206 against $\mathrm{Pb}$

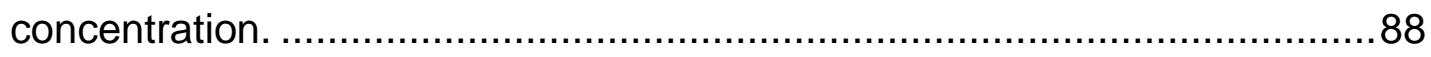

Figure 4.1: Mean plot of normalized mean of mining area vs. control area.......105

Figure 4.2: Mean plot of normalized mean of cancer cases vs. non-cancer cases. 105 


\section{List of Abbreviations, Symbols/Nomenclature}

\%RSD Relative standard deviation in percentage

${ }^{\circ} \mathrm{C} \quad$ Degree celsius

$\begin{array}{ll}\mathrm{Al} & \text { Aluminum } \\ \mathrm{Ar} & \text { Argon } \\ \mathrm{As} & \text { Arsenic } \\ \mathrm{Ba} & \text { Barium } \\ \mathrm{Be} & \text { Beryllium } \\ \mathrm{Bi} & \text { Bismuth } \\ \mathrm{Ca} & \text { Calcium } \\ \mathrm{Cd} & \text { Cadmium } \\ \mathrm{Ce} & \text { Cerium } \\ \mathrm{Co} & \text { Cobalt } \\ \mathrm{Cr} & \text { Chromium } \\ \mathrm{Cs} & \text { Cesium } \\ \mathrm{Cu} & \text { Copper } \\ \mathrm{DI} & \text { Deionized } \\ \mathrm{Dy} & \text { Dysprosium }\end{array}$

EDTA Ethylenediaminetetraacetic acid

EDX Energy dispersion X-ray

EM electron mulitiplier

EPA Environmental Protection Agency

Er Erbium

Eu Europium

$\mathrm{Fe} \quad$ Iron

g Gram

Ga Gallium

Gd Gadolinium

Ge Germanium

GSR Gunshot residue

$\mathrm{H}_{2} \quad$ Hydrogen

$\mathrm{H}_{2} \mathrm{O}_{2} \quad$ Hydrogen peroxide

$\mathrm{HCl} \quad$ Hydrochloric acid

$\mathrm{He} \quad$ Helium

$\mathrm{Hf} \quad$ Hafnium 


$\begin{array}{ll}\mathrm{HF} & \text { Hydrofluoric acid } \\ \mathrm{HNO}_{3} & \text { Nitric acid } \\ \mathrm{Ho} & \text { Holmium } \\ \text { IAEA } & \text { International Atomic Energy Agency } \\ \text { ICP-MS } & \text { Inductively coupled plasma mass spectrometry } \\ \text { In } & \text { Indium } \\ \mathrm{L} & \text { Liter } \\ \mathrm{La} & \text { Lanthanum } \\ \mathrm{LA} & \text { Laser ablation } \\ \mathrm{LOD} & \text { Limit of detection } \\ \mathrm{LOQ} & \text { Limit of quantitation } \\ \mathrm{Lu} & \text { Lutetium } \\ \mathrm{MC} & \text { Multicollector } \\ \mathrm{mg} & \text { Miligram } \\ \mathrm{min} & \text { Minute } \\ \mathrm{mL} & \text { Mililiter } \\ \mathrm{Mn} & \text { Manganese } \\ \mathrm{Mo} & \text { Molybdenum } \\ \mathrm{MURR} & \text { Missouri University Research Reactor } \\ \mathrm{Na} & \text { Sodium } \\ \mathrm{NAA} & \text { Neutron activation analysis } \\ \mathrm{Nb} & \text { Niobium } \\ \mathrm{Nd} & \text { Neodymium } \\ \mathrm{Ni} & \text { Nickel } \\ \mathrm{NIST} & \text { National Institute of Standards and Technology } \\ \mathrm{P} / \mathrm{A} & \text { Pulse to analog } \\ \mathrm{Pb} & \text { Lead } \\ \mathrm{PCA} & \text { Principal component analysis } \\ \mathrm{PCs} & \text { Principal components } \\ \mathrm{ppb} & \text { Parts per billion } \\ \mathrm{ppm} & \text { Parts per million } \\ \mathrm{ppt} & \text { Parts per trillion } \\ \mathrm{Pr} & \text { Praseodymium } \\ \mathrm{r} & \text { Correlation coefficient } \\ \mathrm{Rb} & \text { Rubidium } \\ \mathrm{REE} & \text { Rare earth element } \\ & \end{array}$




$\begin{array}{ll}\mathrm{RF} & \text { Radio frequency } \\ \mathrm{rps} & \text { Rotation per second } \\ \mathrm{Ru} & \text { Ruthenium } \\ \mathrm{Sb} & \text { Antimony } \\ \mathrm{Sc} & \text { Scandium } \\ \mathrm{SD} & \text { Standard deviation } \\ \mathrm{Se} & \text { Selenium } \\ \mathrm{SEM} & \text { Scanning electron microscope } \\ \mathrm{Si} & \text { Silica } \\ \mathrm{Sm} & \text { Samarium } \\ \mathrm{Sn} & \text { Tin } \\ \mathrm{Sr} & \text { Strontium } \\ \mathrm{SRM} & \text { Standard reference material } \\ \mathrm{Ta} & \text { Tantalum } \\ \mathrm{Tb} & \text { Terbium } \\ \mathrm{Th} & \text { Thorium } \\ \mathrm{Ti} & \text { Titanium } \\ \mathrm{TI} & \text { Thallium } \\ \mathrm{U} & \text { Uranium } \\ \mathrm{V} & \text { Vanadium, Volt } \\ \mathrm{W} & \text { Tungsten, Watt } \\ \mathrm{Y} & \text { Yttrium } \\ \mathrm{Yb} & \text { Ytterbium } \\ \mathrm{Zn} & \text { Zinc } \\ \mathrm{Zr} & \text { Zirconium } \\ \mu \mathrm{g} & \text { Microgram } \\ & \end{array}$




\section{Chapter 1: Introduction}

\subsection{Development of the Research}

At first glance, the three studies that constitute this dissertation (archaeological ceramics, gunshot residue, and hair) may seem unrelated. However, there is a unifying underlying theme - the utilization of trace multielement analysis as a tool for investigations pertaining to issues of research and public concern. For example, the hair project required characterization of metals in sub-milligram samples. This drove research into ultra-small sample digestions. In the hair study, the results are being used to determine if there is a link between increased cancer rates in southern West Virginia and contaminants associated with mining. There were several other common elements and these will be noted in the text.

I was attracted to inductively coupled plasma mass spectrometry (ICPMS) due to my professional background. I worked as an analytical chemist in an industrial company in China for three years and focused on metal analysis using atomic absorption spectrometry and titration. During that period, I was looking for major components and minor impurities in metal alloys. This naturally led to an interest in trace metals analysis using ICP-MS, which was not available at the commercial lab. I became interested in method development based on the sample matrices and, in particular, in investigating issues related to very small samples.

Sequentially, the first project I completed was related to the characterization of archaeological ceramics. While sample size was an issue, method validation and data interpretation presented the primary challenges. 
Multivariate statistics and pattern matching were central to this work. Reliability and utility of the statistical analysis require strong and dependable underlying analytical data. Thus, method validation was critical.

The gunshot residue project is part of a bigger project that has been conducted in our lab to integrate inorganic information with organic information derived from post-shooting hand swabs. Different sampling media was evaluated in order to obtain an optimal hand blank background. The analysis of characteristic elements, tin $(\mathrm{Sb})$, barium $(\mathrm{Ba})$, and lead $(\mathrm{Pb})$ revealed differences between shooters and non-shooters, while a lead isotope method was developed with a quadrupole ICP-MS to assist in the differentiation between ammunitions.

The biggest challenge associated with hair samples was the limited quantity, as low as sub-milligram and in some cases, too small to weigh even when using a 5-place analytical balance. The main goal is to develop a method for the analysis of the hair samples using such small samples through identification of "trustworthy" elemental concentrations derived from such small samples. This work focused on standard reference materials and extensive method validation and characterization.

\subsection{Types of Samples}

\subsubsection{Archaeological Pottery}

In this study, 100 samples (provided by Hirshman, 19 clay samples, 5 volcanic ash samples, and 76 pottery sherds) were excavated from Lake Pátzcuaro Basin, Michoacán, Mexico. According to Hasenaka and Carmichael, the Lake Pátzcuaro Basin sits within the Michoacán-Guanajuato Volcanic Field, a 
late Quaternary volcanic region in Western Mexico [1]. The soils (also known as andosols) within the Basin all reflect volcanic origins.

According to Pollard, the pottery wares were from a surface survey of Tzintzuntzan in 1970. They represented late Postclassic Tzintzuntzan (capital of Tarascan State) which dated from 1350-1520 [2]. All the pottery sherds were from the Tzintzuntzan site only. The pottery sherds are characterized by their polychrome decoration and often visually grouped by archaeologist through their paste and surface decoration [2]. Figure 1.1 shows an example of the pottery sherds. 
Figure 1.1: Example pottery sherd (Tz-441)

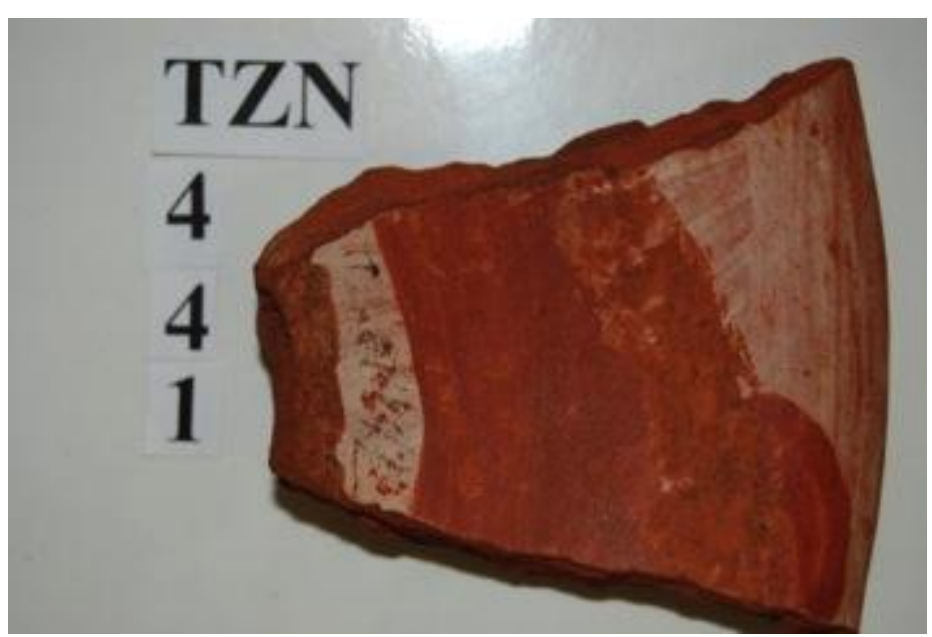


Most of the clay samples came from easily accessible locations around the Basin include brick maker's yards or erosion events [3,4]. The most clayey layer of soil was sampled. These samples start with HPC labels and were collected from multiple sites.

Finally, clay and ash samples from archaeological excavation of the site of Urichu were collected (label start with Tz) [4]. Volcanic ash samples from Urichu represent ash fall from the La Taza volcano, which is located at the southwest margin of the Basin.

Ash was frequently used as an additive (also known as a temper) in ancient ceramics and therefore impacts chemical characterizations. Although the clay and ash samples may not represent resources identical to those used by the Pre-Hispanic potters, they should be chemically similar given the relative homogeneity of the geology of the Basin [4].

The provenience study of pottery, which is a critical step in studying pottery production, is beneficial to archaeologists [5]. The goal of provenience investigation is to find the source of the pottery excavated from a site. This aids in establishing the location of production and possibly the exchange or trade patterns [6]. Elemental analysis is a key tool in provenience studies, while aiding in the study of their production, distribution, and consumption [7]. The provenience study is accomplished through the statistical grouping of pottery samples by their elemental composition and then comparing them to soil samples. 
Neutron activation analysis (NAA) is the preferred analytical technique for elemental characterization of these materials. NAA has a distinguished history in archaeological and ceramic compositional studies dating from the 1950s [7-9]. Due to access and cost issues, NAA is not always feasible [5,7,8,10-14]. Principles of NAA are briefly described, as follows. The incident neutron collides with the target nucleus to make it unstable. The unstable nucleus then becomes radioactive with a characteristic half-life and emits gamma rays with unique characteristics to that element [7]. Measurement of these gamma rays allows the quantitative detection of multiple elements. NAA has advantages such as high precision, accuracy, sensitivity, small sample size, as well as no matrix effects [12].

The disadvantages of NAA are more practical than technical and include: (1) limited access due to the small number of reactors; (2) high costs per sample; (3) lengthy irradiation process; and (4) curation of radioactive samples. According to the reasons above, numerous efforts have been made to seek an alternative analytical method for NAA [15-17]. The approach described here coupled ICP-MS, extensive characterization of reference materials, and statistical analysis and the results were evaluated relative to those produced by NAA.

\subsubsection{Gunshot Residue}

In 2010, there were 12,996 cases of homicide in the United States reported by the Federal Bureau of Investigation (FBI), in which 8,775 people were killed by firearms. Handguns comprised 6,009 cases of homicide, as 
shown in Figure 1.2 [18]. Due to these statistics, firearm related forensic studies are of great importance.

Gunshot residue (GSR) is the most studied trace evidence in a firearm involved criminal investigation $[19,20]$. GSR consists of particles produced during the discharge of a firearm. While most of the GSR comes from the ammunition primer, particles from all parts of the weapon (i.e. propellant powders, grease, and lubricants), may be included. After the discharge of a firearm, vaporized materials escape from the openings and solidify into particles [19]. According to Basu, GSR particles form as droplets before they solidify [21]. It has been found that most inorganic GSR comes from the primer, which contains lead styphnate, barium nitrate, and antimony trisulfate [19]. The residue is composed of varying quantities of antimony $(\mathrm{Sb})$, barium $(\mathrm{Ba})$, lead $(\mathrm{Pb})$, and other organic components of the primer compound [22]. Particles vary in shape and size, ranging from submicron to over 100 microns $(\mu \mathrm{m})$ as a result of gunfire. 
Figure 1.2: Government statistics of types of firearm used in homicide in the United States, 2010 [18].

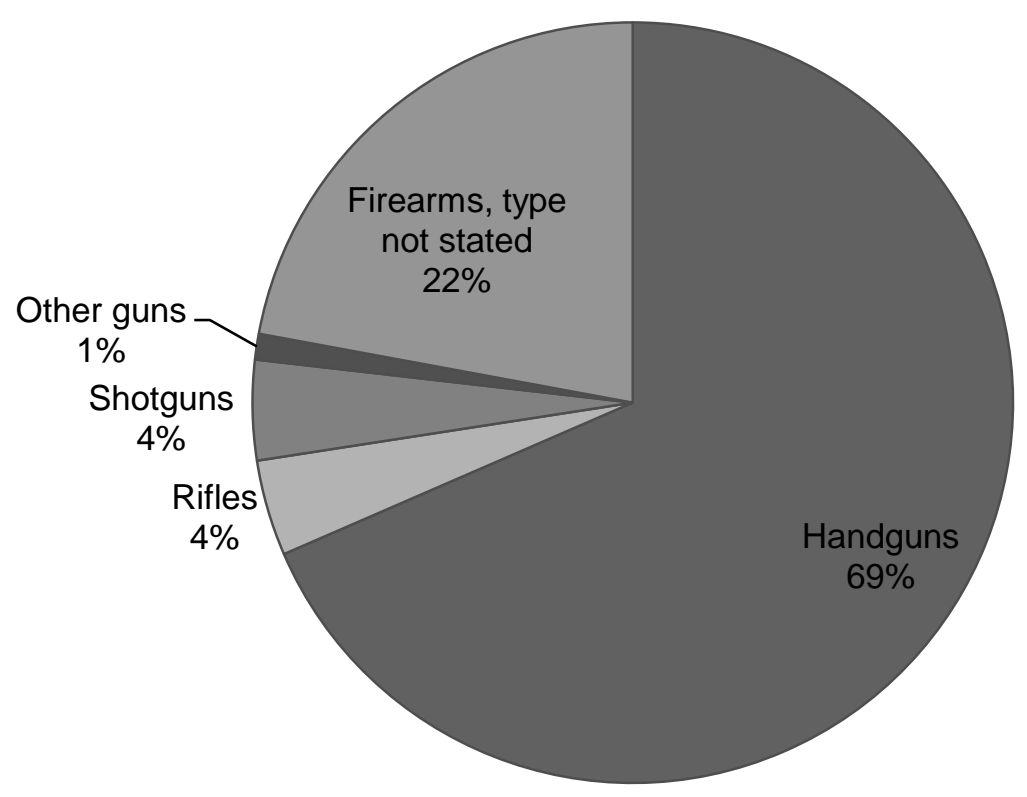


In traditional GSR analysis, the target analytes are particulates containing $\mathrm{Sb}, \mathrm{Ba}$, and $\mathrm{Pb}$ as their oxides. These particles are collected on carbon tape and analyzed by scanning electron microscope (SEM) equipped with energy dispersion X-ray detector (EDX). However, the use of a technique like this, which can identify individual particles both morphologically and chemically, takes a significant amount of analysis time. Even with the use of automated searching, this process can take up to several hours [23]. It is also controversial to determine if one fired a weapon or not depending on a few particles found on the suspect.

The goal of this project was to provide an alternative method for detecting inorganic metals in GSR. This ultimately will be combined with detection of the organic components, a project that is on-going in our laboratory and is currently funded by the U.S. Department of Defense.

\subsubsection{Hair}

Traditionally, blood and urine have been used in order to assess a person's exposure to pollutant or toxins. However, according to Kempson and Lombi, hair composition is related to blood composition; therefore, hair could be an alternative biomonitor in addition to blood and urine in toxicology and disease studies [24]. Hair represents the short- to middle- term of exposure history compared to urine or blood, which are studied only for recent exposure. Hair is relatively easier to collect and preserve than urine or blood. Therefore, hair analysis draws more and more attention in health related studies. 
Hair has been used in drug abuse studies, where metabolites of drugs could be detected and consumption confirmed. Inorganic elements also play an important role in hair analysis for disease detection and toxicology study. By analyzing hair, it is possible to link specific diseases to the elevation or depletion of certain elements [24].

Due to the reasons stated above, hair has become the choice of study in many health related research [25-29]. The effect of mining to human health is of particular concern in West Virginia and neighboring states. Ahern et al. revealed the association between mountaintop mining and birth defects in central Appalachia (a wide range of mountains including West Virginia) [30]. Hendryx et

al. performed a door to door health interview with hair sample collection from 773 adults in 2011 and found a significantly higher rate of cancer in mining area versus the non-mining areas [31].

The samples from mining area were collected from the Coal River in Boone and Raleigh Counties, while the control samples were from the southern portion of Pocahontas County (without coal mining activities) [31]. The goal of the project was to find out if there is an accumulation of specific elements within hair samples in mining area compared to control area with no mining activity. The other goal was to reveal the relationship between the elevation of these elements (if there is) and cancer cases.

\subsection{Instrumentation}

Since first introduced by Houk et al. in 1980 [32], ICP-MS has been applied to various disciplines of sciences, including geochemistry [33,34], 
environmental science [35], and pharmaceutical and biomedical analysis [36] because of the ability to perform a multi-element analysis with low limits of detection [37]. As described in Houk's work, the instrument was the combination of an inductively coupled argon plasma and a quadrupole mass spectrometer [32]. Although the quadrupole mass analyzer is considered to be first generation [38], its low cost compared to others (sector field, time of flight, and ion trap), makes it the most affordable instrument and thus, the most prevalent commercial instrument.

A schematic of a quadrupole ICP-MS is shown in Figure 1.3. The system contains an ICP source, an ion sampling interface, and a vacuum system where the mass spectrometer is located. Compared to the original design [32], there is an addition of a collision cell between the ion lens and the quadrupole. The collision cell was introduced into the system about a decade ago [38]. Helium is used as collision gas to reduce the polyatomic interferences generated by the plasma source. The collision cell is off axis with the ion source and the quadrupole; which is designed to prevent neutral species and photons from reaching the detector. 
Figure 1.3: Schematic of ICP-MS.

Figure used with permission from Agilent, Inc.

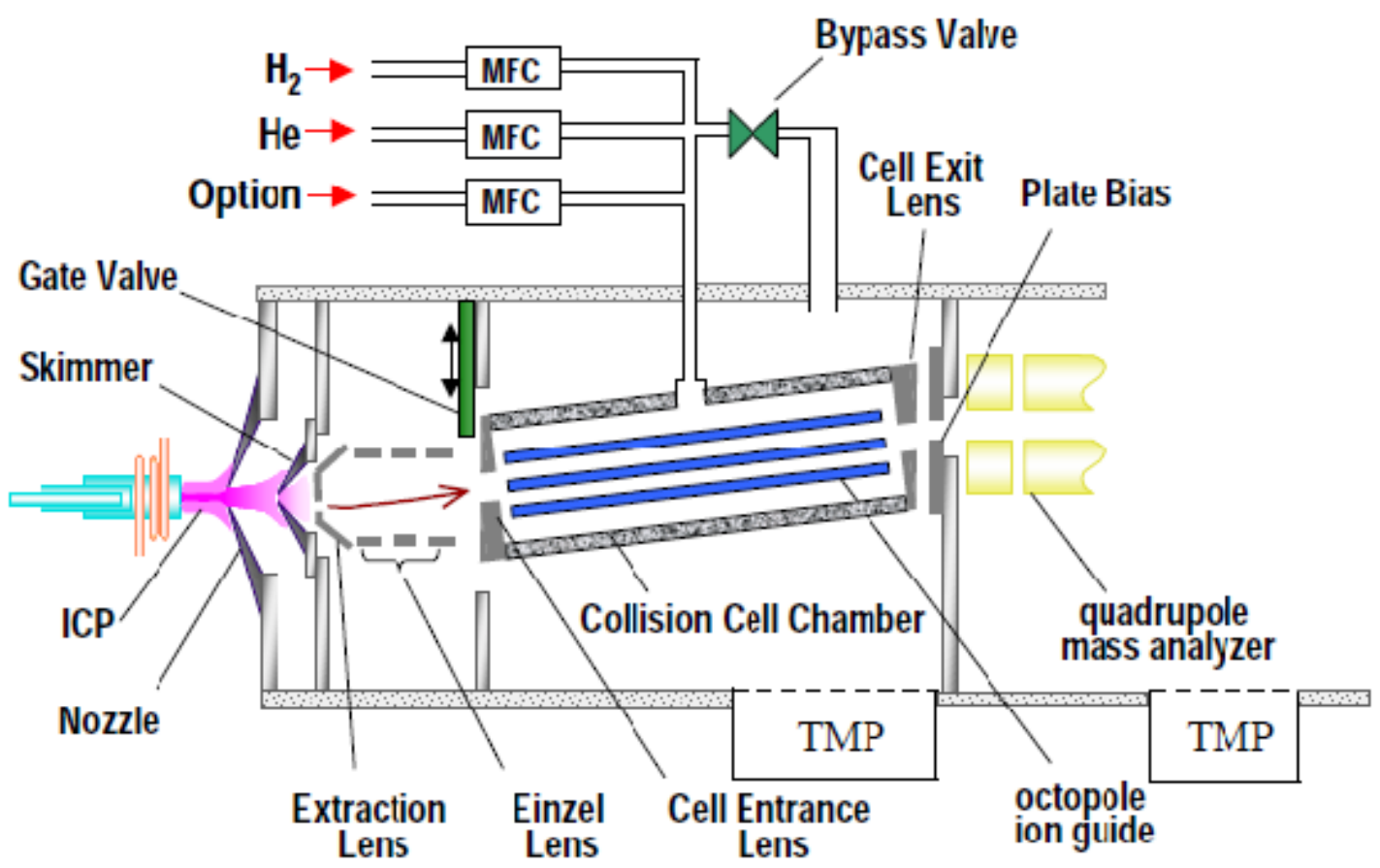


Liquid samples are introduced into the ICP source by a nebulizer. If the samples are in solid form, digestion of the samples is necessary. Laser ablation (LA), which uses a pulsed laser beam to ablate a portion of the solid surface, has been used for direct solid analysis capability $[39,40]$. The sample vaporized by the laser is transported into the plasma and analyzer. The problem with LA is that the quantity of sample removed from the surface is difficult to measure, so it is undetermined how much sample is analyzed. Hence, quantitative analysis is difficult [39], which limits the applicability of LA methods for studies in which quantitative data is essential. In this dissertation, only liquid sample introduction will be discussed.

The ICP torch contains three concentric quartz tubes, including an outer tube, a middle tube, and a sample tube. The plasma gas goes between the outer and middle tubes at a flow rate of $\sim 12-17 \mathrm{~L} / \mathrm{min}$. A second gas flow passes between the middle and sample tubes at $\sim 1 \mathrm{~L} / \mathrm{min}$ and is used to change the position of the base of the plasma. The sample and nebulizer gas, normally argon (at a flow rate of $\sim 1 \mathrm{~L} / \mathrm{min}$ ), are introduced through the inner tube of the ICP torch and pass the radio frequency (RF) induction coil where ionization takes place. A RF field is applied to the end of the torch and the high temperature generates the argon plasma, which contains ionized argon atoms that lose some electrons from the excited state. The aerosol sample introduced by the nebulizer is ionized by collision with these electrons.

Since the MS requires a high vacuum and the ICP is at atmospheric pressure, an interface is needed. The role of this region is to transport the ions 
from the plasma, which is at atmospheric pressure (760 torr) to the mass spectrometer analyzer at $10^{-6}$ torr. The area between sampler cone and skimmer cone is maintained at up to 2 torr. The housing of the interface is water-cooled to reduce the effects of high temperature plasma on the cone. Finally, a high vacuum pump is used for the mass analyzer. Ion counts are detected by an electron multiplier (EM) and the signal is collected.

There are two main interferences in the ICP-MS system, spectroscopic interference and matrix effects. The causes of spectroscopic interferences are: isobaric ions (e.g., ${ }^{40} \mathrm{Ar}^{+}$and ${ }^{40} \mathrm{Ca}^{+}$), polyatomic or adduct ions (e.g., ${ }^{14} \mathrm{~N}_{2}^{+}$with ${ }^{28} \mathrm{Si}^{+}$), and oxide and hydroxide species (e.g., $\mathrm{NaO}^{+}$and $\mathrm{NaOH}^{+}$). There are several approaches used to compensate for spectral interferences. The first is a mathematical correction, which is based on measuring the intensity of interfering species at another mass. By knowing the ratio between the two isotopes, a calculation could be made to eliminate the interference. The second method consists of using a collision cell, which is usually a multipole (quadrupole, hexapole, or octapole) operated in RF-only mode. Collision between polyatomic interferences and the collision gas $\left(\mathrm{He}\right.$ or $\left.\mathrm{H}_{2}\right)$ will convert these interferences to non-interfering species. For example, interfering polyatomic ion ${ }^{40} \mathrm{Ar}^{35} \mathrm{Cl}^{+}$will collide with $\mathrm{He}$ and dissociate, but ${ }^{75} \mathrm{As}^{+}$will not. The best way to remove spectral overlap occurring in isobaric ions is to use a high-resolution mass analyzer such as a double focusing magnetic field sector, but this will compromise the sensitivity. 
Matrix induced interference of the ions become noticeable when the concentration of matrix elements is very high. Matrix refers to the solution environment that contains the analytes. The present of non-analyte ions will introduce a reduction, or sometimes an enhancement, for the signals. Methods that could compensate for the interferences caused by matrix effect include diluting the solution, separating out offending species, and using an internal standard.

The limits for precision and accuracy in ICP-MS are mainly caused by mass discrimination effects and the dead time of the ion detector. Mass discrimination is a result of space-charge effect, brought about by the Coulomb repulsion that affects lighter ions more than heavier ones (as shown in the Figure 1.4). A loss of low mass sensitivity is often a result of this effect. The use of multiple ion optics can help compensate this issue. Mass bias correction can also be used to reduce the discrimination.

The dead time stands for the time interval (normally in nano-seconds) that the detector does not respond to the electron following the previous one when the rate of ions hitting the detector is too fast. The direct effect is that a lower number of counts will be recorded than real if counting rates are higher than $10^{6}$ counts per second. Switching between pulse and analog mode is used to address this issue. The pulse mode is used for ion counts less than a certain value, while the analog mode is for higher ion counts. The ions are collected at the end of the EM in the pulse mode, while in the analog mode, a middle dynode was chosen for the ion detection. By multiplying a pulse to analog factor (P/A 
factor), the final counts can be calculated. The automatic switch between pulse and analog mode is essential for the large linear range availability in ICP-MS.

Figure 1.4: Space charge effect.

Figure used with permission from Agilent, Inc.

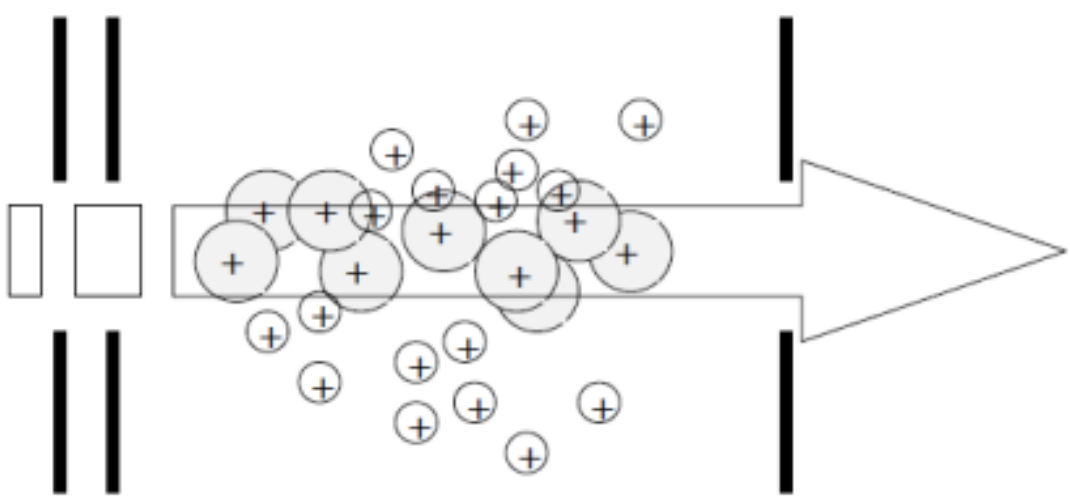




\section{Chapter 2: Application of ICP-MS for Characterization of Archaeological Ceramics}

\subsection{Introduction}

The two main goals of this study were to adapt a simple digestion method for ICP-MS analysis of archaeological ceramics and to generate groups with the ICP-MS data that are comparable to those generated from NAA. While NAA is a true bulk analysis technique, ICP-MS falls into this category only when aggressive total digestion methods are employed using hydrofluoric acid (HF) and microwave techniques. Less aggressive digestions using hydrochloric acid $(\mathrm{HCl})$ and nitric acid $\left(\mathrm{HNO}_{3}\right)$ in open vessels are an option, but inevitably result in the loss of analytical information. The question arises as to how significant this loss of data is. In turn this depends on analytical as well as archaeological considerations. If the latent chemical information obtained from the less aggressive digestion is comparable to that obtained from NAA, then the compromise is a reasonable one.

\subsubsection{Analytical Consideration}

As one of the most powerful multi-elemental analytical techniques, ICPMS has gathered attention in the past decades in pottery studies $[7,10,14-17,41$ 49]. ICP-MS has many advantages over NAA. First, it has the capability to analyze most elements. In the study by Kennett et al., in addition to the ability to analyze elements determined by NAA, ICP-MS can detect 11 additional elements

[15]. Second, it requires shorter detection time than NAA. As reported by Longerich et al., 17 samples were analyzed a day (3-5 days if include sample 
preparation) compared to the minimum three weeks that would be required for NAA [45]. Third, no nuclear waste is generated by ICP-MS. Fourth, it offers good sensitivity with detection limits in the ppb range compared to NAA at 0.1 ppm [15]. Finally, the cost is reasonable, as low as $\$ .10$ per sherd (estimated in 1996 based on consumption of chemicals) by Burton and Simon [46].

The main limitation of traditional ICP-MS for pottery analysis is that only aqueous samples can be introduced. Although LA methods are used in archaeological chemistry [50-52], specialized sample inlets are required and the result is from a surface analysis technique, which is not always directly comparable to bulk methods. Dissolution of pottery requires significant quantities of acids including hydrofluoric acid (HF) and is typically time and labor intensive $[14,46]$. Two main sample preparation methods using acids have been utilized, including acid bomb digestion $[16,41,45]$ and microwave assisted digestion $[14,15,42]$. Both preparations are a complete digestion, which means the pottery samples are totally dissolved in solution. Acid bomb digestion includes dissolving the samples using screw-top Teflon ${ }^{\circledR}$ bombs with $\mathrm{HF}$ and $\mathrm{HNO}_{3}$, and then heated in the oven [45]. Microwave digestion was proposed as a solid sample preparation method for ICP-MS applications in ceramics by Kennett et al. in 2002 [15]. The procedure includes adding ultra-pure $\mathrm{HF}, \mathrm{HNO}_{3}$ and $\mathrm{HCl}$ into the sample vial that is placed in a microwave digestion system. Boric acid $\left(\mathrm{H}_{3} \mathrm{BO}_{3}\right)$ is then added to reduce the formation of calcium fluorides $\left(\mathrm{CaF}_{2}\right)$, which is known to precipitate rare earth elements [42]. 
Beside acid digestions, alkaline fusion with lithium borate is also a method for dissolving pottery. This is performed by mixing and melting sample powder with lithium metaborate $\left(\mathrm{LiBO}_{2}\right)$ then transferring the sample to a $5 \% \mathrm{HNO}_{3}$ solution [44].

Acid digestion and alkaline fusion both have limitations, such as the formation of insoluble compounds in the acid digestion methods, and a significant drift caused by deposition of salts on the sampling cone of the ICP-MS instrument in the alkaline fusion method [17]. A weak acid digestion method has also been described by Burton and Simon [46]. However, this includes soaking powdered samples in diluted acid for weeks, which is impractical for most analytical laboratories.

ICP-MS methods for bulk characterizations are destructive and involve combinations of acid digestion, heat, and microwave systems for sample preparation. Total dissolution of pottery typically requires the use of HF. Due to the handling precautions required when HF is used and the tendency of forming insoluble fluorides, alternative methods are desirable if sufficient chemical information can still be recovered for the application.

The digestion method utilized in this study is an adaption of a United States Environmental Protection Agency (US EPA) sample preparation protocol, EPA 3050B [53]. This method is a well-established protocol used for sediments and soils that are optimized for elements that are typically environmentally mobile: As, Cd, Cr, Co, Fe, Pb, Mo, Se, and Th. This methodology utilizes an aggressive, but not total, digestion scheme including concentrated nitric acid 
$\left(\mathrm{HNO}_{3}\right)$ and $30 \%$ hydrogen peroxide $\left(\mathrm{H}_{2} \mathrm{O}_{2}\right)$. The digestion is rapid, simple, and does not require HF or a microwave system, which also lower the cost. The limitation of this method is that silicates remain relatively intact, and elements contained in silicate structures will not be extracted to any significant degree [53].

Performance of the method was gauged using a standard reference material (SRM 679 Brick Clay) previously applied for similar purposes [14,15,44]. Like the archaeological ceramics, the brick is created as a result of an additive process and thus provides some measure of comparability to the samples of interest here. A second reference material, SRM 2711 Montana II Soil, was also used given as a relatively reasonable matrix match to clays and previous archaeological applications [10]. It is important to emphasize that the goal of this digestion protocol was not bulk characterization of the clays and pottery. Indeed, acid extraction is not considered to be a bulk analysis in the same sense as is NAA $[46,54]$. However, elements that are environmentally mobile may be used for classifying pottery. The goal was development and evaluation of a simplified extraction method for reliable and reproducible quantitation of selected elements, such that the chemical data produced encodes the same archaeological information as captured by NAA analysis.

\subsubsection{Data Analysis}

Analytical data obtained from ceramics are challenging to interpret because, unlike soil or rock, ceramics are created as a result of human activity in an additive fashion [4]. Potters begin with water and clay and then add temper (such as shell, organic materials or ash) to create the desired physical properties 
of the final paste [4]. After mixing and the appropriate amount of kneading, the vessel is formed and fired, which can also affect the vessel's chemistry. The focus of this work is to determine whether the clay and ash samples collected from the Basin (described in an earlier section) can be related to the pottery made from these materials via statistical methods.

The Missouri University Research Reactor (MURR) statistically analyzed most of the samples studied here. At MURR, obtained data was log normalized before analysis. MURR claimed that logarithmic data provide quasistandardization, therefore, compensation the differences of magnitude between major and trace elements [7]. Mahalanobis distance was recommended because it accounts for correlations among variables [7]. Bivariate plots, cluster analysis, and principal components analysis (PCA) are the main tools to differentiate groups. Through this work, these methods were also examined.

Compositional analysis of pottery generates a large amount of data. It is important that these data are correctly interpreted. When there are only two variables (concentration of elements), a biplot is used and the similar samples will be close to each other and form a cluster. When the variables are more than three, it is impossible to plot them in the diagram. Computer based multivariate methods then became critical. These methods use mathematic calculations to reveal relationship between the samples and groups of samples. Such methods include principal component analysis (PCA) and cluster analysis. While PCA is considered unsupervised method, both supervised and unsupervised methods are available in cluster analysis. Supervised methods can be used when the 
groups are known, and the unsupervised methods are for the samples with unknown clustering. Since the goal of this study was to look for possible clusters in the pottery samples, unsupervised methods were used.

Since the elemental concentrations are in different magnitude, normalization is needed to prevent one variable dominating the others. There are two methods that can be used for data normalization: logarithms $(\log 10)$ of the concentration used by MURR [7] and z-transform mostly used in chemometrics [55]. A log transform will convert a concentration to logarithm and compensate for differences in the magnitudes between major components and trace elements [7]. A z-transform standardizes the elements based on the mean and standard deviation:

$$
x_{1}^{*}=\frac{x_{1}-\bar{x}}{s}
$$

where $x_{1}{ }^{*}$ is the standardized data of $x_{1}, \bar{x}$ is the mean of the variable $x$, while $s$ is the standard deviation of variable $\mathrm{x}$. Both methods aim to make the dataset normally distributed and suitable for further analysis. Z-transform is chosen in this study because it helps to prevent one variable with large variance dominate the others.

PCA is a technique aiming to explain the data with a few new uncorrelated variables (principal components, PCs) that represents the majority of original correlated ones. The basic idea of PCA in this study is that PCs (PC1, PC2, .. PCn) can be calculated to a linear combination of the concentrations of different elements $(C 1, C 2, \ldots C n)$ :

$$
P C_{1}=a_{11} C_{1}+a_{21} C_{2}+\ldots+a_{n 1} C_{n}
$$


where coefficients $a_{11}, a_{21}$ etc. were chosen so that the PCs are not correlated with each other [55]. Also, the PCs are calculated so that PC1 accounts for most of the variation in the original dataset, PC2 for the next largest variation and so on. The idea can also be explained with a matrix of original dataset $C(m \times n)$, where $\mathrm{n}$ is the number of elements detected, $\mathrm{m}$ is the number of samples analyzed [56],

$$
C=\left[\begin{array}{ccc}
C_{11} & \cdots & C_{1 n} \\
\vdots & \ddots & \vdots \\
C_{m 1} & \cdots & C_{m n}
\end{array}\right]
$$

then $P C(m \times n)=C(m \times n) \times a(n \times n)$

$$
P C=\left[\begin{array}{ccc}
P C_{11} & \cdots & P C_{1 n} \\
\vdots & \ddots & \vdots \\
P C_{m 1} & \cdots & P C_{m n}
\end{array}\right]=C \times\left[\begin{array}{ccc}
a_{11} & \cdots & a_{1 n} \\
\vdots & \ddots & \vdots \\
a_{n 1} & \cdots & a_{n n}
\end{array}\right]^{T}
$$

where T standards for "transpose". In most of the cases, first few PCs account for a majority of variation. The PCs are considered eigenvectors in mathematical terms, and have eigenvalues associate with them. Percentage of explained variance can be calculated by these eigenvalues. A biplot of PC2 or PC3 against PC1 is used to visually checking the possible grouping (Figure 2.8). However, this method is not always successful in finding less obvious groups [55]. Therefore, other methods are needed to find latent groups.

Cluster analysis is a statistical tool aiming to look for groups that contains similar samples. As mentioned earlier, unsupervised cluster analysis (also known as hierarchical clustering) is preferred in the archaeological study. In hierarchical clustering, all cases are considered as individual clusters first. The distance between two clusters will then be calculated and the cases are closer to 
each other will be merged into a new cluster. This process continues until there is only one cluster left. While there are different methods to calculate the distances, Euclidean distance and squared Euclidean distance are the most commonly used. Euclidean distance is calculated as follows [55]:

$$
d=\sqrt{\left(x_{1}-y_{1}\right)^{2}+\left(x_{2}-y_{2}\right)^{2}+\cdots+\left(x_{n}-y_{n}\right)^{2}}
$$

$\left(x_{1}, x_{2}, \ldots x_{n}\right)$ are the variables from sample $x$ and $\left(y_{1}, y_{2}, \ldots y_{n}\right)$ from sample $y$.

Different agglomerative clustering methods are also available. Two of them are used the most dominant, average linkage and Ward's method [57]. A detailed example of average linkage method can be found in Otto's textbook [56]. The average linkage accesses similarity by computing the average of distances between all members in the formed cluster and the new sample. In the Ward's method on the other hand, clusters are formed so that the resulting cluster has the minimum increase of within-cluster variance. The results will then be presented in a dendrograms (also known as tree diagram, Figure 2.4 and 2.5). The delineation between separate clusters was identified using a scree plot (sample plots can be found in Appendix A) of linkage distances versus amalgamation step. An exponential increase in the slope correlates with significant separation of the points being linked, which in turn suggests that the latest point being considered is significantly separated from the others in the multi-dimensional data space. This would be expected to occur when points from separate clusters are linked. The limitation of the hierarchical clustering is that once a cluster is formed, it cannot be reversed [58]. In this work, average 
linkage was chosen since it is the represented method in archaeological study [7].

MURR argued that Mahalanobis distance is also needed to account for the correlation between variables. The Mahalanobis distance is defined as the Euclidean distance between the sample $k$ and centroid of cluster $A$ divided by the group variance in the direction of the sample [7]:

$$
D_{k A}^{2}=\sum_{i=1}^{n} \sum_{j=1}^{n}\left[C_{i k}-A_{i}\right] I_{i j}\left[C_{j k}-A_{j}\right]
$$

where $A_{i}$ and $A_{j}$ are the mean concentration of elements $i$ and $j$ in the cluster and $\mathrm{I}_{\mathrm{ij}}$ is the $\mathrm{ijth}$ element of the inverse of the variance-covariance matrix. However, this distance is useful only when there is a large cluster present [58]. Therefore, Euclidean distance is used first until the cluster is large enough.

Out of a number of data exploratory methods that are available, a single method cannot solve all the problems. Therefore, it is recommended that more than one statistical method are needed for the data analysis [57]. In this work, PCA and cluster analysis is thus combined to achieve better separation.

\subsection{Experimental}

\subsubsection{Materials}

The acids (ACS Plus grade) and $\mathrm{H}_{2} \mathrm{O}_{2}(30 \%)$ used were obtained from Fisher Scientific (Fair Lawn, NJ, USA). Elemental standards in acid were obtained from VHG labs (Manchester, NH, USA) and SPEX CertiPrep (Metuchen, NJ, USA). The SRMs $(679,2711)$ were obtained from the National 
Institute of Standards and Technology (NIST, Gaithersburg, MD, USA). The deionized (DI) water was from the Barnstead system (Dubuque, IA, USA).

\subsubsection{Sample Preparation}

EPA 3050B is an acid digestion method, which can be used for ICP-MS, flame atomic absorption, ICP-atomic emission, and graphite furnace atomic absorption. The method is based on the digestion of $\sim 1-2 \mathrm{~g}$ of a sample. In order to preserve the pottery sherds, a sample size of $100 \mathrm{mg}$ was used with proportional reduction in reagents.

A total of 76 pottery samples and 24 clay/ash samples were analyzed, and the whole list can be found in Table 2.6. Ceramic samples were obtained by burring the exterior surface of the sherd using a diamond burr, powdering using an agate mortar and pestle, and desiccating in a drying oven by Dr. Hirshman. All clays and ashes in the ICP-MS trial were analyzed as supplied.

The dried material was weighed in a $50 \mathrm{~mL}$ polypropylene tube and 2.0 $\mathrm{mL}$ of a $1: 1(\mathrm{v} / \mathrm{v})$ of nitric acid/water was added and the tube was closed and heated for 10 minutes at $95 \pm 5^{\circ} \mathrm{C}$ on a heating block. An additional $1.0 \mathrm{~mL}$ of concentrated nitric acid was added to the tube and heated for another 2.5 hours. At the conclusion of the second heating, $0.2 \mathrm{~mL}$ of DI water and $0.3 \mathrm{~mL}$ of $30 \%$ $\mathrm{H}_{2} \mathrm{O}_{2}$ were added to the tube and mixed. An additional 6 aliquots of $0.1 \mathrm{~mL} \mathrm{H}_{2} \mathrm{O}_{2}$ were added, followed by mixing and another 2 hours of heating as described above. At the end of the heating, DI water was added to bring the volume to 25.0 $\mathrm{mL}$. After a settling period, the supernatant was placed in a $15 \mathrm{~mL}$ polypropylene 
tube and centrifuged for 15 minutes. Finally, this solution was aspirated directly into the ICP-MS.

\subsubsection{Instrumental Conditions}

An Agilent 7500cx ICP-MS (Santa Clara, CA, USA) was employed in this study. This instrument is equipped with a collision cell operated in helium mode. Typical operation parameters are shown in Table 2.1.

Stock solutions of each of the elements were prepared at $10.0 \mathrm{mg} / \mathrm{L}$ in $2 \%$ $\mathrm{HNO}_{3}$ and $0.5 \% \mathrm{HCl}$. The stock solution was diluted to a series of standards in concentration units of $\mu \mathrm{g} / \mathrm{L}: 1.0,5.0,10.0,50.0,100.0,500.0$ and 1000.0. Initially, 39 elements were included in the target analyte list for ICP-MS. The instrument was calibrated for these elements and the data obtained for the SRMs was used to determine which elements were best suited for further study. This determination was based on several criteria with emphasis on recovery of the element in the SRMs and the reproducibility of the recovery as measured by the percent relative standard deviation (\%RSD). Other factors considered included availability of standards, compatibility of concentration ranges (to avoid multiple separate dilutions), and certified concentration value. Table 2.2 summarizes the elements quantified using both instrumental methods. The elements that had too many missing data are omitted. 
Table 2.1: Sample ICP-MS Parameters

$\begin{array}{ll}\text { RF Power } & 1500 \mathrm{~W} \\ \text { Carrier Gas } & 0.81 \mathrm{~L} / \mathrm{min} \\ \text { Makeup Gas } & 0.20 \mathrm{~L} / \mathrm{min} \\ \text { Nebulizer Pump } & 0.1 \mathrm{rps}\end{array}$

Octapole Reaction Cell

Helium

Octapole Bias

$4.5 \mathrm{~mL} / \mathrm{min}$

$-6 \mathrm{~V}$

Detector Parameters

Discriminator

$8 \mathrm{mV}$

Analog HV

$1780 \mathrm{~V}$

Pulse HV

$1100 \mathrm{~V}$

Data Acquisition Parameters

Dwell time per mass

Replicate

Monitored lons

$0.10 \mathrm{sec}$

3

${ }^{45} \mathrm{Sc},{ }^{47} \mathrm{Ti},{ }^{51} \mathrm{~V},{ }^{53} \mathrm{Cr},{ }^{55} \mathrm{Mn},{ }^{59} \mathrm{Co},{ }^{60} \mathrm{Ni}$, ${ }^{63} \mathrm{Cu},{ }^{66} \mathrm{Zn},{ }^{69} \mathrm{Ga},{ }^{72} \mathrm{Ge},{ }^{75} \mathrm{As},{ }^{82} \mathrm{Se}$, ${ }^{85} \mathrm{Rb},{ }^{88} \mathrm{Sr},{ }^{89} \mathrm{Y},{ }^{90} \mathrm{Zr},{ }^{93} \mathrm{Nb},{ }^{95} \mathrm{Mo},{ }^{118} \mathrm{Sn}$, ${ }^{137} \mathrm{Ba},{ }^{139} \mathrm{La},{ }^{140} \mathrm{Ce},{ }^{141} \mathrm{Pr},{ }^{146} \mathrm{Nd},{ }^{147} \mathrm{Sm}$, ${ }^{153} \mathrm{Eu},{ }^{157} \mathrm{Gd},{ }^{159} \mathrm{~Tb},{ }^{163} \mathrm{Dy},{ }^{165} \mathrm{Ho},{ }^{166} \mathrm{Er}$, ${ }^{172} \mathrm{Yb},{ }^{178} \mathrm{Hf},{ }^{182} \mathrm{~W},{ }^{205} \mathrm{TI},{ }^{208} \mathrm{~Pb},{ }^{209} \mathrm{Bi}$, ${ }^{232} \mathrm{Th}$ 
Table 2.2: Elements in the study

\begin{tabular}{|c|c|c|c|c|c|}
\hline Element & NAA & ICP-MS & Element & NAA & ICP-MS \\
\hline $\mathrm{Al}$ & Yes & & $\mathrm{Nb}$ & & Yes \\
\hline$A s^{*}$ & Yes & Yes & $\mathrm{Nd}$ & & Yes \\
\hline $\mathrm{Ba}^{*}$ & Yes & Yes & $\mathrm{Ni}$ & & Yes \\
\hline $\mathrm{Ca}$ & Yes & & $\mathrm{Pb}$ & & Yes \\
\hline $\mathrm{Ce}^{*}$ & Yes & Yes & $\mathrm{Pr}$ & & Yes \\
\hline Co* & Yes & Yes & $\mathbf{R} \mathbf{b}^{*}$ & Yes & Yes \\
\hline $\mathrm{Cr}^{*}$ & Yes & Yes & $S c^{*}$ & Yes & Yes \\
\hline Cs & Yes & & $\mathrm{Se}$ & & Yes \\
\hline $\mathrm{Cu}$ & & Yes & $\mathrm{Sm}^{*}$ & Yes & Yes \\
\hline$D y^{*}$ & Yes & Yes & $\mathrm{Sr}$ & & Yes \\
\hline $\mathrm{Er}$ & & Yes & $\mathrm{Ta}$ & Yes & \\
\hline $\mathrm{Eu}^{*}$ & Yes & Yes & $\mathrm{Tb}$ & Yes & \\
\hline $\mathrm{Fe}$ & Yes & & Th* & Yes & Yes \\
\hline $\mathrm{Ga}$ & & Yes & $\mathrm{Ti}^{*}$ & Yes & Yes \\
\hline $\mathrm{Gd}$ & & Yes & $U$ & Yes & \\
\hline $\mathrm{Ge}$ & & Yes & $\mathbf{V}^{*}$ & Yes & Yes \\
\hline $\mathrm{Hf}^{*}$ & Yes & Yes & W & & Yes \\
\hline $\mathrm{La}^{*}$ & Yes & Yes & $Y$ & & Yes \\
\hline Lu & Yes & & $\mathrm{Yb}^{*}$ & Yes & Yes \\
\hline$M n^{*}$ & Yes & Yes & $\mathrm{Zn}^{*}$ & Yes & Yes \\
\hline $\mathrm{Na}$ & Yes & & $\mathrm{Zr}^{*}$ & Yes & Yes \\
\hline
\end{tabular}




\subsubsection{Statistical Method}

All data analysis was carried out using Statistica (Version 10, Statsoft, Tulsa, OK, USA). The original elemental concentrations were plotted via biplots. The data was then standardized to the mean for each element (z-transform). Any values that were less than zero due to background correction were assigned values of zero prior to the application of the transform. As explained earlier, cluster analysis was performed using average linkage and squared Euclidean distances as recommended by Glasscock [7]. In the cluster analysis, 4 clusters were identified based on the critical linkage distance and substructure within these clusters. This quantitative criterion for identifying distinct data clusters mentioned in the introduction section was employed in all cluster analyses described here. Cluster analysis was combined with PCA, a practice that is also common and recommended for analysis of chemical data used for grouping studies $[57,58]$.

\subsection{Results and Discussion}

\subsubsection{ICP-MS}

Ten replicates of each SRM (679, Brick Clay and 2711, Montana Soil) were prepared for intra-day and inter-day analysis following the procedure described above. The replicates of each reference materials were evaluated and the results are summarized in Tables 2.2 and 2.3. The \%RSD of the elements analyzed in SRM 679 is less than $3.2 \%$ with most below $2.0 \%$ and that in SRM 2711 is less than $5.3 \%$ with most below $3.0 \%$. Mn, Co, Rb, Sr, Eu and Th have similar recovery for both SRMs. Among these, Mn, Co, Eu and Th have greater 
than $50 \%$ recovery. Although there are no certified values for rare earth elements (REEs) such as La, Ce, Nd, Sm, Dy, Ho and Yb in SRM 679, the values found in SRM 2711 have more than 50\% recovery and low \%RSD (less than $2.0 \%$ ). Based on \%Recovery and \%RSD criteria (as well as other considerations previously noted), 32 elements were selected as a subset for additional ICP-MS study. Analytical results for the reference materials are summarized in Tables 2.3 and 2.4. Table 2.5 summarizes the limit of detection (LOD) and limit of quantitation (LOQ) values for the 32 elements selected for study. The LOD is calculated for each element by three times of the blank standard deviation (SD) divided by the slope of calibration curve (sensitivity), while the LOQ is ten times of that value. Blanks were prepared the same as the samples so that the method variation is captured in the calculation. 
Table 2.3: SRM 679 (Brick Clay) 10 replicates (intra and inter day)

\begin{tabular}{ccccc}
\hline Element & Average $\left(\mu \mathrm{g} \mathrm{g}^{-1}\right)$ & Certified $\left(\mu \mathrm{g} \mathrm{g}^{-1}\right)$ & \%Recovery & \%RSD \\
\hline $\mathrm{Ba}$ & 64.9 & $432.2 \pm 9.8$ & 15 & 1.8 \\
$\mathrm{Ce}^{*}$ & 47.3 & 105 & 45 & 1.1 \\
$\mathrm{Co}^{*}$ & 17 & 26 & 66 & 1.6 \\
$\mathrm{Cr}$ & 31.9 & $109.7 \pm 4.9$ & 29 & 2.4 \\
$\mathrm{Eu}^{*}$ & 1.15 & 1.9 & 60 & 1.2 \\
$\mathrm{Hf}^{*}$ & 0.68 & 4.6 & 15 & 3.2 \\
$\mathrm{Mn}^{*}$ & 148 & 1730 & 85 & 0.60 \\
$\mathrm{Rb}^{*}$ & 38.9 & 190 & 21 & 1.8 \\
$\mathrm{Sc}^{*}$ & 7.52 & 22.5 & 33 & 1.4 \\
$\mathrm{Sr}$ & 15.2 & $73.4 \pm 2.6$ & 21 & 1.5 \\
$\mathrm{Th}^{*}$ & 7.58 & 14 & 54 & 1.0 \\
$\mathrm{Ti}$ & 161.3 & $5770 \pm 330$ & 2.8 & 2.5 \\
$\mathrm{Zn}^{*}$ & 66.5 & 150 & 44 & 1.4 \\
\hline
\end{tabular}

*: Not NIST certified 
Table 2.4: SRM 2711 (Soil) 10 replicates (intra and inter day)

\begin{tabular}{|c|c|c|c|c|}
\hline Element & Average $\left(\mu \mathrm{g} \mathrm{g}^{-1}\right)$ & Certified $\left(\mu \mathrm{g} \mathrm{g}^{-1}\right)$ & \%Recovery & $\%$ RSD \\
\hline As & 79.8 & $105 \pm 8$ & 76 & 1.2 \\
\hline $\mathrm{Ba}$ & 182.4 & $726 \pm 38$ & 25 & 0.90 \\
\hline $\mathrm{Ce}^{*}$ & 45.3 & 69 & 66 & 0.90 \\
\hline Co* & 6.9 & 10 & 69 & 1.0 \\
\hline $\mathrm{Cr}^{*}$ & 15.2 & 47 & 32 & 2.4 \\
\hline $\mathrm{Cu}$ & 96.2 & $114 \pm 2$ & 84 & 1.2 \\
\hline Dy* & 3.1 & 5.6 & 55 & 1.1 \\
\hline $\mathrm{Eu}^{*}$ & 0.7 & 1.1 & 60 & 1.5 \\
\hline $\mathrm{Ga}^{*}$ & 62.6 & 15 & 417 & 2.2 \\
\hline $\mathrm{Ho}^{*}$ & 0.6 & 1 & 65 & 1.2 \\
\hline$H f^{*}$ & 0.7 & 7.3 & 9.5 & 1.7 \\
\hline $\mathrm{La}^{*}$ & 23.0 & 40 & 58 & 1.4 \\
\hline $\mathrm{Mn}$ & 508.7 & $638 \pm 28$ & 80 & 1.6 \\
\hline $\mathrm{Mo}^{*}$ & 1.3 & 1.6 & 82 & 3.1 \\
\hline $\mathrm{Nd}^{*}$ & 20.0 & 31 & 65 & 1.0 \\
\hline $\mathrm{Ni}$ & 15.0 & $20.6 \pm 1.1$ & 73 & 0.90 \\
\hline $\mathrm{Pb}$ & 1009.4 & $1162 \pm 31$ & 87 & 1.4 \\
\hline $\mathrm{Rb}^{*}$ & 27.1 & 110 & 25 & 2.2 \\
\hline $\mathrm{Sc}^{*}$ & 3.5 & 9 & 39 & 3.2 \\
\hline $\mathrm{Se}$ & 2.5 & $1.52 \pm 0.14$ & 167 & 5.3 \\
\hline $\mathrm{Sm}^{*}$ & 4.3 & 5.9 & 72 & 1.1 \\
\hline $\mathrm{Sr}$ & 45.5 & $245.3 \pm 0.7$ & 19 & 0.90 \\
\hline $\mathrm{Th}^{*}$ & 8.4 & 14 & 60 & 2.4 \\
\hline $\mathrm{Ti}$ & 415.3 & $3060 \pm 230$ & 14 & 4.4 \\
\hline $\mathrm{TI}$ & 1.2 & $2.47 \pm 0.15$ & 50 & 1.7 \\
\hline$U^{*}$ & 0.9 & 2.6 & 35 & 4.7 \\
\hline V & 31.9 & $81.6 \pm 2.9$ & 39 & 4.6 \\
\hline$W^{*}$ & 2.1 & 3 & 71 & 3.1 \\
\hline$Y^{*}$ & 16.6 & 25 & 67 & 1.4 \\
\hline $\mathrm{Yb}^{*}$ & 1.4 & 2.7 & 53 & 1.8 \\
\hline $\mathrm{Zn}$ & 282.4 & $350.4 \pm 4.8$ & 81 & 1.0 \\
\hline $\mathrm{Zr}^{*}$ & 12.8 & 230 & 5.6 & 2.8 \\
\hline
\end{tabular}

*: Not NIST certified 
Table 2.5: Final elements used in ICP-MS

\begin{tabular}{ccc}
\hline Element & $\mathrm{LOD}\left(\mu \mathrm{g} \mathrm{kg}{ }^{-1}\right)$ & $\left.\mathrm{LOQ}(\mu \mathrm{g} \mathrm{kg})^{-1}\right)$ \\
\hline $\mathrm{As}$ & 0.0777 & 0.259 \\
$\mathrm{Ba}$ & 3.48 & 11.6 \\
$\mathrm{Ce}$ & 0.0502 & 0.167 \\
$\mathrm{Co}$ & 0.101 & 0.338 \\
$\mathrm{Cr}$ & 1.90 & 6.32 \\
$\mathrm{Er}$ & 0.0374 & 0.125 \\
$\mathrm{Eu}$ & 0.0421 & 0.140 \\
$\mathrm{Ga}$ & 0.912 & 3.04 \\
$\mathrm{Gd}$ & 0.0411 & 0.137 \\
$\mathrm{Ge}$ & 0.649 & 2.16 \\
$\mathrm{Hf}$ & 0.0990 & 0.330 \\
$\mathrm{La}$ & 0.0448 & 0.149 \\
$\mathrm{Mn}$ & 19.8 & 65.9 \\
$\mathrm{Nb}$ & 0.752 & 2.51 \\
$\mathrm{Nd}$ & 0.0444 & 0.148 \\
$\mathrm{Ni}$ & 1.11 & 3.69 \\
$\mathrm{~Pb}$ & 0.444 & 1.48 \\
$\mathrm{Pr}$ & 0.0385 & 0.128 \\
$\mathrm{Rb}$ & 2.49 & 8.29 \\
$\mathrm{Sc}$ & 0.0718 & 0.239 \\
$\mathrm{Se}$ & 1.30 & 4.32 \\
$\mathrm{Sm}$ & 0.0385 & 0.128 \\
$\mathrm{Sr}$ & 2.61 & 8.69 \\
$\mathrm{Th}$ & 0.0474 & 0.158 \\
$\mathrm{Ti}$ & 0.110 & 0.367 \\
$\mathrm{~V}$ & 0.0678 & 0.226 \\
$\mathrm{~W}$ & 0.379 & 1.26 \\
$\mathrm{Y}$ & 0.0417 & 0.139 \\
$\mathrm{Yb}$ & 0.0418 & 0.139 \\
$\mathrm{Zn}$ & 8.18 & 27.3 \\
$\mathrm{Zr}$ & 0.279 & 0.931 \\
\hline & &
\end{tabular}




\subsubsection{Statistical Analysis}

In archaeology pottery analysis, samples are similar to geological samples (clay), but different in that they reflect in human activity in the manufacture process. Therefore, simple compositional comparison between pottery and clay is not always feasible. There is no standard statistical methodology that can be used in all cases, and the issue has not been fully resolved $[7,59]$.

In this work, the bivariate plot was applied to the raw data of elemental concentrations to reveal obvious grouping in the pottery. The reason for analyzing clay or ash separately from pottery is that these materials are expected to be chemically different from each other. By observing the plots, one group of eleven samples is well separated from others in several combinations of elements. These samples include Tz-404, Tz-408, Tz-417, Tz-471, Tz-473, Tz474, Tz-477, Tz-479, Tz-481, Tz-483, and Tz-15. Figure 2.1 and 2.2 show example plots found that can be used to reveal groups. Figure 2.1 is the biplot of $\mathrm{Y}$ against $\mathrm{Hf}$, and Figure 2.2 is the biplot of $\mathrm{Zn}$ against $\mathrm{Rb}$. Notice in Figure 2.2, several substructures can be observed. There are two samples (Tz-432, Tz-439) separated from the larger group. 
Figure 2.1: Pottery samples biplot of $\mathrm{Y}$ against $\mathrm{Hf}$ (concentration data, unprocessed)

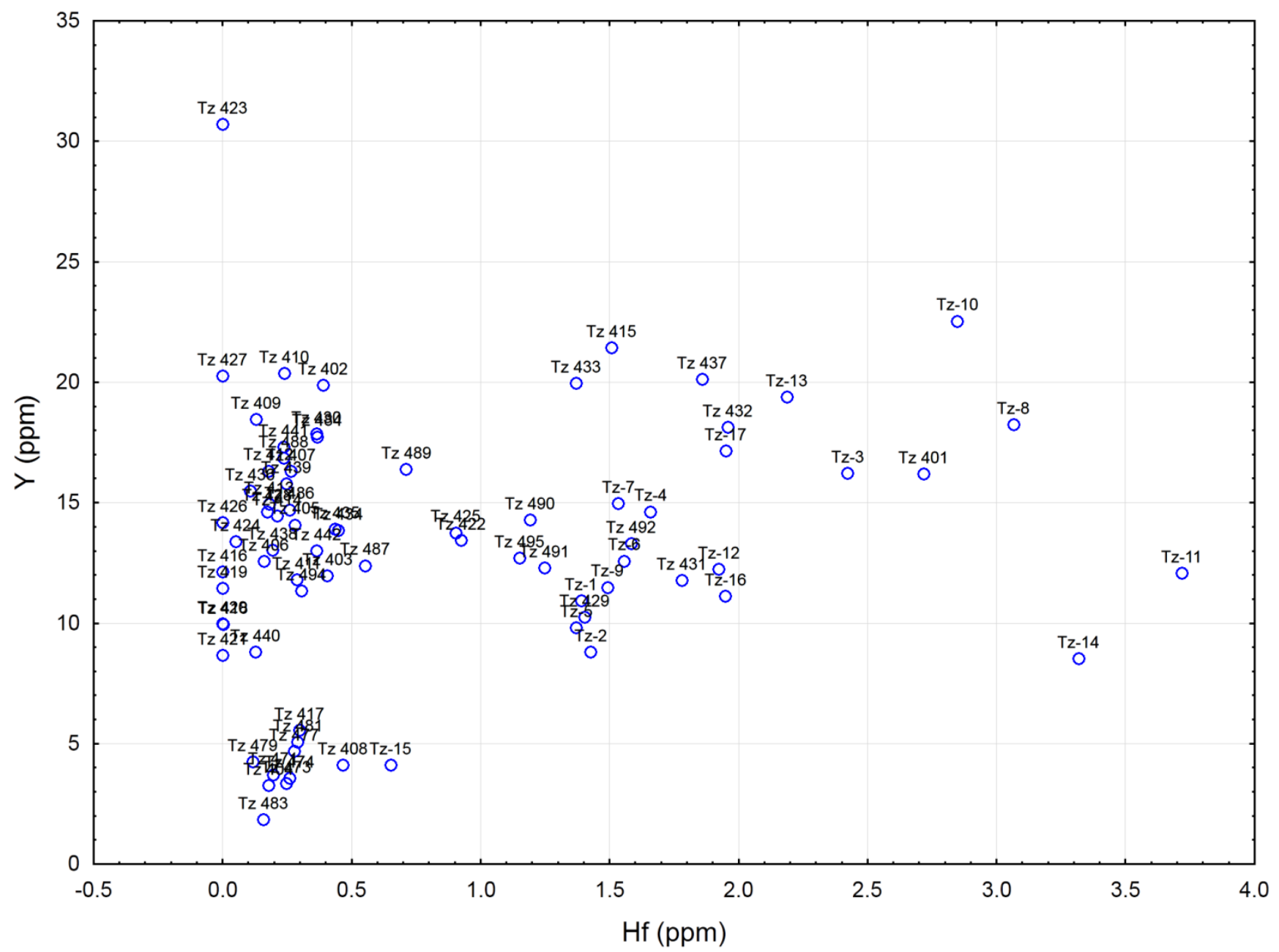


Figure 2.2: Pottery samples biplot of $\mathrm{Zn}$ against $\mathrm{Rb}$ (concentration data, unprocessed).

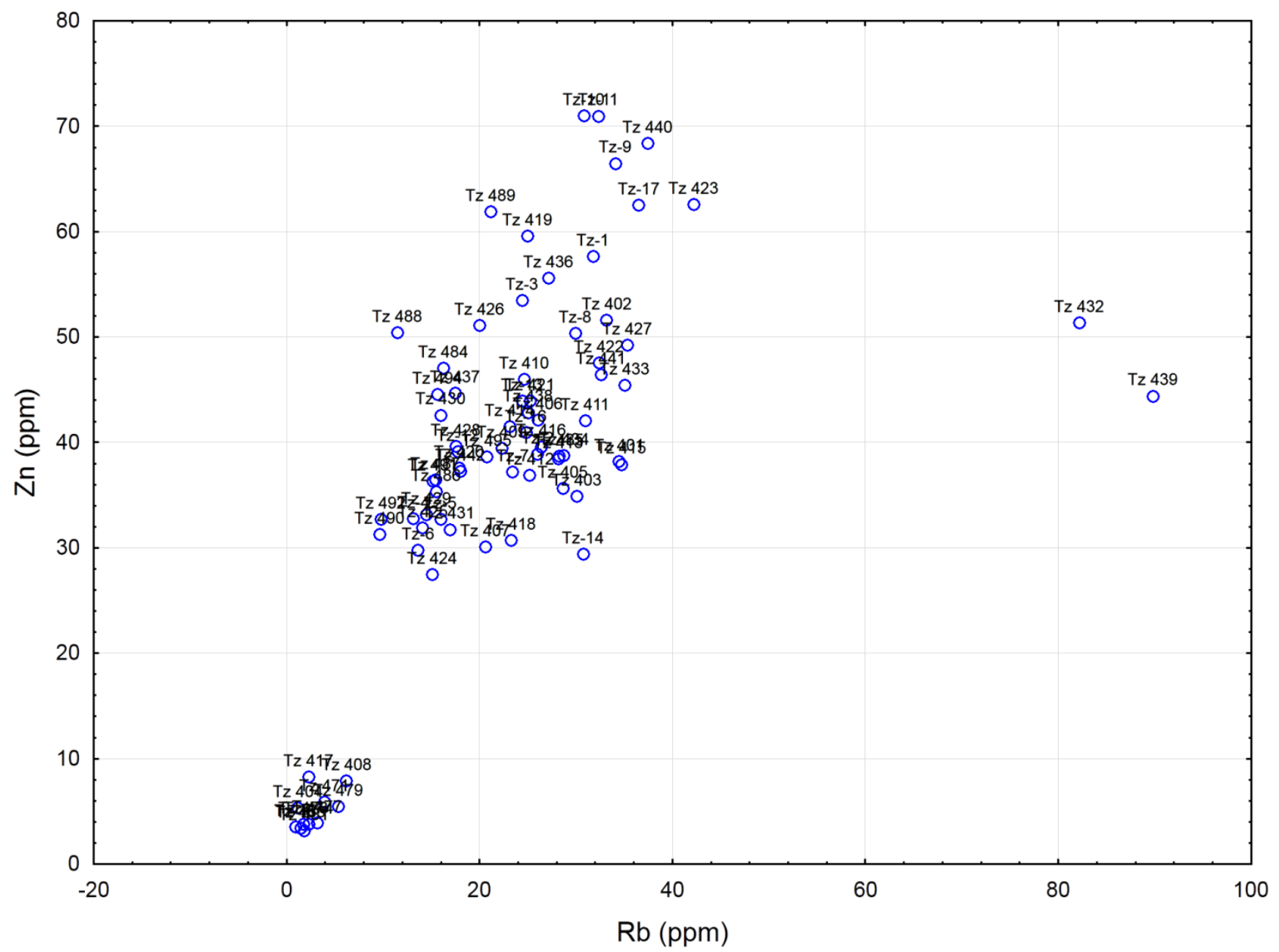


Figure 2.3: Pottery samples scatterplot of $\mathrm{Ga}$ against $\mathrm{Ba}$ (concentration data, unprocessed)

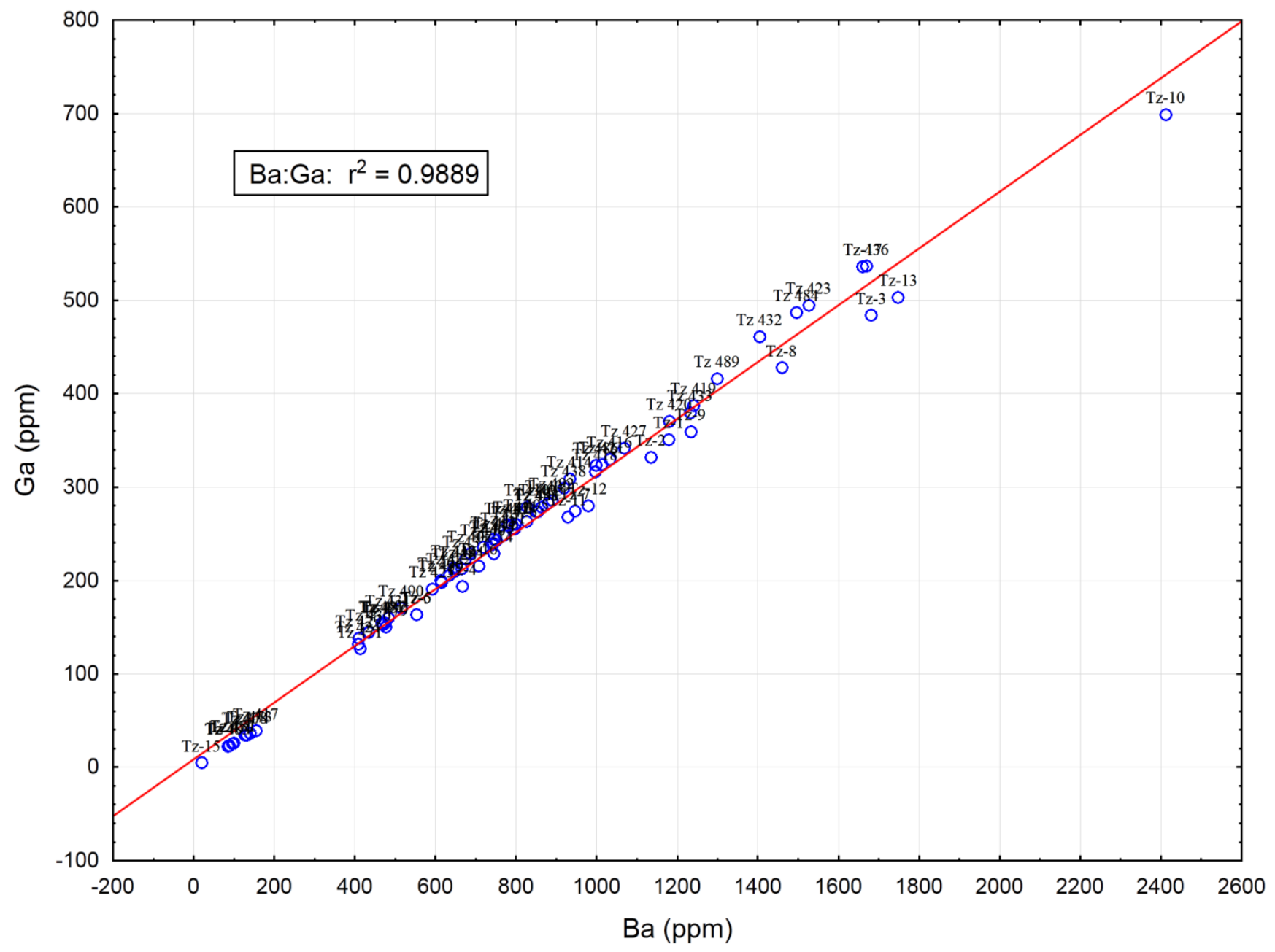


Another observation is that some elements, such as $\mathrm{Ga}$ and $\mathrm{Ba}$ are highly correlated with each other as shown in Figure 2.3. Here, the two elements are almost perfectly linearly correlated. This means that they provide the same information in the grouping. In some archaeological papers, reduction of variables was suggested based on these correlations [59]. The authors also calculated the ratio between REEs and altered their data whose ratio seems different than others. In this study, all the elements were retained and the data remained unchanged for further analysis to avoid any possible loss of information though may add to the complexity of interpretation.

As explained earlier, data was normalized by z-transform. Since the preparation method used here is based on extractability, different elements have different recovery. However, the portion extracted does proceed as expected, to be relatively reproducible to the extent that the samples are similar. The standardization will essentially eliminate this problem by forcing the elemental concentrations into the same scale. The question that arises is whether or not to normalize the clay and ash samples together with the pottery. If all of the data is normalized together, the results will decrease the difference between the clay, ash and the pottery. However, if they are normalized separately, it is impossible to compare the clay and ash samples to the pottery by the normalized data from pottery only.

The same concern was raised for the PCA. If the PCs were calculated separately from pottery and clay/ash, it is again difficult to make a meaningful comparison based on the different scales. Unfortunately, although MURR stated 
this issue and chose to calculate PCs based on total dataset, the reason was not clearly stated [7]. In this study, the following methods were examined: first, the pottery sub set was normalized followed by PCA and cluster analysis; second, the overall dataset was normalized followed by PCA, and cluster analysis was applied to the pottery only.

At first stage of the analysis, PCA was applied to the normalized pottery dataset and the PCs were calculated for each sample. First two PCs account for about $70 \%$ variables, while five PCs accounts for more than $85 \%$ of variance. The correlation matrix was analyzed here, but essentially it is the same to the covariance matrix since the dataset has already been standardized. All elements but $\mathrm{W}$ are negatively loaded in first PC, while most REEs are positively loaded in second and third PC. This shows that the REEs are highly correlated with each other.

Cluster analysis was applied to the first five PCs to incorporate most of the variance. The hierarchical clustering is preferred because it is considered to be unsupervised, therefore suitable in archaeological study since the groups are unknown [55]. Average linkage and squared Euclidean distance were the most used in the archaeological cluster analysis [7]. Figure 2.4 shows the resulting tree plot of the clusters. The scree plot of linkage distances versus amalgamation step was used to determine the delineation between separated groups. The scree plots can be found in Appendix A. The tree diagram shows that there are six separated groups, however, two together only contain a total of five samples (Tz-8, Tz-10, Tz-11, Tz-13, Tz-14). These are likely to be 
unassigned samples that do not belong to any group. The remaining four groups include a group (D) that contains mostly Pottery Group 1 (PG1) members described in Hirshman's previous work, one group (C) that stands alone in the scatterplot, and two groups (A and B) that mostly have the Main Pottery Group (MainPG) members [4]. The grouping shows more details in the previously found MainPG.

Mahalanobis distance was then calculated using the five PCs to confirm the grouping. As described by Glascock, the Mahalanobis distance takes into account the correlation between variables [7]. When the dataset is converted to PCs, the two PCs have no correlation between each other. Therefore, Euclidean distance calculated based on standardized PCs offers the same results compared to Mahalanobis distance. Although the PCs in the whole dataset are not correlated, a possible correlation may exist between the PCs within the smaller groups [7]. Each sample was calculated to the centroid of the groups. One sample (Tz-403) was reassigned from group $D$ to group $A$ according to the Mahalanobis distance. The complete table of Mahalanobis distances can be found in Appendix B. 
Table 2.6: The complete dataset

\begin{tabular}{|c|c|c|c|c|}
\hline ID & Material & MURR & Method 1 & Method 2 \\
\hline Tz-1 & Pottery & Unassigned & $B$ & $A^{\prime}$ \\
\hline Tz-2 & Pottery & MainPG & B & $A^{\prime}$ \\
\hline Tz-3 & Pottery & MainPG & B & $\mathrm{B}^{\prime}$ \\
\hline Tz-4 & Pottery & Unassigned & B & $A^{\prime}$ \\
\hline Tz-5 & Pottery & MainPG & B & $A^{\prime}$ \\
\hline Tz-6 & Pottery & MainPG & B & $A^{\prime}$ \\
\hline Tz-7 & Pottery & MainPG & B & $\mathrm{B}^{\prime}$ \\
\hline Tz-8 & Pottery & Unassigned & Unassigned & Unassigned \\
\hline Tz-9 & Pottery & MainPG & A & Unassigned \\
\hline Tz-10 & Pottery & Unassigned & Unassigned & $D^{\prime}$ \\
\hline Tz-11 & Pottery & PG1 & Unassigned & Unassigned \\
\hline Tz-12 & Pottery & MainPG & B & $A^{\prime}$ \\
\hline Tz-13 & Pottery & MainPG & Unassigned & $A^{\prime}$ \\
\hline Tz-14 & Pottery & Unassigned & Unassigned & Unassigned \\
\hline Tz-15 & Pottery & PG1 & C & $C^{\prime}$ \\
\hline Tz-16 & Pottery & PG1 & A & $D^{\prime}$ \\
\hline Tz-17 & Pottery & PG1 & A & $D^{\prime}$ \\
\hline Tz-401 & Pottery & & D & $D^{\prime}$ \\
\hline Tz-402 & Pottery & & D & $D^{\prime}$ \\
\hline Tz-403 & Pottery & & A & $D^{\prime}$ \\
\hline Tz-404 & Pottery & PG1 & C & $C^{\prime}$ \\
\hline Tz-405 & Pottery & PG1 & D & $\mathrm{D}^{\prime}$ \\
\hline Tz-406 & Pottery & PG1 & D & $D^{\prime}$ \\
\hline Tz-407 & Pottery & PG1 & D & $\mathrm{D}^{\prime}$ \\
\hline Tz-408 & Pottery & PG1 & C & $C^{\prime}$ \\
\hline Tz-409 & Pottery & PG1 & D & $D^{\prime}$ \\
\hline Tz-410 & Pottery & PG1 & D & $B^{\prime}$ \\
\hline Tz-411 & Pottery & PG1 & A & $D^{\prime}$ \\
\hline Tz-412 & Pottery & PG1 & D & $D^{\prime}$ \\
\hline Tz-413 & Pottery & PG1 & D & $\mathrm{D}^{\prime}$ \\
\hline Tz-414 & Pottery & PG1 & D & $D^{\prime}$ \\
\hline Tz-415 & Pottery & PG1 & D & $\mathrm{B}^{\prime}$ \\
\hline Tz-416 & Pottery & PG1 & $A$ & $A^{\prime}$ \\
\hline Tz-417 & Pottery & PG1 & C & $C^{\prime}$ \\
\hline Tz-418 & Pottery & PG1 & $A$ & $A^{\prime}$ \\
\hline Tz-419 & Pottery & MainPG & A & $A^{\prime}$ \\
\hline Tz-420 & Pottery & MainPG & A & $A^{\prime}$ \\
\hline Tz-421 & Pottery & MainPG & A & $A^{\prime}$ \\
\hline Tz-422 & Pottery & MainPG & A & $A^{\prime}$ \\
\hline
\end{tabular}


Table 2.6: continued

\begin{tabular}{|c|c|c|c|c|}
\hline ID & Material & MURR & Method 1 & Method 2 \\
\hline Tz-423 & Pottery & Unassigned & D & $\mathrm{D}^{\prime}$ \\
\hline Tz-424 & Pottery & MainPG & A & $A^{\prime}$ \\
\hline Tz-425 & Pottery & MainPG & B & $\mathrm{B}^{\prime}$ \\
\hline Tz-426 & Pottery & MainPG & A & $A^{\prime}$ \\
\hline Tz-427 & Pottery & MainPG & D & $\mathrm{B}^{\prime}$ \\
\hline Tz-428 & Pottery & MainPG & A & $A^{\prime}$ \\
\hline Tz-429 & Pottery & Unassigned & A & $A^{\prime}$ \\
\hline Tz-430 & Pottery & Unassigned & D & $\mathrm{B}^{\prime}$ \\
\hline Tz-431 & Pottery & Unassigned & B & $\mathrm{B}^{\prime}$ \\
\hline Tz-432 & Pottery & Unassigned & D & $\mathrm{B}^{\prime}$ \\
\hline Tz-433 & Pottery & PG1 & D & $D^{\prime}$ \\
\hline Tz-434 & Pottery & MainPG & A & $A^{\prime}$ \\
\hline Tz-435 & Pottery & PG1 & A & $A^{\prime}$ \\
\hline Tz-436 & Pottery & MainPG & A & $\mathrm{B}^{\prime}$ \\
\hline Tz-437 & Pottery & Unassigned & D & $\mathrm{B}^{\prime}$ \\
\hline Tz-438 & Pottery & MainPG & A & $\mathrm{B}^{\prime}$ \\
\hline Tz-439 & Pottery & MainPG & A & $D^{\prime}$ \\
\hline Tz-440 & Pottery & Unassigned & A & $A^{\prime}$ \\
\hline Tz-441 & Pottery & MainPG & A & $D^{\prime}$ \\
\hline Tz-442 & Pottery & MainPG & A & $A^{\prime}$ \\
\hline Tz-471 & Pottery & & C & $C^{\prime}$ \\
\hline Tz-473 & Pottery & & C & $C^{\prime}$ \\
\hline Tz-474 & Pottery & & C & $C^{\prime}$ \\
\hline Tz-477 & Pottery & & C & $C^{\prime}$ \\
\hline Tz-479 & Pottery & & C & $C^{\prime}$ \\
\hline Tz-481 & Pottery & & C & $C^{\prime}$ \\
\hline Tz-483 & Pottery & & C & $C^{\prime}$ \\
\hline Tz-484 & Pottery & & A & $A^{\prime}$ \\
\hline Tz-486 & Pottery & & D & $B^{\prime}$ \\
\hline Tz-487 & Pottery & & A & $A^{\prime}$ \\
\hline Tz-488 & Pottery & & D & $A^{\prime}$ \\
\hline Tz-489 & Pottery & & A & $A^{\prime}$ \\
\hline$T z-490$ & Pottery & & B & $A^{\prime}$ \\
\hline Tz-491 & Pottery & & B & $A^{\prime}$ \\
\hline Tz-492 & Pottery & & B & $A^{\prime}$ \\
\hline Tz-494 & Pottery & & A & $A^{\prime}$ \\
\hline Tz-495 & Pottery & & B & $\mathrm{B}^{\prime}$ \\
\hline
\end{tabular}


Table 2.6: Continued

\begin{tabular}{|c|c|c|c|c|}
\hline ID & Material & MURR & Method 1 & Method 2 \\
\hline Tz-443 & Ash & $P G 1^{*}$ & & $A^{\prime}$ \\
\hline Tz-444 & Ash & MainPG* & & $A^{\prime}$ \\
\hline Tz-445 & Ash/clay & MainPG* & & $A^{\prime}$ \\
\hline Tz-446 & Clay & & & \\
\hline Tz-447 & Ash & & & $A^{\prime}$ \\
\hline Tz-448 & Clay & & & \\
\hline HPC601 & Clay & & & \\
\hline HPC602 & Clay & & & \\
\hline HPC603 & Clay & & & \\
\hline HPC604 & Clay & & & \\
\hline HPC605 & Clay & & & \\
\hline HPC606 & Clay & & & \\
\hline HPC607 & Clay & & & \\
\hline HPC608 & Clay & & & \\
\hline HPC609 & Clay & & & \\
\hline HPC610 & Clay & & & \\
\hline HPC611 & Ash/clay & & & $C^{\prime}$ \\
\hline HPC612 & Clay & & & \\
\hline HPC613 & Clay & & & \\
\hline HPC614 & Clay & & & \\
\hline HPC615 & Clay & & & \\
\hline HPC616 & Clay & & & \\
\hline HPC617 & Clay & & & \\
\hline HPC618 & Clay & & & \\
\hline
\end{tabular}
standardized pottery separately, method 2 standardized the whole dataset. Group labeled in blue are the overlapping members.

* The grouping was a result of mathematically modeling clay-ash combinations. 
Figure 2.4: Tree diagram of PC 1-5 of pottery in separately standardized dataset

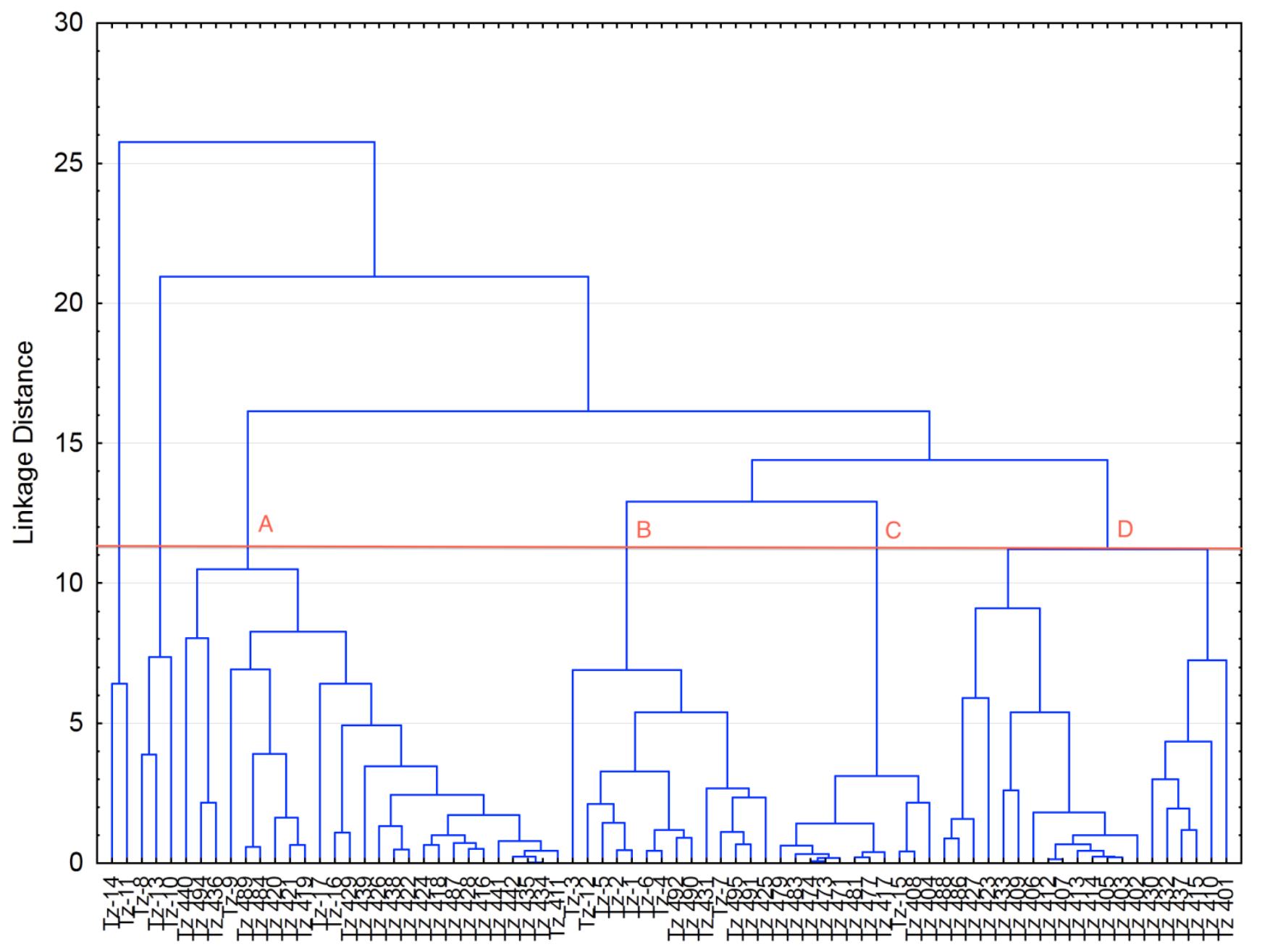


The resulting grouping is then compared to the grouping assigned by MURR in the previous study [4]. As mentioned earlier, most members formed groups that similar to MURR grouping. In Group A, there are several samples that are either unassigned or PG1 in previous study, including Tz-440 and Tz429 (unassigned), Tz-16, Tz-17, Tz-411, Tz-416, Tz-418, and Tz-435 (PG1). In Group B, Tz-1 and Tz-4 was unassigned. Total ten samples were assigned differently in groups A and B (previously MainPG). In Group C, Tz-404 was unassigned. In Group D, Tz-427 was previously in MainPG, while Tz-423, Tz430, Tz-432, Tz-437 were unassigned. Total six samples were assigned differently in groups $C$ and $D$ (previously PG1).

To better understand the chemical relationship that defined the groupings, plots of the mean of analyzed elemental concentrations were generated for each group with the $95 \%$ confidence interval. An examination of the plots showed that five elements, $\mathrm{Ti}, \mathrm{Mn}, \mathrm{Ga}, \mathrm{Sr}$, and $\mathrm{Ba}$ had mean concentrations significantly and consistently higher than that of all other elements and were plotted separately (Figure 2.5). Group C had the lowest concentration of all the elements except $\mathrm{Nb}, \mathrm{Hf}$, and $\mathrm{W}$ compare to other groups, therefore very distinctive. Group C consists the eleven-sample group that observed earlier in the biplots. Group A, $\mathrm{B}$, and D show similar mean concentration in Figure 2.5. 
Figure 2.5: Mean plots of Ti, Mn, Ga, Sr, and Ba of the groups A, B, C, and D.

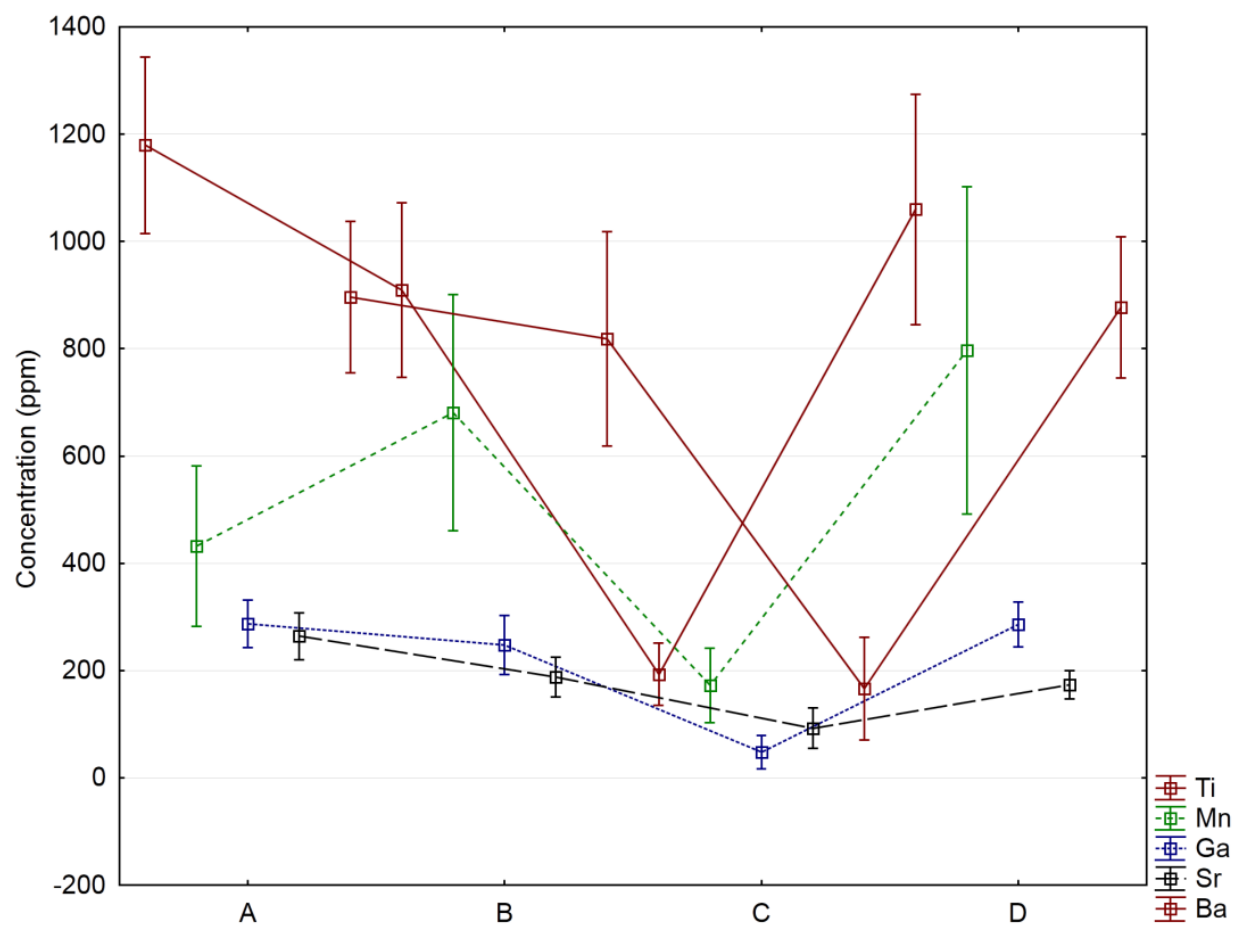


Figure 2.6: Mean plots of Eu, Gd, Dy, Er, and $\mathrm{Yb}$ of the groups $\mathrm{A}, \mathrm{B}, \mathrm{C}$, and D.

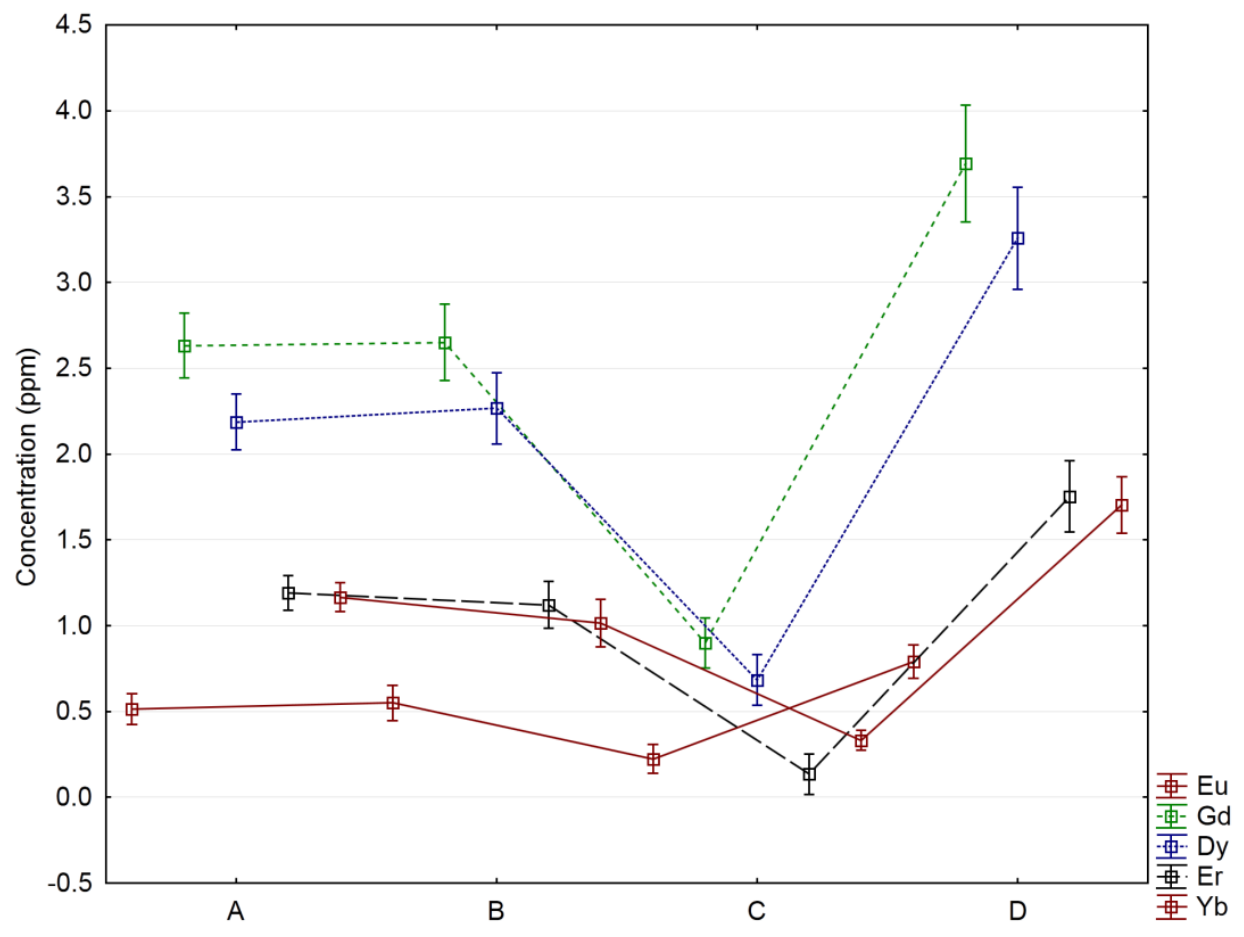


Group $D$ is distinguishable from $A, B$, and $C$ through the enrichment of most REEs such as $\mathrm{Y}, \mathrm{La}, \mathrm{Pr}, \mathrm{Nd}, \mathrm{Sm}$, Eu, Gd, Dy, Er, $\mathrm{Yb}$, as well as $\mathrm{Pb}$ and Th. Example mean plots of Eu, Gd, Dy, Er, and $\mathrm{Yb}$ are shown in Figure 2.6. Notice that the concentration scale is considerably less than that of Figure 2.5. The other mean plots can be found in Appendix C. The REEs have similar trend.

Group A and B have comparable means for most elements. The only difference is that group B has considerably higher $\mathrm{Hf}$ and $\mathrm{Zr}$, than group $\mathrm{A}$. It is worth mentioning that $\mathrm{Hf}$ and $\mathrm{Zr}$ belong to the same group in the periodic table and would be expected to co-occur in nature.

Although the above analysis offered good separation of groups within the pottery samples, it is difficult to compare the clay and ash samples to the grouping. As mentioned earlier, the concentration data from clay and ash samples was not normalized with the pottery samples, so they are not in the same scale for comparison. Therefore, the second method was examined as follows.

For the second method, the whole dataset was normalized and PCA was performed. Similarly, first two PCs account for about $70 \%$ variables, while five PCs accounts for more than $85 \%$ of variance. All elements but $\mathrm{Sr}$ and $\mathrm{W}$ are negatively loaded in first PC, while some REEs are positively loaded in second PC and most are negatively loaded in third PC. This is different from the PCs calculated from pottery data subset. This indicates that the PCs calculated from 
the whole dataset accounted for different elements than the PCs calculated from pottery only. This is likely the reason of the moving of samples in the groups.

Cluster analysis was performed on the first five PCs of pottery samples only. The resulting tree diagram is shown in Figure 2.7. The results show six groups with two groups contain only four samples total (Tz-8, Tz-9, Tz-11, Tz14), similar to the two groups in the first method. The remaining four groups contain a group $\mathrm{C}^{\prime}$, equal to group $\mathrm{C}$ in first method, which contains the eleven standalone samples. Group $D^{\prime}$ is similar to group D, which contains mostly PG1 in MURR study. While group $A^{\prime}$ and $B^{\prime}$ combined is similar to $A$ and $B$ combined, the two groups are rearranged in distribution. Notice the groups are labeled according to the similarity to the previous groups for easier comparison.

After the cluster analysis, Mahalanobis distance was calculated to confirm the groups. Three samples were marked as incorrectly classified: Tz-434 and Tz-435 changed from group $D^{\prime}$ to group $A^{\prime}$, while Tz-488 changed from group $B^{\prime}$ to group $A^{\prime}$. After readjusting the groups, Mahalanobis distance was calculated again to make sure all samples were in the correct group. 
Figure 2.7: Tree diagram of PC 1-5 of pottery in standardized whole dataset.

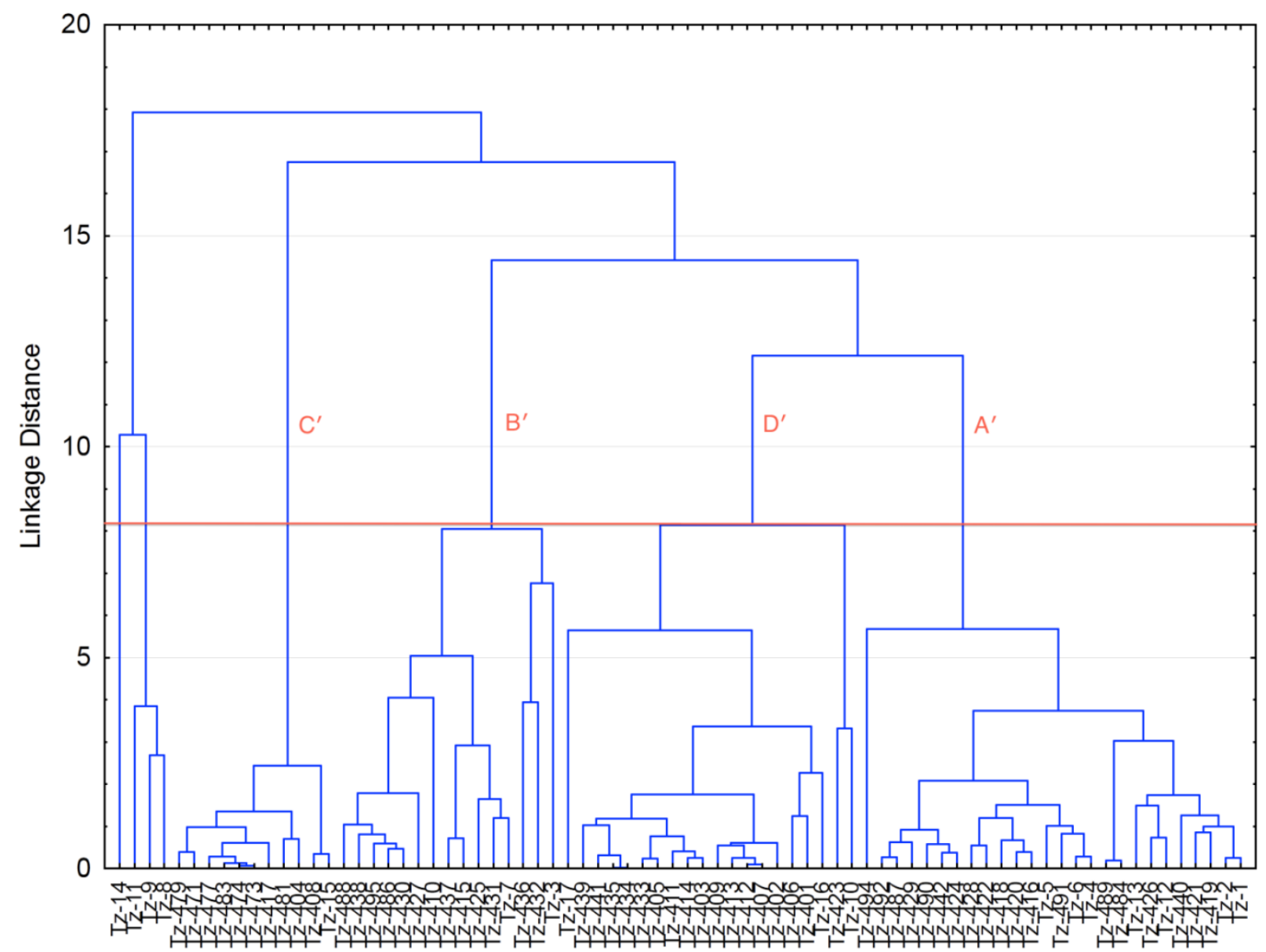


The groups were then compared to the groups from MURR. In group $A^{\prime}$, two samples were from PG1 (Tz-416 and Tz-418), and four samples were unassigned (Tz-2, Tz-4, Tz-429, and Tz-440). In group B', two PG1 samples (Tz410, Tz-415) and four unassigned samples (Tz-430, Tz-431, Tz-432, and Tz437), were also found. The twelve total samples were assigned differently in groups $A^{\prime}$ and $B^{\prime}$ (MainPG). Group $D^{\prime}$ has three MainPG samples (Tz-434, Tz439, and Tz-441) and two unassigned samples (Tz-10 and Tz-423). A total of six samples were assigned differently in groups $C^{\prime}$ and $D^{\prime}(P G 1)$. This is similar to the first method. While the groups overlap with the MURR groups, the ICP-MS method can reveal more diversity within the group.

Again, plots of the mean of analyzed elemental concentrations were generated for each group with the $95 \%$ confidence interval. Group $C^{\prime}$ is the same as group $\mathrm{C}$, has the lowest concentration of most elements except $\mathrm{Nb}, \mathrm{Hf}$, and $\mathrm{W}$. The reason that this group is lower in most elements is possibly because these samples contain more silicate related minerals than the others. Since silicates are not dissolved in the digestion method used here, the elements trapped in the silicates cannot be recovered. Groups $\mathrm{A}^{\prime}, \mathrm{B}^{\prime}$ and $\mathrm{D}^{\prime}$ have similar mean concentration in most elements take into consideration of $95 \%$ confidence interval. Group $D^{\prime}$ is separated from groups $A^{\prime}$ and $B^{\prime}$ by lower mean concentration of Ni. Group B' has higher mean concentrations of Mn, Co, Se, Y, $\mathrm{La}, \mathrm{Ce}, \mathrm{Pr}$, and $\mathrm{Nd}$ than group $\mathrm{A}^{\prime}$. The compositional difference of group $\mathrm{D}^{\prime}$ is not as clear as the first method, but the difference between groups $A^{\prime}$ and $B^{\prime}$ is larger than the first method. The mean plots can be found in Appendix C. 
Mahalanobis distance was calculated for the clay and ash samples together using the first five PCs. The squared Mahalanobis distance between groups can be found in Table 2.7. The distances show that group $C^{\prime}$ and $D^{\prime}$ are the closest. However, distances between $\mathrm{A}^{\prime}$ and $\mathrm{B}^{\prime}$ are longer than distances between $\mathrm{A}^{\prime}$ and $\mathrm{D}^{\prime}$ or $\mathrm{B}^{\prime}$ and $\mathrm{D}^{\prime}$. Based on the distance to the different centroid of groups, ashes Tz-443, Tz-444, Tz-445, and Tz-447 can be assigned to group A', while ash HPC611 can be assigned to group $C^{\prime}$ (Table 2.8). The complete calculated distances can be found in Appendix B. All the clays are far away from the centroid of all groups, causing no link between them and any group. This result also confirmed the previous study that none of the clays can be grouped with pottery directly [4]. 
Table 2.7: Squared Mahalanobis distances between groups

\begin{tabular}{lllll}
\hline Group & $\mathrm{A}^{\prime}$ & $\mathrm{B}^{\prime}$ & $\mathrm{C}^{\prime}$ & $\mathrm{D}^{\prime}$ \\
\hline $\mathrm{A}^{\prime}$ & 0 & & & \\
$\mathrm{~B}^{\prime}$ & 26.31 & 0 & & \\
$\mathrm{C}^{\prime}$ & 33.28 & 25.49 & 0 & \\
$\mathrm{D}^{\prime}$ & 18.75 & 19.95 & 11.76 & 0 \\
\hline
\end{tabular}

Table 2.8: Selected squared Mahalanobis distances

\begin{tabular}{lccccc}
\hline & Observed & $\mathrm{A}^{\prime}$ & $\mathrm{B}^{\prime}$ & $\mathrm{C}^{\prime}$ & $\mathrm{D}^{\prime}$ \\
\hline HPC611 & --- & 10.4 & 32.1 & 6.79 & 26.7 \\
Tz 443 & --- & 9.87 & 47.0 & 19.0 & 30.9 \\
Tz 444 & --- & 5.17 & 35.0 & 26.6 & 23.1 \\
Tz 445 & --- & 15.3 & 49.1 & 43.5 & 39.4 \\
Tz 447 & --- & 10.8 & 40.6 & 23.9 & 34.5 \\
\hline
\end{tabular}


Figure 2.8 shows the biplot of the first two PCs, which account for $70.5 \%$ of the variance. It is clear that clay samples are cluster together, away from pottery and ash samples. HPC611 is very close to the cluster of eleven samples (group $\mathrm{C} / \mathrm{C}^{\prime}$ ), and the other ash samples are closer to the pottery samples. HPC611 is found previously unable to match with any compositional group. The group $\mathrm{C} / \mathrm{C}^{\prime}$ found here contains mainly new samples analyzed by ICP-MS, three PG1 samples, and an unassigned MURR sample. All ashes matching group $A^{\prime}$ came from the Urichu site.

Although the clays cannot be assigned to groups based on the Mahalanobis distance, there are several clays that are closer to one group than to others. These include HPC602, 603, 608, 614, 618, and Tz-446 that close to $\mathrm{A}^{\prime}$, and HPC 612 and 617 to $\mathrm{B}^{\prime}$. This indicates that pottery was possibly made from a mixture of clay and ash. Clay also has a higher mean concentration of most elements compared to ash and pottery samples. As mentioned earlier, the ash samples are mostly from an archaeological excavation, and clay samples are from easily accessible areas. The match of excavated samples could also mean that the clay samples collected around the Basin were not the same clay sources that available to the potters hundreds of years ago. 
Figure 2.8: Plot of PC1 and PC2 of all samples

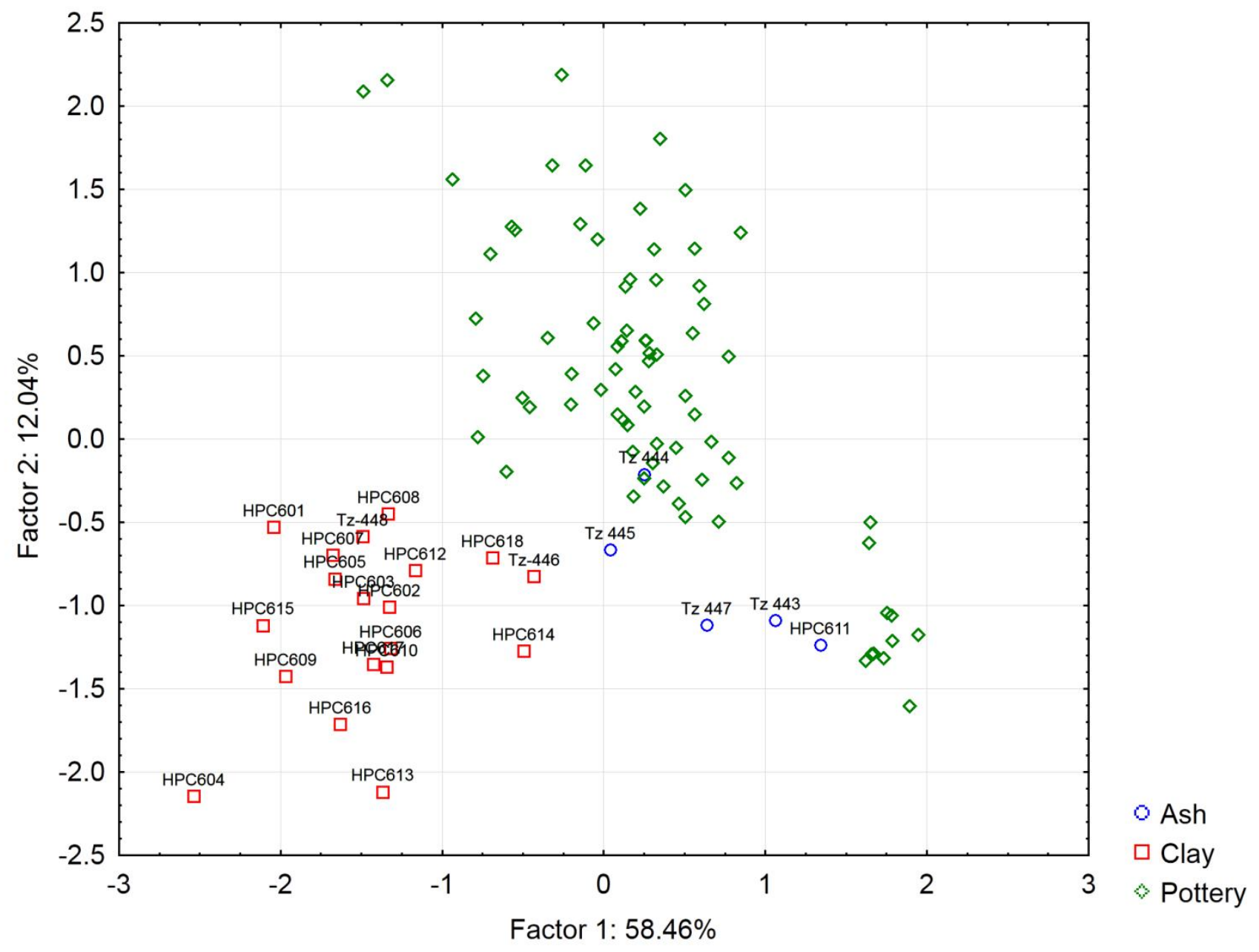




\subsection{Conclusions}

The simplified acid digestion method proposed here can be used successfully for the classification of archaeological ceramics. Archaeologically meaningful data can be derived from this ICP-MS digestion method and the statistical treatment used here.

The analytical work and statistical analysis conducted here reinforced the understanding of the general chemical relationship between the ashes, clays, and ceramics within the Basin. Ceramic production occurred on a broad scale within the Basin. By comparing to previous groups in MURR data, the groups generated here roughly matched yet provided more diversity within the MainPG.

The analytical method described here is acceptably reproducible (as gauged using standard reference materials), so additional samples can be analyzed as they are collected from the Basin and added to the existing dataset as long as the figures of merit from SRMs are verified. Additional samples should help clarify and stabilize grouping assignments. Once this is accomplished, the target element list for the ICP-MS protocols can be fine-tuned based on analytical as well as archaeological merit. 


\section{Chapter 3: Gunshot Residues}

\subsection{Introduction}

The objective of this research is to differentiate shooters from nonshooters through the detection of inorganic gunshot residue (GSR) on hands. The primary goal was to develop a sample protocol that can be used in the forensic field, while the ultimate goal was to integrate these results with organic GSR and generate a more comprehensive method.

GSR is considered to be one of the most important forms of evidence in a crime involving firearms. The details about GSR can be found in section 1.2.2. Despite the importance of GSR, there is no standard method that can tell whether a suspect discharged a weapon. SEM has been used for the inorganic GSR particle detection for years [20,60,61]; however, this type of evidence is coming under increasing scrutiny. It is not the analytical method per se that is questioned, but rather the interpretation of the meaning and the value of a positive result. Thus, a designation of shooters vs. non-shooters based solely on SEM-EDS results is being questioned [62]. This method cannot tell the time at which the shot was fired because it does not provide quantitative information.

Other techniques have been explored as well. Koons et al. analyzed gunshot primer residue on swabs using flameless atomic absorption spectrometry (AAS) [63], as well as inductively coupled plasma atomic emission spectrometry (ICP-AES) [64]. Koons first introduced ICP-MS to the GSR study in 1998 [65]. Although there have been several studies since then, the method was still not used in casework to any significant degree [61,66-68]. Santos et al. studied the firing distance through the analysis of gunshot residue deposit 
patterns around the bullet entrance [69]. Sarkis et al. indicated a possibility to differentiate between shooting and non-shooting hand as well as different weapons using ternary plots based on $\mathrm{Sb}, \mathrm{Ba}$, and $\mathrm{Pb}[70]$. Udey et al. studied different bullet types by analyzing the shot and unshot tissue using ${ }^{56} \mathrm{Fe}$ and ${ }^{63} \mathrm{Cu}$ in combination with ${ }^{121} \mathrm{Sb},{ }^{138} \mathrm{Ba}$, and ${ }^{208} \mathrm{~Pb}$. Udey concluded that these five elements were able to distinguish between the two bullet types [68]. Yañez et al. applied regularized discriminant analysis on a range of metals $(\mathrm{Al}, \mathrm{Ba}, \mathrm{Ca}, \mathrm{Cu}$, $\mathrm{Fe}, \mathrm{K}, \mathrm{Mg}, \mathrm{Pb}, \mathrm{Sb}$, and $\mathrm{Zn}$ ) to differentiate two ammunition brands [71]. More recently, Abrego et al. characterized GSR and detected additional elements $\left({ }^{27} \mathrm{Al}\right.$, ${ }^{29} \mathrm{Si},{ }^{31} \mathrm{P},{ }^{33} \mathrm{~S},{ }^{35} \mathrm{Cl},{ }^{39} \mathrm{~K},{ }^{44} \mathrm{Ca},{ }^{57} \mathrm{Fe},{ }^{60} \mathrm{Ni},{ }^{63} \mathrm{Cu},{ }^{66} \mathrm{Zn}$, and ${ }^{118} \mathrm{Sn}$ ) using scanning LA-ICP-MS [72].

In typical GSR samples, lead is the most abundant element. Lead also has several natural isotopes present at levels detectable by ICP-MS. Lead isotopes, including ${ }^{204} \mathrm{~Pb},{ }^{206} \mathrm{~Pb},{ }^{207} \mathrm{~Pb}$, and ${ }^{208} \mathrm{~Pb}$, vary in the environment because the last three are the products of radioactive decay from uranium (U) and thorium (Th). These isotopes have been used to trace the source or determine the age of rock formation in the geological field [73]. Since the material obtained to produce the ammunitions comes from various sources, the lead composition from different manufactures may be different. Keisch and Callahan examined lead isotopes in paint in 1976 and determined that the ratio 206/204 in white lead changed from 16 to 22 during the past 50 years [74]. They then looked into the potential application to gunshot cases in 1978, but only studied a limited number of samples [75]. Andrasko et al. investigated both lead 
smears and bullet fragments recovered from victims' clothing, from which they concluded that the lead isotope ratio had a good potential for bullet differentiation [76]. The paper mentioned above mostly used thermal ionization mass spectrometry (TIMS).

Dufose and Touron compared bullet alloys through the detection of lead isotope ratios and trace element profiles by ICP-MS [77]. Zeichner et al. studied the changing of ammunition using the same firearm through the comparison of projectile, primer, cartridge cases, swab from barrels, and cotton target by multicollector-ICP-MS (MC-ICP-MS) [66]. Although the lead memory effect was a hindrance to link the firearm to the ammunition or the gunshot entry, there is a potential that lead isotope ratio can be used in differentiating firearms [66]. Steffen et al. investigated the possibility of differentiating primers by lead isotope ratios as additional information to the SEM-EDX [61]. Wunnapuk et al. discussed the possibility of discrimination of bullet types in gunshot entry wounds using lead isotope ratios of $208 / 206$ or $208 / 207$ to $207 / 206$ [67]. A limited number of papers have discussed the lead isotope ratio analysis on hand swabs [65].

Sample collection is a critical first step in the GSR research. Previously, tape lift and glue lifts were used for particle analysis, while swabbing is the main method for bulk analysis [19]. Cotton swabs are the most common sampling method for this type of analysis $[71,78]$.

As described by Havekost et al., $5 \% \mathrm{HNO}_{3}$ is used as moistener in the standard kit provided by the FBI Laboratory [79]. They examined $\mathrm{Ba}$ and $\mathrm{Sb}$ levels from the non-shooters' hands and determined that the profile of non- 
shooters was differentiable from shooters. According to Reis et al., ethylenediaminetetraacetic acid (EDTA) showed better recovery of GSR analytes [78]. EDTA is a well know chelating agent that is used in multiple disciplines. Six ligands in EDTA can bind to the metal ion and form a stable complex.

In this research, swabbed GSR samples from the back and palm of both of the shooter's hands will be studied based on the concentration of $\mathrm{Sb}, \mathrm{Ba}$, and $\mathrm{Pb}$ compared to the non-shooter's hands. The lead isotope ratios of different weapons and ammunitions were also studied. A simple method based on quadrupole ICP-MS was developed to assist the field GSR detection. Both

moisteners, $\mathrm{HNO}_{3}$ and EDTA, as well as sampling media mentioned in the literature, including cotton swab, Q-tip, cotton square, and a new sampling media, CapSure ${ }^{\mathrm{TM}}$ wipe (details can be found in the later section) were examined in the study. The lead isotope ratio application was also explored.

\subsection{Experimental}

\subsubsection{Materials}

All standards were made from ICP-MS standard solutions. Antimony (Sn, $100 \mu \mathrm{g} / \mathrm{mL}$ ) and barium (Ba, 9,985 $\mu \mathrm{g} / \mathrm{mL}$ ) are obtained from VHG, Manchester, $\mathrm{NH}$, and $\mathrm{Pb}(1,000 \mathrm{mg} / \mathrm{L})$ is from Spex, Meuchen, NJ. Internal standard indium (In, $1000 \mathrm{mg} / \mathrm{L})$ and bismuth $(\mathrm{Bi}, 10,028 \mathrm{mg} / \mathrm{L})$ are from VHG (Manchester, $\mathrm{NH}$, USA). EDTA is from Sigma-Aldrich (St. Louis, MO, USA). 2\% EDTA (w/v) was prepared by dissolving $1 \mathrm{~g}$ EDTA (Sigma-Aldrich, St. Louis, MO, USA) in $50 \mathrm{~mL}$ DI water with the adjustment of $\mathrm{pH}$ to around 8 with sodium hydroxide $(\mathrm{NaOH}$, Fisher Scientific, Fair Lawn, NJ, USA). Lead stable isotope standard (100 
$\mu \mathrm{g} / \mathrm{mL}, \mathrm{VHG}$, Manchester, $\mathrm{NH}$ ) was used to check the lead isotope ratio. Nitric acid $\left(\mathrm{HNO}_{3}, 69.3 \%\right.$, certified A.C.S. plus, Fisher Scientific) and 18 megohm.cm deionized water (Thermo Scientific, USA) was used for sample collection and preparation. CapSure ${ }^{\mathrm{TM}}$ wipes were obtained from Birkshire (Whitsett, NC, USA). Metal free centrifuge tubes were from VWR (Radnor, PA, USA). Heating block was also from VWR (Manchester, NH, USA).

\subsubsection{Instrumentation}

The samples were analyzed by a 7500cx ICP-MS equipped with an ASX500 Model 510 Auto Sampler (Agilent Technologies, Santa Clara, CA). Typical operation parameters are presented in Table 3.1. Both helium mode and no gas mode were evaluated. ${ }^{121} \mathrm{Sb},{ }^{137} \mathrm{Ba}$ and ${ }^{208} \mathrm{~Pb}$ were analyzed quantitatively. Lead isotope ratios ${ }^{208} \mathrm{~Pb} /{ }^{204} \mathrm{~Pb},{ }^{207} \mathrm{~Pb} /{ }^{206} \mathrm{~Pb},{ }^{208} \mathrm{~Pb} /{ }^{206} \mathrm{~Pb},{ }^{207} \mathrm{~Pb} /{ }^{204} \mathrm{~Pb}$, and ${ }^{206} \mathrm{~Pb} /{ }^{204} \mathrm{~Pb}$, were checked. To minimize the instrument drift and obtain the best results, isotope ratios were analyzed in the order of blank-standard-sample for each sample. Blank correction and mass bias correction was done by the Agilent ChemStation software using wipe blanks and spiked isotope standards. Statistica (Statsoft, Tulsa, OK, USA) was used in the data analysis. 
Table 3.1 ICP-MS Parameters

\begin{tabular}{ll}
\hline RF Power & $1500 \mathrm{~W}$ \\
Carrier Gas & $0.6 \mathrm{~L} / \mathrm{min}$ \\
Makeup Gas & $0.45 \mathrm{~L} / \mathrm{min}$ \\
Nebulizer Pump & $0.1 \mathrm{rps}$ \\
& \\
Octapole Reaction Cell & $4 \mathrm{~mL} / \mathrm{min}$ \\
Helium & $-6 \mathrm{~V}$ \\
Octapole Bias & \\
& $8 \mathrm{mV}$ \\
Detector Parameters & $1780 \mathrm{~V}$ \\
Discriminator & $1100 \mathrm{~V}$ \\
$\begin{array}{l}\text { Analog HV } \\
\text { Pulse HV }\end{array}$ & \\
& \\
Data Acquisition Parameters & \\
Concentration & $0.30 \mathrm{sec}$ \\
Dwell time per mass & 3 \\
Replicate & $115 \mathrm{In}^{\mathrm{a}},{ }^{121} \mathrm{Sb},{ }^{137} \mathrm{Ba},{ }^{206,207,208} \mathrm{~Pb}^{209} \mathrm{Bi}^{\mathrm{a}}$ \\
Monitored lons & \\
& \\
Isotope Ratio & $2 \mathrm{sec}$ \\
Dwell time per mass & 10 \\
Replicate & $204,206,207,208 \mathrm{~Pb}$ \\
Monitored lons &
\end{tabular}

${ }^{a}$ Internal standard 


\subsubsection{Procedure}

Scissors to cut the CapSure ${ }^{\mathrm{TM}}$ wipe were first cleaned with $10 \% \mathrm{HNO}_{3}$. The wipe was then cut into 2 in $\times 2$ in pieces. GSR samples were collected from the back and palm of gun hand and support hand by $0.5 \mathrm{~mL} 2 \%$ EDTA moistened clean wipe. Samples were then sonicated in $5 \mathrm{~mL} 10 \% \mathrm{HNO}_{3}$ for 5 min before heating at $80{ }^{\circ} \mathrm{C}$ for $30 \mathrm{~min}$ in a heating block. $20 \mathrm{~mL}$ D.I. water was then added to the digested solution resulting in a $2 \% \mathrm{HNO}_{3}$ matrix. All samples were digested in $50 \mathrm{~mL}$ metal free centrifuge tubes and transferred into $15 \mathrm{~mL}$ metal free centrifuge tubes.

A working standard solution $(\mathrm{Ba}, \mathrm{Pb})$ at a concentration of $100 \mathrm{ppm}$ was prepared from purchased standard solutions, while $\mathrm{Sb}$, at a concentration of 10 ppm was purchased. A series of standards (50 ppb, 100 ppb, 250 ppb, 500 ppb for $\mathrm{Ba}$ and $\mathrm{Pb} ; 25 \mathrm{ppb}, 50 \mathrm{ppb}, 125 \mathrm{ppb}, 250 \mathrm{ppb}$ for $\mathrm{Sb}$ ) were prepared from the working standard solution. To match the matrix of the wipe digestion, calibration standards were prepared by spiking the correct amount of standards on the wipe (with EDTA) and going through the digestion procedure to generate the desired concentration. $\mathrm{Pb}$ isotope standards were prepared in the same manner as the calibration standards ranging from $15 \mathrm{ppb}$ to $500 \mathrm{ppb}$.

\subsection{Results and Discussion}

3.3.1 Comparison between Shooter and Non-shooter's Hand Based on Sb, $\mathrm{Ba}$, and $\mathrm{Pb}$ Concentration

Different sample collecting media, including ion mobility spectroscopy (IMS) paper swabs, Q-tips, cotton balls, and cotton squares were tested before 
the CapSure ${ }^{\mathrm{TM}}$ wipe was chosen (details can be found in the later section). IMS paper swabs were moistened by acetone and detected by IMS for organic compounds before acid digestion. Q-tips, cotton balls, and cotton squares were moistened with $1 \% \mathrm{HNO}_{3}$ and digested directly. A sample digestion method was adapted from Sarkis and Zeichner [66,70]. Since paper swabs and Q-tips are small, $2 \mathrm{~mL}$ of $10 \% \mathrm{HNO}_{3}$ was used, while $5 \mathrm{~mL}$ was used for cotton balls and squares. After digestion, samples were diluted to $10 \mathrm{~mL}$ for paper swabs and Qtips, and $25 \mathrm{~mL}$ for cotton balls and squares resulting $2 \% \mathrm{HNO}_{3}$ matrix. All the samples were analyzed semi-quantitatively for a preliminary study to choose the best sampling media. The results were then corrected for dilution factors and shown in Figure 3.1. $\mathrm{Sb}, \mathrm{Ba}$ and $\mathrm{Pb}$ concentrations for each type of media was shown as a mean plot with $95 \%$ confidence intervals. The cotton squares showed less variation and obtained higher mean concentrations of all the elements. Therefore, the cotton square was chosen to perform the sample collection at the first stage of this research. 
Figure 3.1: Comparison of sample media.

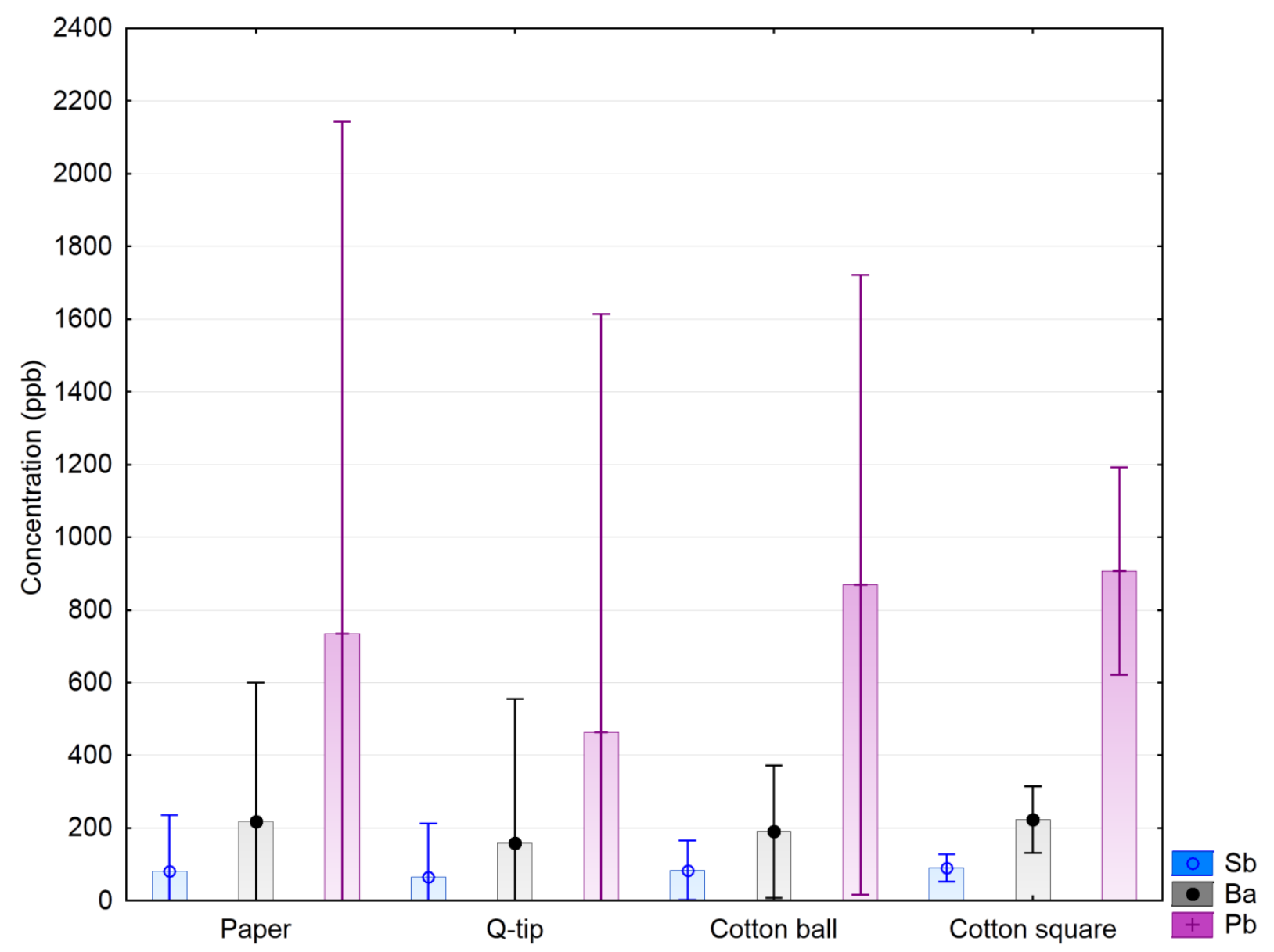


Three days of shooting activities were recorded with cotton squares to study the persistency of GSR on the back of the shooter's gun hand. The sampling procedure is described as follows: (1) shoot 3 times and collect GSR samples; (2) collect hand blank; (3) repeat steps (1) and (2); (4) shoot 3 times and wait for one, two, and three hours on different days before GSR sample collection. Mean plots of $\mathrm{Sb}, \mathrm{Ba}$ and $\mathrm{Pb}$ as well as the $95 \%$ confidence interval error bars are shown in Figure 3.2 and 3.3.

In Figure 3.2, "Hand Blank" $(n=20)$ is representative of all the swabs collected from volunteers' hands during the three days study; "3 Shots" $(n=10)$ is samples collected in step (1) during the three days; " 3 Shots after blank" ( $\mathrm{n}=$ 10 ) is samples collected in step (3) after a round of shooting and hand blank. $\mathrm{Pb}$ is the dominant element in all the samples. Notice that the $\mathrm{Pb}$ in the "Hand Blank" had no significant difference compared to the "3 Shots" samples. Also, samples collected in step (3) were slightly higher in concentration of all elements than samples from step (1). The results suggest that there might be carryover from the last shooting or contamination in the range during the sampling period. Five hand blanks were then collected outside the range in a working environment. The mean concentration of each element in the hand blank decreased about $50 \%$, confirming this hypothesis. This was corrected in later experiments by allowing only one shooting to be recorded for each day, with sample collection performed outside of the shooting range to limit the contamination. 
Figure 3.2: GSR of 3 consecutive shooting.

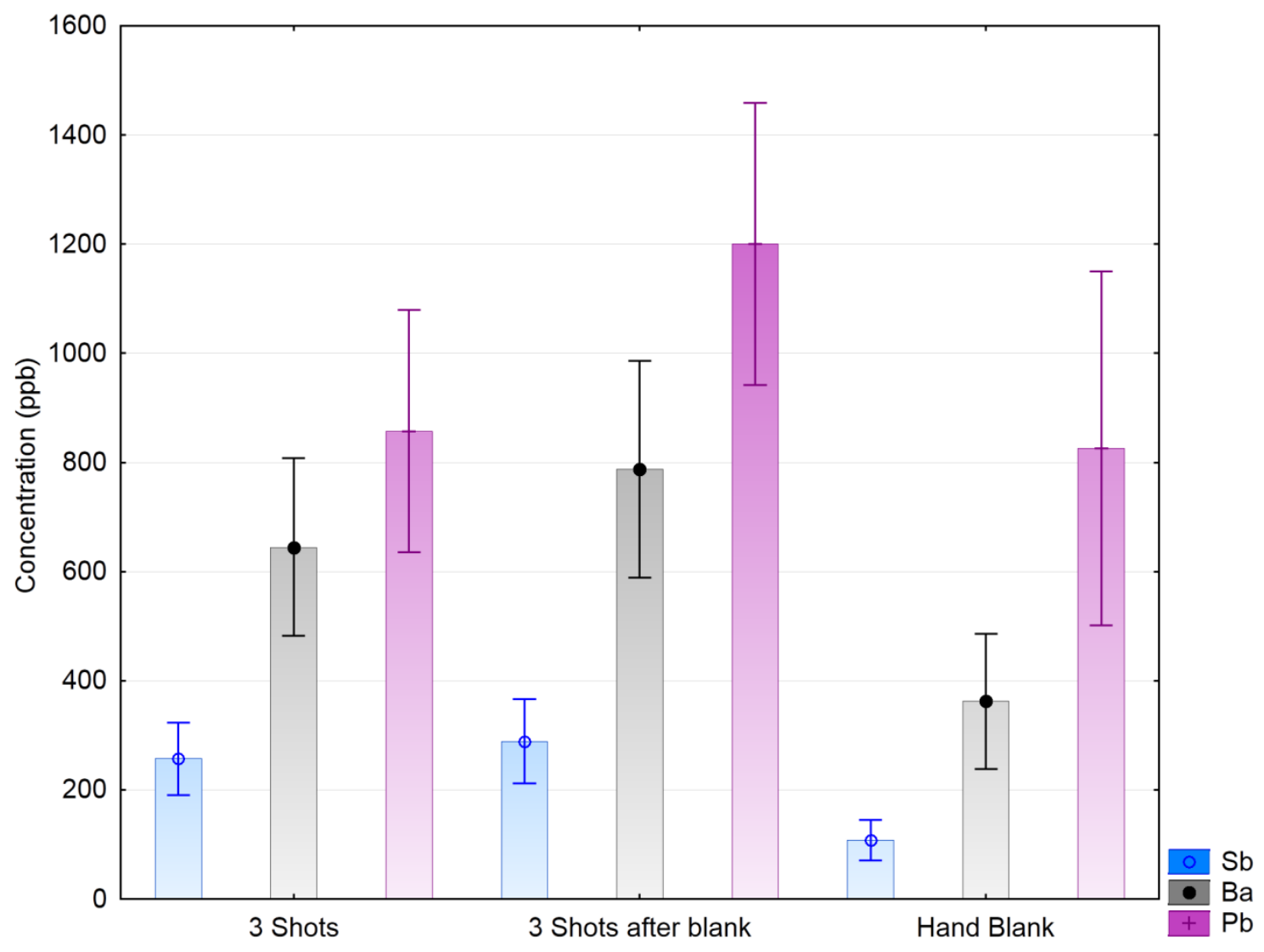


Figure 3.3: Persistence study by cotton square.

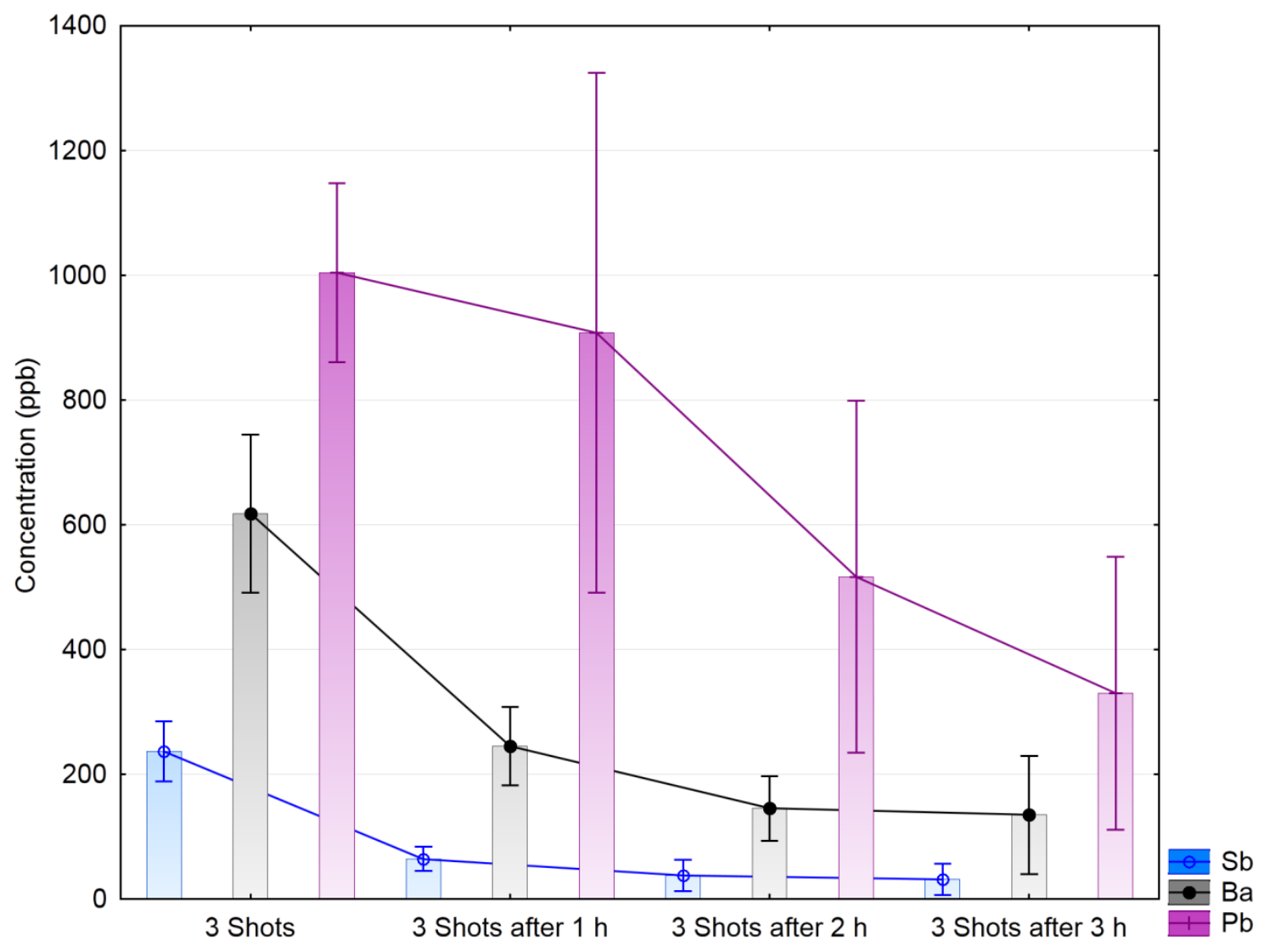


In Figure 3.3, "3 Shots" $(\mathrm{n}=20)$ are the samples collected right after shooting, that includes samples from both step (1) and step (3); 3 Shots after $1 \mathrm{~h}$ $(n=4)$ is collected an hour after shooting; " 3 Shots after $2 h$ " $(n=3)$ is collected two hours after shooting; " 3 Shots after $3 \mathrm{~h}$ " $(n=3)$ is collected three hours after shooting. This persistency study showed that as time increased, the concentration decreased. While this trend is true for all three elements, Sb and $\mathrm{Ba}$ decreased faster than $\mathrm{Pb}$, meaning that $\mathrm{Pb}$ is more persistent. This finding is coincident with a "lead memory" effect Zeichner et al. found that prevented lead to be removed by mechanical or chemical methods [66]. This could also be the reason that $\mathrm{Pb}$ stayed on the hand in the hand blanks.

At this point, the sampling media became a concern since it showed a large variation of the concentration in the hand blanks and procedure blanks. Therefore, different sampling media was needed to perform further studies. CapSure $^{\mathrm{TM}}$ clean wipe was then examined as the sampling media. The reason for choosing this media is because this wipe is designed for the cleaning in a clean room. It was made to capture more particles and itself has minimum particle contamination. The CapSure ${ }^{\mathrm{TM}}$ wipe was tested as procedure blank together with several hand blanks. Since purchased wipe is 9 by 9 inches, cutting became necessary. Details about cutting can be found in section 3.2.3. For the wipe blank, the same procedure was followed. Fifteen hand blanks were collected using 10 drops of $1 \% \mathrm{HNO}_{3}$ to wet the wipe and digested using the same sample digestion procedure as previously stated. The mean concentration 
of the blanks decreased to $10 \%$ that of previous cotton square samples. Therefore, the wipe was determined to be a promising sampling media.

As mentioned earlier, a carryover issue was observed for the hand blank after shooting. Therefore, a single shot was fired followed by swabbing. According to Reis et al., 2\% EDTA gives better recovery than that of $2 \% \mathrm{HNO}_{3}$ through the formation of a chelating complex [78]. Only one shot was fired this time before sample collection, instead of three. In order to establish a database of how the GSR was distributed on the hand, the samples were collected from volunteer's right back, right palm, left back, and left palm. Swabs from nonshooters were collected during the non-shooting days. A total of 13 nonshooters' hands were swabbed resulting in 52 samples.

The samples collected after shooting were labeled as gun hand back, gun hand palm, support hand back, and support hand palm because left handed shooters were involved. 33 volunteers participated in the shooting. Two different handguns were used, Smith \& Wesson 38 Medium Frame and Glock 19. Four different ammunitions were used for the two handguns. Handguns and ammunitions include Smith \& Wesson 38 Medium Frame with Mountaineer 38 SP (11 volunteers 44 samples), Smith \& Wesson 38 Medium Frame with home load 148 Grain (4 volunteers 16 samples), Glock 19 with Lawman Speer 9mm (12 volunteers 48 samples), and Glock 19 with American Eagle 9 mm (6 volunteers 24 samples). At the same time, procedure blanks were processed (7 samples) the same way as samples. All samples from shooters, non-shooters, and procedure blanks are shown by mean plot in Figure 3.4. 
Figure 3.4: All samples mean plot of $\mathrm{Sb}, \mathrm{Ba}$, and $\mathrm{Pb}$ grouped by sample area.

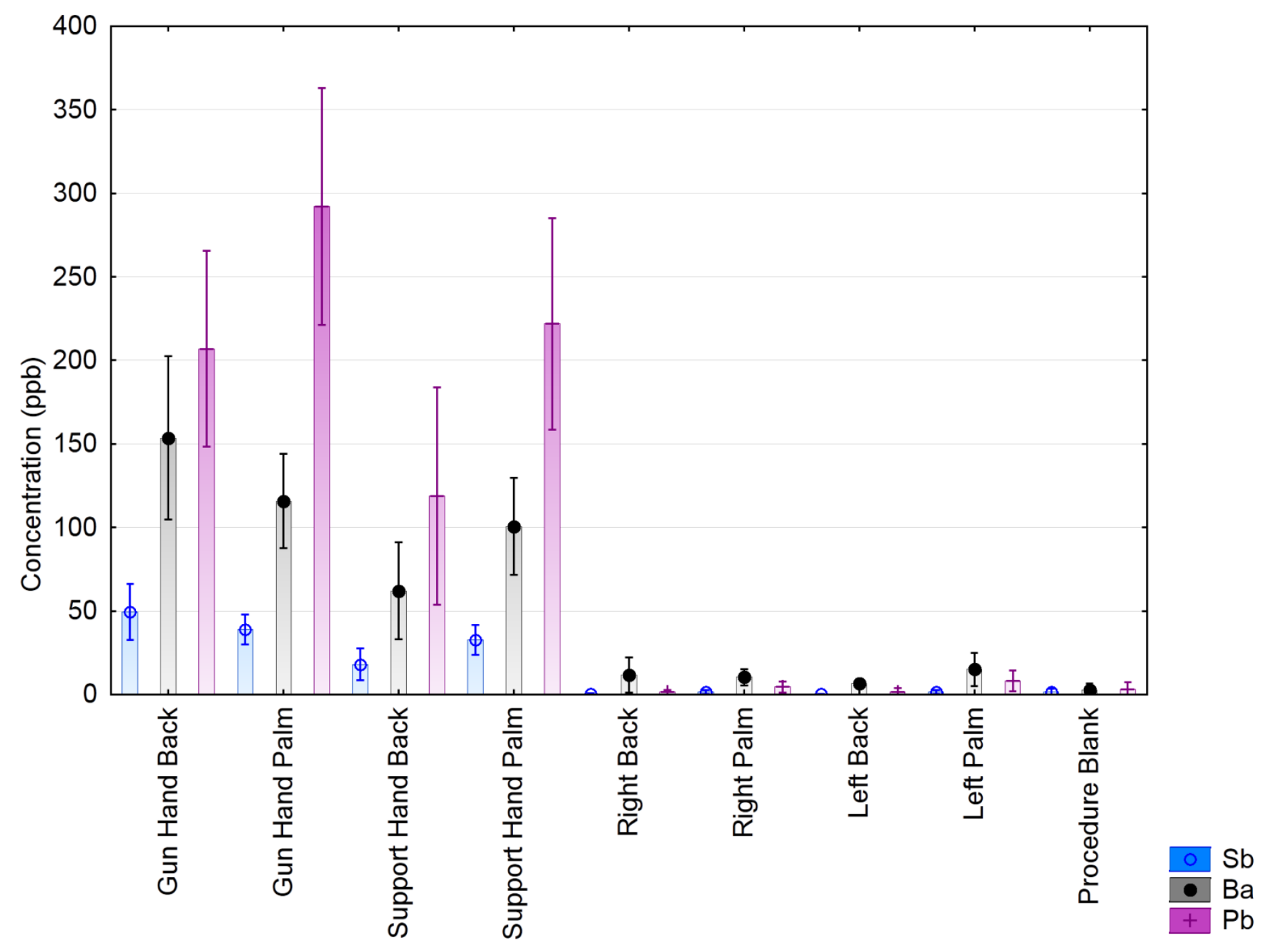


Figure 3.4 illustrates that the samples collected from shooters after firing a handgun have a much larger mean concentration of all elements compared to the non-shooters and the procedure blanks. Within the shooters, the gun hand had higher concentrations than the support hand. The support hand back gave the lowest mean concentration in all the elements. It is interesting to notice that although the support hand mostly does not contact the gun, there is considerably a higher amount of GSR deposited. The reason why the support hand palm has more GSR than the support hand back is because when shooting the gun, shooters hold the gun with the gun hand, while the support hand will be holding the bottom of the gun and the palm is thus positioned towards the gun. When GSR particles come out of the gun, the support hand palm will collect more particles than the back.

As for the shooting hand, while the gun hand back showed the highest mean concentration in $\mathrm{Sb}$ and $\mathrm{Ba}$, the gun hand palm showed the highest concentration in $\mathrm{Pb}$. The reason for this is unknown, however, according to the previous finding, $\mathrm{Pb}$ is more persistent than the other two. Also, Zeichner et al. found that even with mechanical or chemical means of cleaning, $\mathrm{Pb}$ cannot be removed completely [66]. Therefore, since the gun was not cleaned in between shootings, there could be some $\mathrm{Pb}$ deposit on the gun and thus be picked up by the shooters.

To better show the data grouped by sample area, the plot was then rescaled in Figure 3.5. 
Figure 3.5: Hand blanks and GSR samples grouped by sample area (re-scaled).

a)

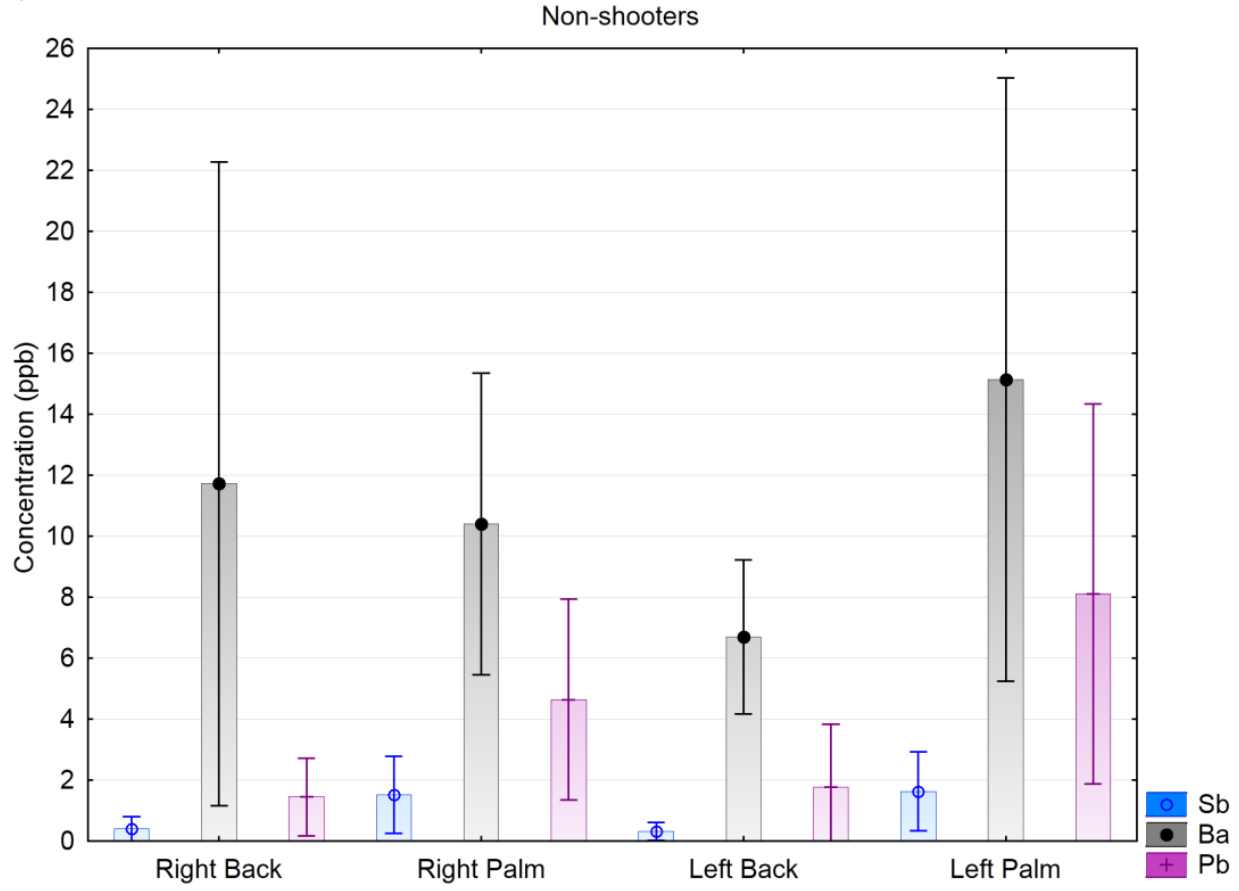

b)

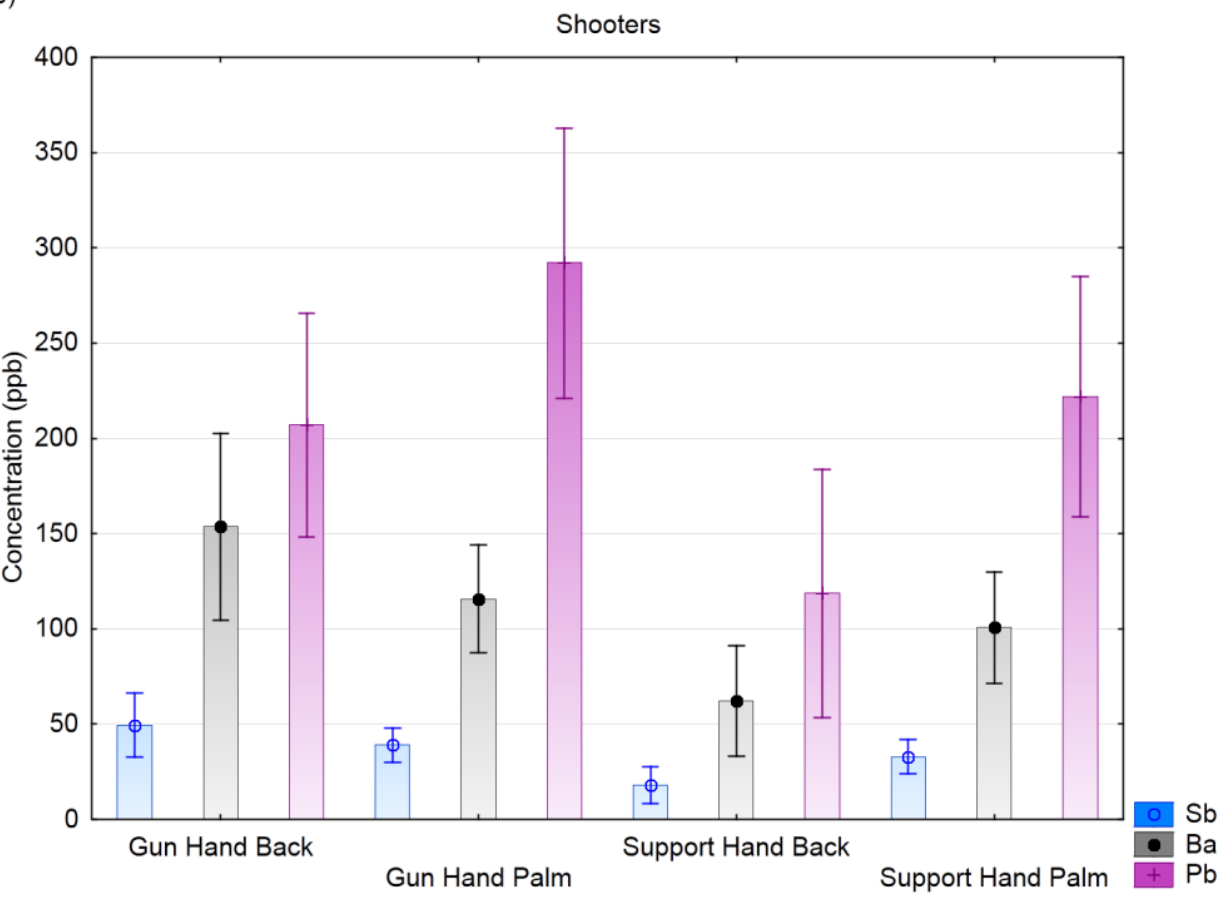


Figure 3.5 (top) is a mean plot of $\mathrm{Sb}, \mathrm{Ba}$, and $\mathrm{Pb}$ of non-shooters grouped by sample area, while the bottom is that of shooters. The plot shows that the mean concentration of $\mathrm{Ba}$ is higher in the samples from non-shooters. In the samples from shooters, $\mathrm{Pb}$ is more dominant in all sample areas. When comparing shooters to non-shooters, not only is the concentration level much higher in the former, but also the concentration ratios between the three elements are different. Therefore, shooters and non-shooters can be differentiated through the comparison of the three elements. Although concentration on the shooters' hand varies person by person, the ratio of the values stays the same. In non-shooters, the ratio of the values shows much larger variation.

To better visualize the difference between shooters and non-shooters, the data from different sample areas were combined in Figure 3.6. 
Figure 3.6: Mean plot of $\mathrm{Sb}, \mathrm{Ba}$, and $\mathrm{Pb}$ comparison of shooters and nonshooters.

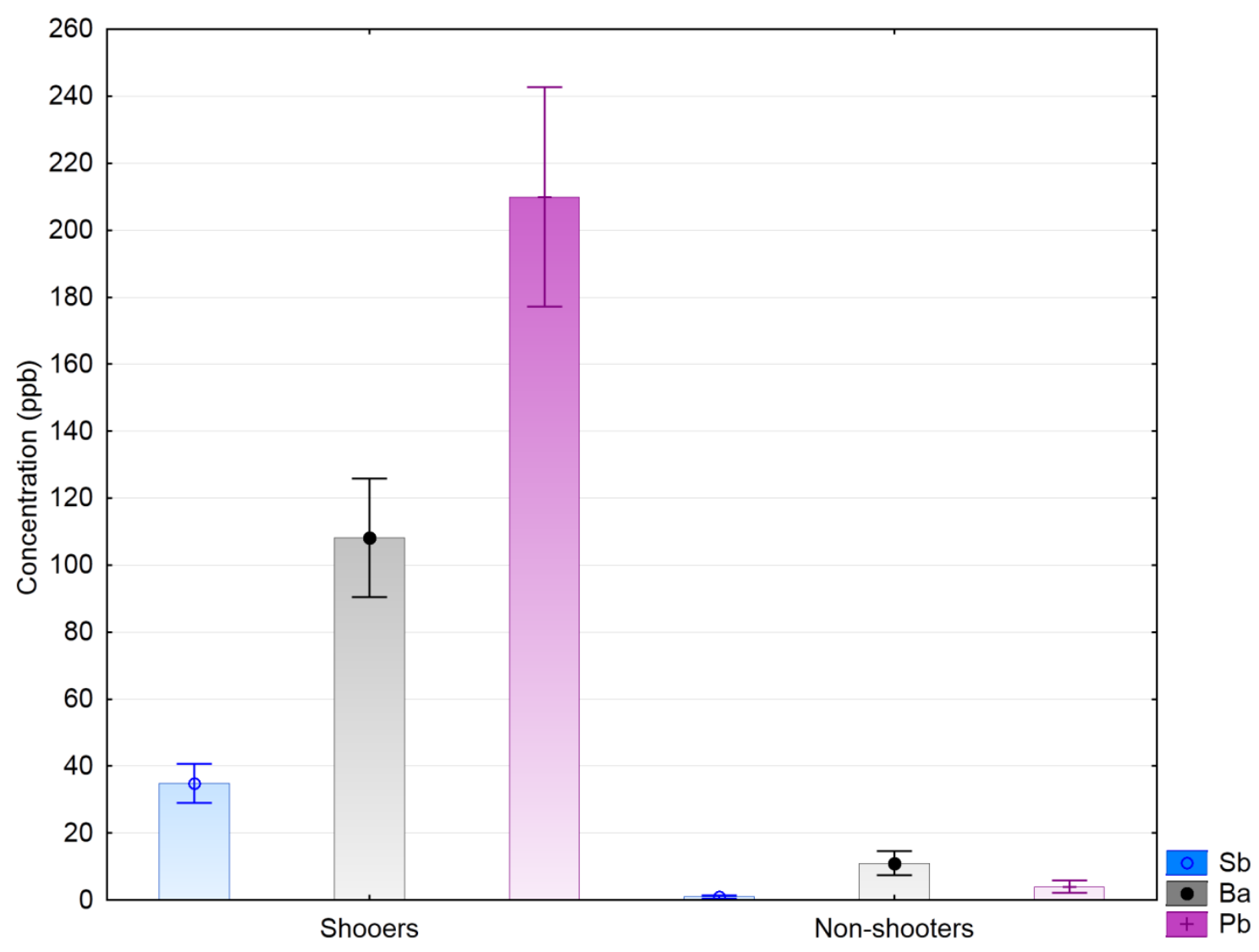


Figure 3.7: GSR samples mean plot of $\mathrm{Sb}, \mathrm{Ba}$, and $\mathrm{Pb}$ grouped by handgun.

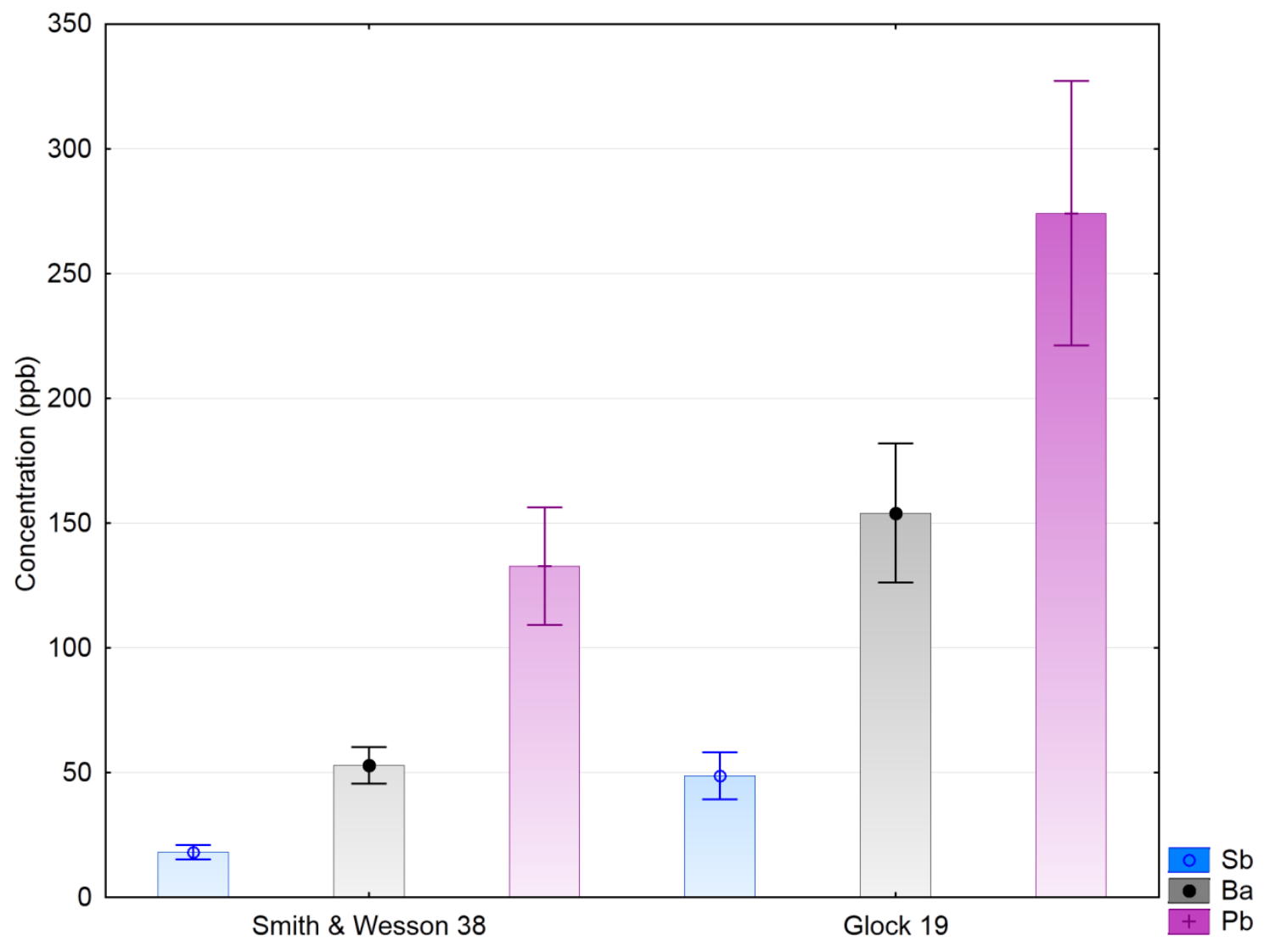


By comparing the mean and the error bars of the $95 \%$ confidence interval, it is clearly observable that the concentration of non-shooters' samples is much lower in all elements. The $F$ test and the $p$ values were calculated for each element. The F test tells us whether two standard deviations are "significantly" different from each other based on certain probability. According to the value, this difference is significant at more than $99 \%$ of confidence level.

To further study whether the two handguns used have any difference in the concentration of $\mathrm{Sb}, \mathrm{Ba}$ and $\mathrm{Pb}$, Figure 3.7 was generated to show the mean plot of the three elements of the two different handguns. Based on the samples obtained, the Glock 19 resulted in more GSR on the hand than the Smith \& Wesson 38. This could be explained by the plume study. Schwoeble and Exline explained that larger caliber revolvers have a widespread plume and larger caliber semi-automatic weapons with ejection ports have more compact plume [22]. Therefore, the GSR deposit on shooters' hand by the Smith \& Wesson (revolver) is likely less than Glock 19 (semi-automatic); the data reported here supports this hypothesis.

\subsubsection{Lead Isotope Study on GSR Samples}

As discussed in section 3.1, the differences exist in the manufacturer, which may affect the lead isotope ratios in the ammunitions. Researchers have been trying to determine the possibility of using lead isotope ratios as a tool to differentiate handguns or ammunitions. However, limited studies looked into the isotope ratios in hand swabs. The instrumentations used in these studies were either TIMS or MC-ICP-MS. Although these instruments have high resolution 
and offer higher precision, they are not widely available due to the cost and the need for an experienced operator. Also, TIMS is known for its extensive sample purification procedure, thus making it more time consuming. The goal of this work was to develop a simple method using a quadrupole ICP-MS (ICP-QMS) that is available in most forensic labs.

It is known that ICP-QMS gives lower precision than TIMS or MC-ICP-MS [66]. This is due to the design and operation of the quadrupole analyzer [80]. Nonetheless, with carefully validated parameters, ICP-QMS can provide acceptably accurate and precise results for many applications, including isotope ratio calculations [80]. To optimize the precision of the isotope ratio analysis, two sample introduction methods were evaluated, peristaltic pump and selfaspiration. A peristaltic pump is typically used in sample introduction that connects to the auto sampler. As the pump rotates, the sample in the sampling tube is pushed into the nebulizer. The self-aspiration method allows the sample to bypass the pump and be introduced into the nebulizer through a flow of argon. A total of 10 replicates were analyzed and the results are shown in Table 3.2. Self-aspiration offered better \%RSD and the \%error was considerably lower than the peristaltic pump. This could be because that flow generated by the pump is considered pulsed, which may cause the signal to fluctuate. Therefore, selfaspiration was chosen for the isotope ratio study.

The integration time was also optimized for better precision. An increase of the integration time will result in more ions being counted, thus improving the 
precision. As shown in Table 3.3, increasing the integration time from $0.1 \mathrm{sec}$ to 2 sec decreased both inter- and intra- run \%RSD.

Table 3.2: Comparison between sample introduction methods $(n=10)$

\begin{tabular}{lcclllc}
\hline & & $208 / 204$ & \multicolumn{2}{c}{$207 / 206$} & \multicolumn{2}{c}{$208 / 206$} \\
\hline & Pump & Self-aspiration & Pump & Self-aspiration & Pump & Self-aspiration \\
Mean & 37.20 & 36.69 & 0.9153 & 0.9149 & 2.173 & 2.164 \\
\%RSD & 1.1 & 0.76 & 0.42 & 0.27 & 0.18 & 0.34 \\
\%Error & 1.3 & -0.065 & 0.049 & 0.026 & 0.22 & -0.19 \\
\hline
\end{tabular}

Table 3.3: Effect of integration time on \%RSD

\begin{tabular}{lcccccc}
\hline & \multicolumn{2}{c}{$208 / 204$} & \multicolumn{2}{c}{$207 / 206$} & \multicolumn{2}{c}{$208 / 206$} \\
\hline & $0.1 \mathrm{sec}$ & $2 \mathrm{sec}$ & $0.1 \mathrm{sec}$ & $2 \mathrm{sec}$ & $0.1 \mathrm{sec}$ & $2 \mathrm{sec}$ \\
Intra-run & $1.5 \%$ & $0.20 \%$ & $0.56 \%$ & $0.35 \%$ & $0.30 \%$ & $0.28 \%$ \\
Inter-run & $0.76 \%$ & $0.13 \%$ & $0.27 \%$ & $0.17 \%$ & $0.34 \%$ & $0.21 \%$ \\
\hline
\end{tabular}


Figure 3.8: Effect of concentration on isotope ratio.
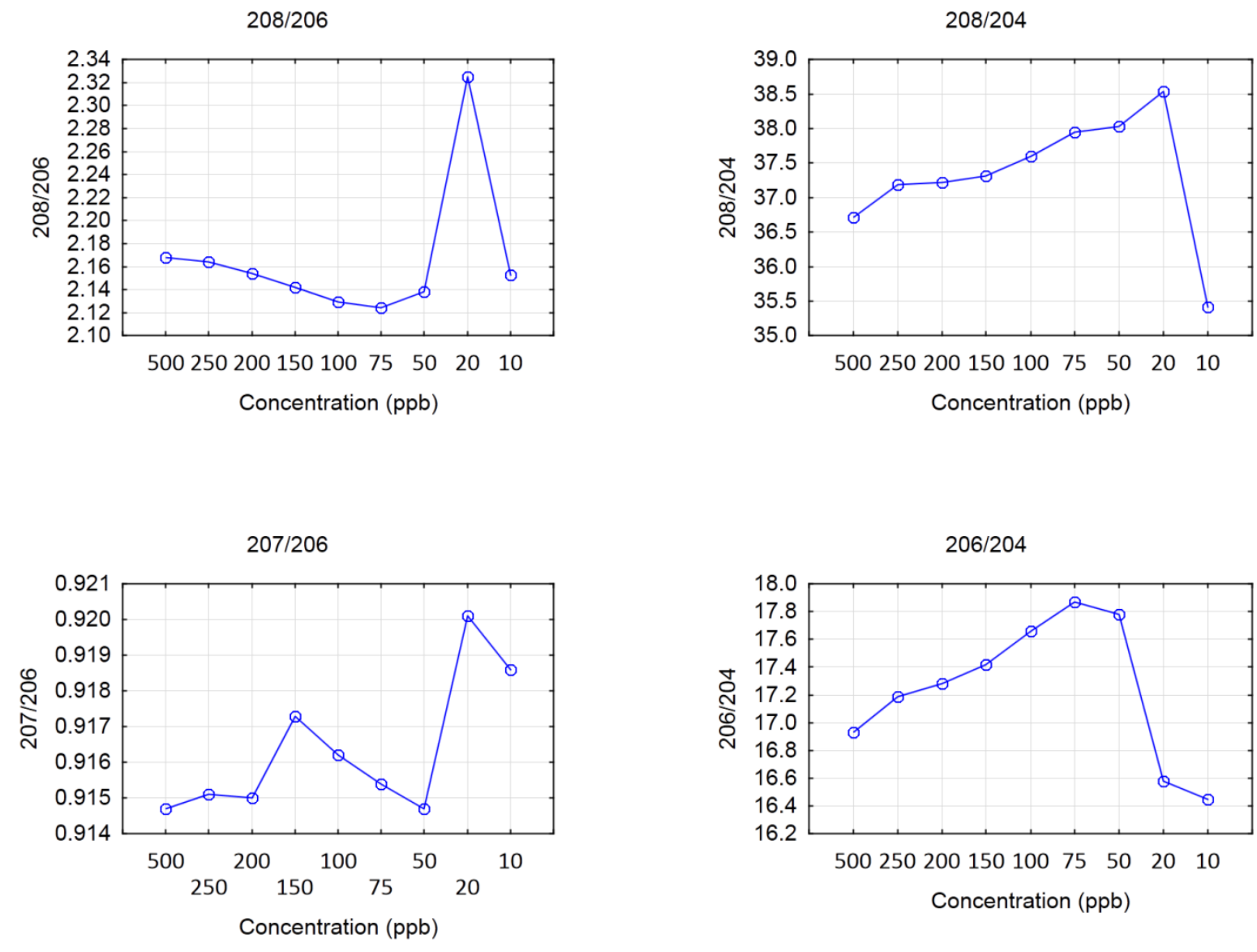
During the experiment, it was found that concentrations of the standards were an important factor in isotope ratio determination. A range of lead isotope standards was analyzed as samples using a $500 \mathrm{ppb}$ lead isotope standard as a correction standard. The results are shown in Figure 3.8. The first point of each graph is the $500 \mathrm{ppb}$ standard that was analyzed as a sample corrected by itself. The value is the certified value of the standard. As the concentration decreased, the $\mathrm{Pb}$ isotope ratios 208/204 and 206/204 increased, while 208/206 decreased to a concentration of $75 \mathrm{ppb}$. For the concentrations below $75 \mathrm{ppb}$, all three ratios behave differently than the main trend. The ratio of 207/206 stayed relatively stable to $200 \mathrm{ppb}$, increased at $150 \mathrm{ppb}$, and decreased thereafter till $50 \mathrm{ppb}$, but the scale of the variation is relatively smaller than that of the other three ratios. The reason is that when the concentration is different, the counts of ions will be different as well. As mentioned earlier, P/A factor is an important parameter in tuning the detector. Depending on the signal, the detector will switch between pulse and analog modes automatically to prevent saturation. In this research, ${ }^{204} \mathrm{~Pb}$ signal detection are all in pulse mode, while ${ }^{206} \mathrm{~Pb}$ and ${ }^{207} \mathrm{~Pb}$ are in pulse mode below $50 \mathrm{ppb}$ and ${ }^{208} \mathrm{~Pb}$ is in pulse mode below $20 \mathrm{ppb}$. The signal ratio will be considerably different if the standard is in one mode and the sample is in the other. Therefore, different concentrations of lead isotope standards were prepared to cover the range of $\mathrm{Pb}$ in samples from $15 \mathrm{ppb}$ to 500 ppb. All the GSR samples were analyzed for lead isotope ratios and the results are shown in Figure 3.9 and 3.10. 
Figure 3.9: Lead isotope ratios grouped by handgun.
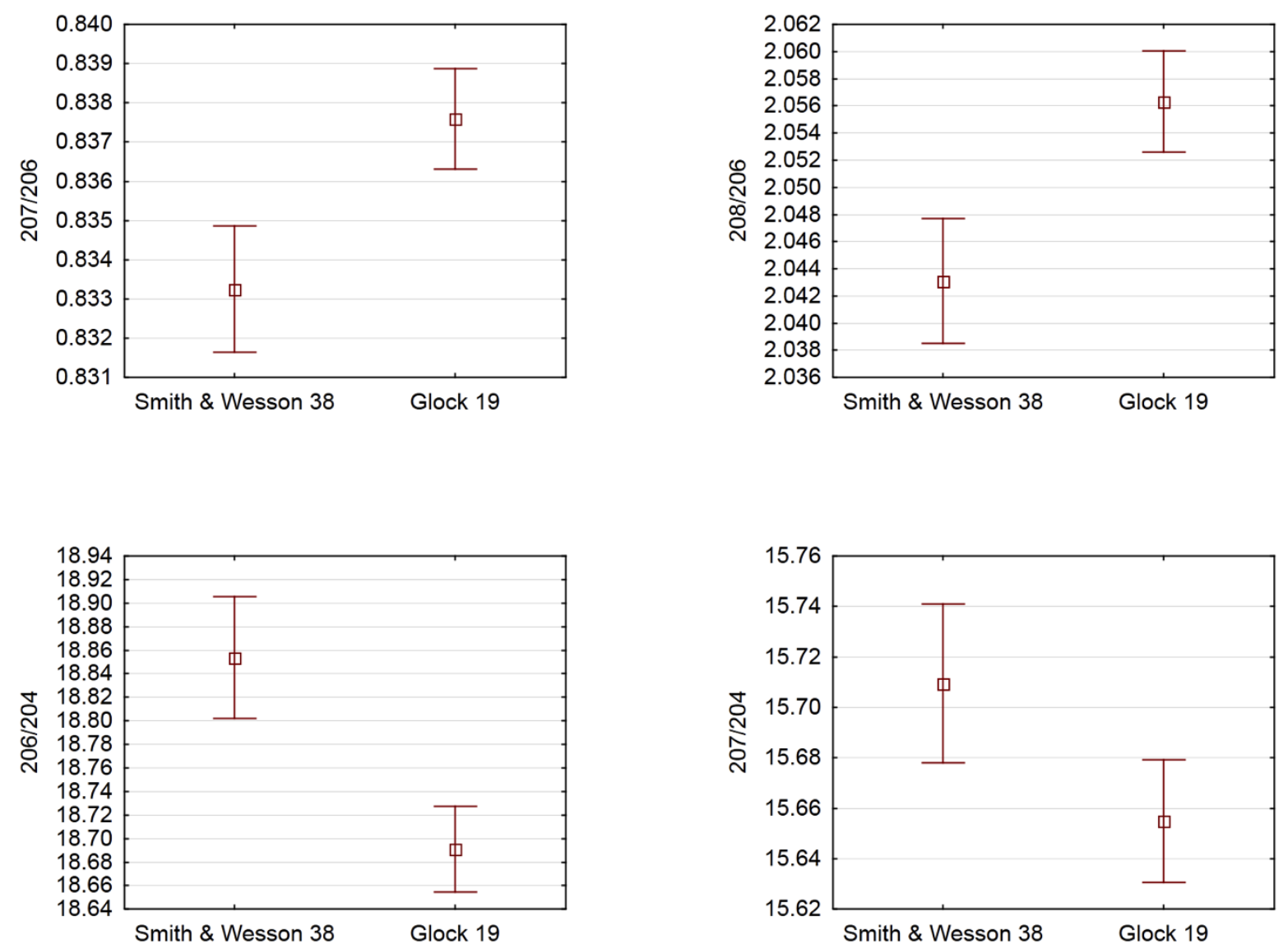

The range bracketed by error bars represents the $95 \%$ confidence interval. 
Figure 3.10: 208/206 grouped by ammunition.

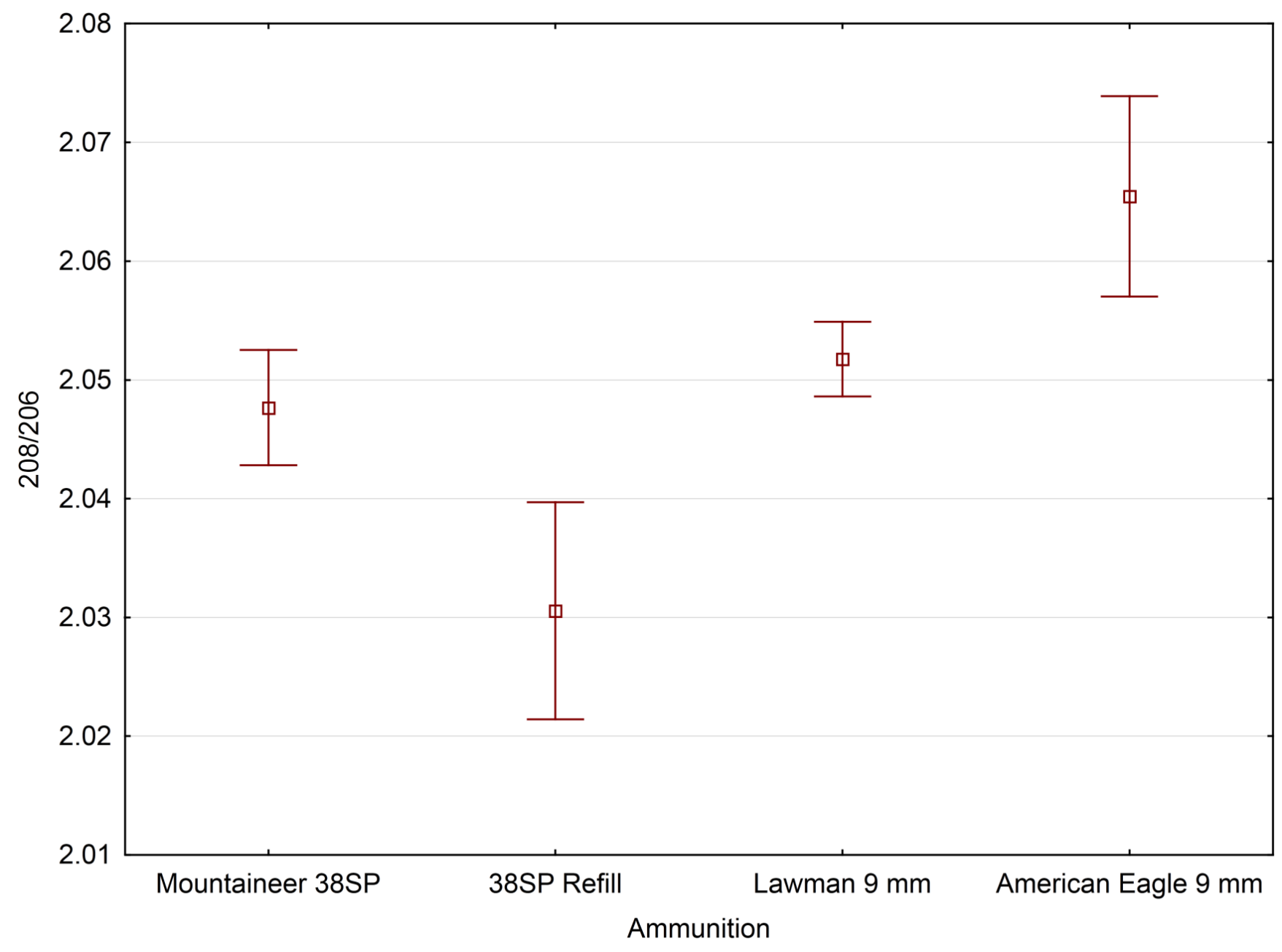

The range bracketed by error bars represents the $95 \%$ confidence interval. 
Figure 3.9 is the mean plot of lead isotope ratios 208/206, 207/206, $207 / 204$, and $206 / 204$ grouped by handgun type. Notice that ratios $208 / 206$ and 207/206 are lower for the Smith \& Wesson 38, but in ratios 207/204 and 206/204, this trend is opposite. Therefore, based on the isotope ratios, one can differentiate between the two handguns in this specific dataset.

It is also interesting to know if there is a difference between the four ammunitions. Figure 3.10 shows a mean plot of $208 / 206$ grouped by ammunition as an example. Although the 38 Refill seems to have the lowest value, American Eagle $9 \mathrm{~mm}$ has the highest value; the other two ammunitions are very close. This means one isotope ratio is not enough for the ammunition differentiation. Different parameters are then plotted against each other. The represented results are shown in Figure 3.11 and 3.12.

Figure 3.11 shows the mean biplot of 206/204 against 208/206 grouped by ammunitions. The error bars show that within the $95 \%$ confidence interval, 38 Refill and American Eagle are differentiable. Although Mountaineer and Lawman are close together, there is still a noticeable difference.

Figure 3.12 shows the mean bi-plot of 208/206 against $\mathrm{Pb}$ grouped by ammunitions. This time, the Mountaineer and Lawman show a better discrimination between each other. It is clear that the four ammunitions (single batch) studied here can be differentiated by the two biplots. This could be because the sources of lead, which used in the production of ammunitions, are 
different from manufacturer to manufacturer. Different manufacture process may also contribute to the fractionation of the isotopes. 
Figure 3.11: Comparison between ammunitions by 206/204 against 208/206.

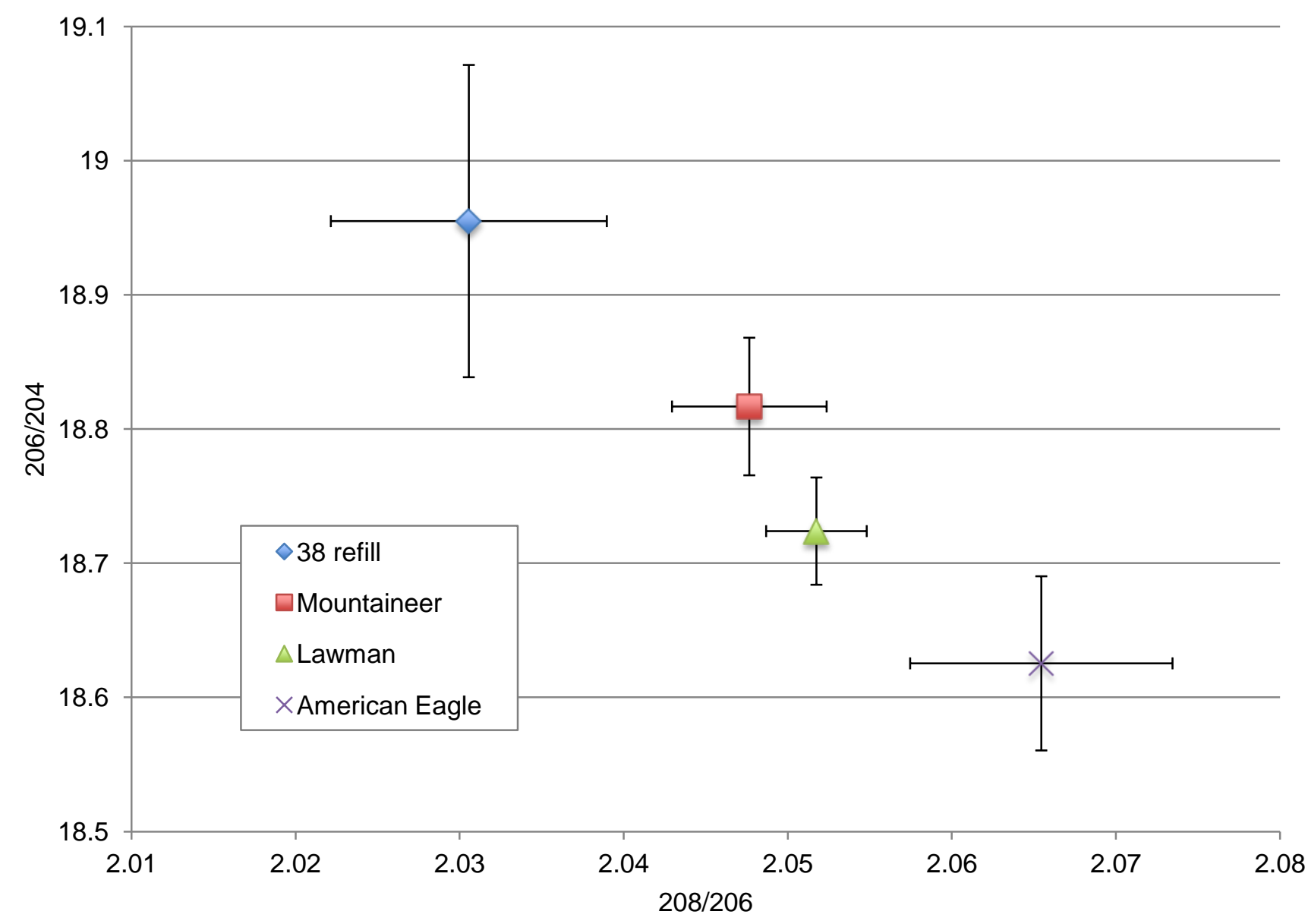

The range bracketed by error bars represents the $95 \%$ confidence interval for both $\mathrm{x}$ - and $\mathrm{y}$-axis. 
Figure 3.12: Comparison between ammunitions by 208/206 against $\mathrm{Pb}$ concentration.

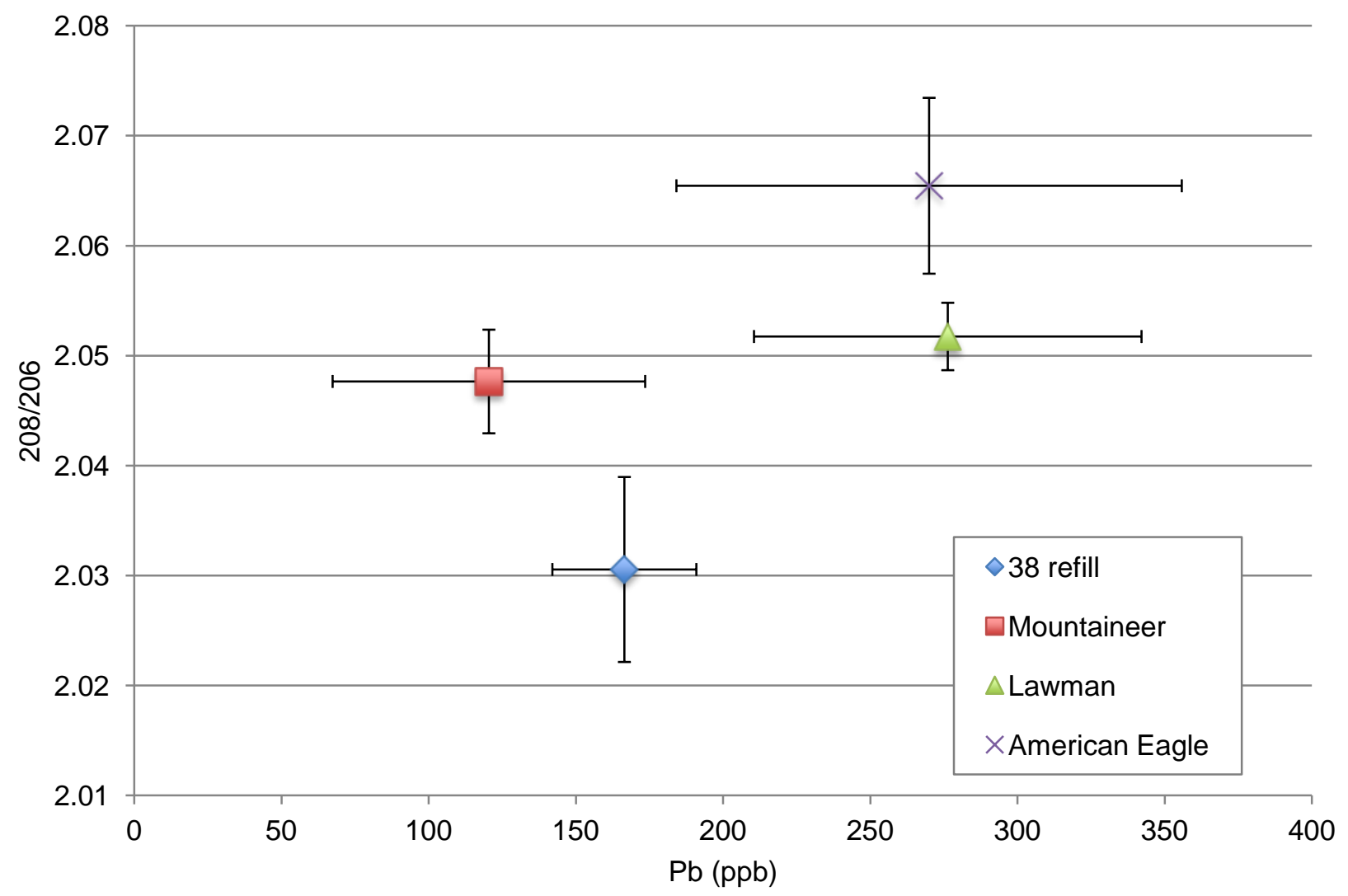

The range bracketed by error bars represents the $95 \%$ confidence interval for both $\mathrm{x}$ - and $\mathrm{y}$-axis. 


\subsection{Conclusion}

The aim of this work was to develop a method that can be used to differentiate shooters from non-shooters based on hand swabbing and ICP-MS analysis. The preliminary study showed that this aim can be achieved by ICPMS analysis of hand swabs with $2 \%$ EDTA wetted CapSure $^{\mathrm{TM}}$ wipe. The concentrations of $\mathrm{Sb}, \mathrm{Ba}$, and $\mathrm{Pb}$ were considerably higher in the shooters compared to the non-shooters. The study of the back and palm of both hands also showed that the concentration profiles of the three elements are different. This could be used to assist in the differentiation of shooters from non-shooters. Lead isotope ratios studied using quadrupole ICP-MS offered a potential parameter in differentiating between ammunitions. This work was recently presented at the American Chemical Society Central Regional Meeting in Dearborn, MI, on June 7, 2012. 


\section{Chapter 4: Hair}

\subsection{Introduction}

This final part of research is to develop a method that can be used to determine elemental concentration in rather small sizes of hair samples (as low as sub milligram) that were collected from the survey by Hendryx et al. [31]. Ultimately, the research is aimed at finding the relationship between the development of cancer and the area of coal mining with a subset of hair samples mentioned above based on the different metal concentration profiles.

According to Hendryx et al., the mining area is mainly mountaintop mining, which uses heavy machinery and explosives to remove topsoil and rock before coal seams can be found. Therefore, this is a public health concern due to the environment damage caused by the mining [31]. The environment pollutant can be the cause of the high self-report cancer rate. For example, As and $\mathrm{Cd}$ has been linked to different forms of cancer $[81,82]$.

According to Kempson and Lombi [24], bulk analysis is useful for the study of diseases that affected by elemental concentration. However, care should be taken to interpret the results since there are multiple variables in the hair analysis. These include contamination from the environment, age, gender, ethnicity etc.

There are many previous studies that looked into elemental information regarding different populations $[25,26,83]$. Rodushkin and Axelsson determined a range of elements using microwave-assisted digestion. The sample size was $50 \mathrm{mg}$ and the ratio of $\mathrm{HNO}_{3}$ and $\mathrm{H}_{2} \mathrm{O}_{2}$ was $1: 1$ [83]. The authors also found that a list of elements have severe memory effects, including $\mathrm{Au}, \mathrm{Th}, \mathrm{Zr}, \mathrm{Hf}, \mathrm{W}, \mathrm{Ir}, \mathrm{Pd}$, 
$\mathrm{Br}$, and $\mathrm{I}$. Although they claimed that prolonged washing of the introduction system with $0.1 \%$ EDTA solution eliminated the effects. The detection limits for most of the elements were in ppb or even ppt range.

Rao et al. validated a method for dissolving hair samples for ICP-AES analysis [26]. The authors studied the mixture ratio of $\mathrm{HNO}_{3}$ and $\mathrm{H}_{2} \mathrm{O}_{2}$, the temperature, and the digestion time needed. The optimized parameters for digestion were 2:1 $\mathrm{HNO}_{3} / \mathrm{H}_{2} \mathrm{O}_{2}, 150{ }^{\circ} \mathrm{C}$, and $30 \mathrm{~min}$. The study presented here is based upon these parameters, however, since the amount of hair is limited, the digestion time was re-examined for the hair samples involved here. In the samples, 25 out of 88 are in low milligram range $(<10 \mathrm{mg})$, while over $70 \%$ of the samples are below the lowest sample mass $25 \mathrm{mg}$ found in literature [84].

According to Assarian and Oberieas, the washing procedure is a critical step in trace element detection in hair [85]. In order to obtain meaningful results, the ideal washing step is to remove all the exogenous contaminations and leave the elements that are bound into the hair. Although the washing procedure still remains unknown for hair analysis, most studies used method proposed by Rodushkin and Axelsson (acetone, DI water, and $0.5 \%$ triton X-100 solution) [83]or the IAEA (acetone, DI water, and acetone) [24]. Here, the IAEA method was followed since the reference material IAEA-086 was used to assess the analysis method. 


\subsection{Experimental}

\subsubsection{Materials}

All standards are ICP-MS standard solution, including Al $(100 \mu \mathrm{g} / \mathrm{mL}$, VHG, Manchester, NH, USA), Ba $(9,985 \mu \mathrm{g} / \mathrm{mL}, \mathrm{VHG}$, Manchester, $\mathrm{NH}, \mathrm{USA})$, and lead $(\mathrm{Pb}, 1,000 \mathrm{mg} / \mathrm{L}$, Spex, Meuchen, NJ, USA). Internal standard $\mathrm{Y}$ $(10,072 \mu \mathrm{g} / \mathrm{mL})$, In $(1,000 \mathrm{mg} / \mathrm{L})$, and $\mathrm{Bi}(10,028 \mu \mathrm{g} / \mathrm{mL})$ were purchased from VHG Labs (Manchester, $\mathrm{NH}$, USA). $\mathrm{HNO}_{3}(69.6 \%$, certified A.C.S. plus, Fisher Scientific, USA), $\mathrm{H}_{2} \mathrm{O}_{2}$ (LC grade, Fisher Scientific), and 18 megohm·cm DI water (Dubuque, IA, USA) was used for sample collection and preparation. Human hair IAEA-086 (International Atomic Energy Agency, Vienna, Austria) was used as reference material.

\subsubsection{Instrumentation}

The samples were analyzed by a 7500cx ICP-MS (Agilent Technologies, Santa Clara, CA) equipped with an ASX-500 Model 510 Auto Sampler. Typical operation parameters are presented in Table 3.1. Hydrogen, helium, and no gas mode were utilized to detect different elements. Al, Mn, Fe, Zn, Ni, Co, Cr, Ti, $\mathrm{Mo}, \mathrm{Cd}, \mathrm{Se}$, and $\mathrm{Pb}$ were analyzed quantitatively. All samples were digested in $50 \mathrm{~mL}$ centrifuge tubes (metal free, VWR) and transferred to $15 \mathrm{~mL}$ centrifuge tubes (Falcon). 
Table 4.1: ICP-MS Conditions and Parameters

\begin{tabular}{|c|c|}
\hline RF Power & $1500 \mathrm{~W}$ \\
\hline Carrier Gas & $0.6 \mathrm{~L} / \mathrm{min}$ \\
\hline Makeup Gas & $0.45 \mathrm{~L} / \mathrm{min}$ \\
\hline Nebulizer Pump & $0.1 \mathrm{rps}$ \\
\hline \multicolumn{2}{|c|}{ Octapole Reaction Cell } \\
\hline Helium & $4 \mathrm{~mL} / \mathrm{min}$ \\
\hline Hydrogen & $1.5 \mathrm{~mL} / \mathrm{min}$ \\
\hline Octapole Bias & $-6 \mathrm{~V}$ \\
\hline \multicolumn{2}{|l|}{ Detector Parameters } \\
\hline Discriminator & $8 \mathrm{mV}$ \\
\hline Analog HV & $1780 \mathrm{~V}$ \\
\hline Pulse HV & $1100 \mathrm{~V}$ \\
\hline \multicolumn{2}{|c|}{ Data Acquisition Parameters } \\
\hline Dwell time per mass & $0.30 \mathrm{sec}$ \\
\hline Replicate & $47-53055,56-590.601$. \\
\hline Monitored lons & $\begin{array}{l}{ }^{27} \mathrm{Al},{ }^{47} \mathrm{Ti},{ }^{53} \mathrm{Cr},{ }^{55} \mathrm{Mn},{ }^{56} \mathrm{Fe},{ }^{59} \mathrm{Co},{ }^{60} \mathrm{Ni}, \\
{ }^{63} \mathrm{Cu},{ }^{66} \mathrm{Zn},{ }^{75} \mathrm{As},{ }^{82} \mathrm{Se}, 89 \mathrm{Y}^{\mathrm{a}},{ }^{95} \mathrm{Mo}, \\
{ }^{115} \mathrm{In}^{\mathrm{a}},{ }^{206,207,208} \mathrm{~Pb},{ }^{209} \mathrm{Bi}^{\mathrm{a}}\end{array}$ \\
\hline
\end{tabular}

${ }^{\mathrm{a}}$ Internal standard 


\subsubsection{Procedure}

The hair samples $(n=88)$ were cut from the base of the neck with scissors, taped to a 3 in by 5 in index card, and sealed in a paper envelope. They were stored in the sealed envelope until analysis. A few of the samples were removed from the envelope and placed in a plastic Ziploc ${ }^{\circledR}$ bag and sealed. These samples were collected before any analytical methods had been identified; therefore, the collection methods and sample size was dictated and fixed.

The hair samples were cleaned with acetone and DI water according to the procedure developed by the IAEA [86]. The washed hair samples were then digested with an adapted method developed by Rao et al. [26]. Hair samples ranging from $0.0002-0.3970 \mathrm{~g}$ were weighed into a metal free centrifuge tube. A mixture of $2: 1 \mathrm{HNO}_{3} / \mathrm{H}_{2} \mathrm{O}_{2}$ was added to the tube followed by heating on a heating block at $140{ }^{\circ} \mathrm{C}$ for $10 \mathrm{~min}$. The resulting solution was then diluted accordingly by DI water. A detailed standard operation procedure can be found in Appendix D. According to Rao et al., digestion was completed between 120 ${ }^{\circ} \mathrm{C}$ and $200{ }^{\circ} \mathrm{C}$, therefore $150{ }^{\circ} \mathrm{C}$ was used. The temperature of $140{ }^{\circ} \mathrm{C}$ was used since that was the maximum allowable temperature for the heating block used. Moreover, the sample size was $1 \mathrm{~g}$ due to the ICP-AES used by Rao et al. In this study, since the hair sample size is limited, the reagent was reduced to one tenth of what the authors used. Due to the reduced quantity of both the sample and the reagent, the heating time was re-evaluated in this work.

Single standard solutions (Al, Ti, Cr, Mn, Fe, Co, Ni, Zn, Se, Mo, Cd, Se, and $\mathrm{Pb}$ ) at a concentration of $1000 \mathrm{ppm}$ or $10 \mathrm{ppm}$ was prepared in $2 \% \mathrm{HNO}_{3}$ 
from purchased standards. Then, a series of mixture standards (Table 4.2) was prepared in a sample digestion matrix. Internal standard $\mathrm{Y}$ is used for $\mathrm{Al}, \mathrm{Ti}, \mathrm{Cr}$, $\mathrm{Mn}, \mathrm{Fe}, \mathrm{Co}, \mathrm{Ni}, \mathrm{Zn}, \mathrm{As}$, Se, and Mo, while In is for $\mathrm{Cd}$, and $\mathrm{Bi}$ is for $\mathrm{Pb}$. The sample digestion matrix was prepared using the same procedure as the sample. Different calibration ranges were chosen for different elements because different concentrations were observed in hair samples. For every 20 samples prepared, an IAEA-086 sample and a volunteer's hair sample were prepared, as well as the sample digestion procedure blank. 
Table 4.2: Calibration standard concentration (all in ppb)

\begin{tabular}{lrrrrrr}
\hline Element & Level 1 & Level 2 & Level 3 & Level 4 & Level 5 & Level 6 \\
\hline Al & 0 & 1.00 & 10.00 & 100.00 & 250.00 & 500.00 \\
As & 0 & 0.01 & 0.10 & 1.00 & 2.50 & 5.00 \\
$\mathrm{Cd}$ & 0 & 0.01 & 0.10 & 1.00 & 2.50 & 5.00 \\
$\mathrm{Co}$ & 0 & 0.01 & 0.10 & 1.00 & 2.50 & 5.00 \\
$\mathrm{Cr}$ & 0 & 0.10 & 1.00 & 10.00 & 25.00 & 50.00 \\
$\mathrm{Fe}$ & 0 & 1.00 & 10.00 & 100.00 & 250.00 & 500.00 \\
$\mathrm{Mn}$ & 0 & 0.10 & 1.00 & 10.00 & 25.00 & 50.00 \\
$\mathrm{Mo}$ & 0 & 0.01 & 0.10 & 1.00 & 2.50 & 5.00 \\
$\mathrm{Ni}$ & 0 & 0.10 & 1.00 & 10.00 & 25.00 & 50.00 \\
$\mathrm{~Pb}$ & 0 & 0.10 & 1.00 & 10.00 & 25.00 & 50.00 \\
$\mathrm{Se}$ & 0 & 1.00 & 10.00 & 100.00 & 250.00 & 500.00 \\
$\mathrm{Ti}$ & 0 & 0.10 & 1.00 & 10.00 & 25.00 & 50.00 \\
$\mathrm{Zn}$ & 0 & 1.00 & 10.00 & 100.00 & 250.00 & 500.00 \\
\hline
\end{tabular}




\subsection{Results and Discussion}

For this project, matrix matching of the samples and standards was not possible; the only available hair reference is IAEA-086. Therefore, complete method validation using current accepted criteria is difficult. However, the goal of this work is to compare the two groups of samples (based on the presence or absence of cancer); therefore, as long as the analytical data is acceptably accurate and reproducible, the comparison can be completed with confidence. This situation is very much like that of the pottery analysis in that sense.

The replicates of reference material and volunteer's hair were evaluated and the results are summarized in Table 4.3. Mn and $\mathrm{Zn}$ offer a recovery close to $100 \%$ and $\%$ RSD of $3 \%$, which means the method is both accurate (gauged by recovery) and precise (gauged by \%RSD) for both elements. Fe has a recovery of $65 \%$ and $5 \% \mathrm{RSD}$, and Se has more than $100 \%$ recovery and a high \%RSD. The Fe seems always lower than the certified value and Se is always

high. ${ }^{56} \mathrm{Fe}$ suffers from the polyatomic interference from ${ }^{40} \mathrm{Ar}^{16} \mathrm{O}^{+} .{ }^{82} \mathrm{Se}$ suffers from interference from ${ }^{82} \mathrm{Kr}$ that maybe present in $\mathrm{Ar}$, which may cause the poor reproducibility. Although the collision cell was used to reduce the polyatomic interferences for $\mathrm{Fe}$, and interference equation was used for Se to correct for isotopic interference, the correction may not be adequate. However, since Fe has a low \%RSD (5\%), it is reproducible in this method, while Se is not $(61 \%)$. Therefore, Se should be used with caution in the comparison. Notice that the \%RSD obtained for IAEA-086 is considerably lower than most of that from the volunteer. This is probably because real samples are heterogeneous concentration [83]. 
Table 4.3: IAEA-086 and Volunteer control $(\mathrm{ppm}, \mathrm{n}=11)$

\begin{tabular}{lcccccc}
\hline & & \multicolumn{2}{c}{ IAEA-086 } & & \multicolumn{2}{c}{ Volunteer } \\
& Certified & Mean & RSD & Recovery & Mean & RSD \\
\hline $\mathrm{Al}$ & & 36.3 & $12 \%$ & & 11.5 & $12 \%$ \\
$\mathrm{Ti}$ & & 3.96 & $5 \%$ & & 2.20 & $11 \%$ \\
$\mathrm{Cr}$ & & 1.04 & $32 \%$ & & 0.72 & $103 \%$ \\
$\mathrm{Mn}$ & $9.6 \pm 0.7$ & 9.12 & $3 \%$ & $95 \%$ & 0.334 & $25 \%$ \\
$\mathrm{Fe}$ & $123 \pm 13$ & 79.7 & $5 \%$ & $65 \%$ & 13.4 & $28 \%$ \\
$\mathrm{Co}$ & & 0.0851 & $3 \%$ & & 0.0262 & $27 \%$ \\
$\mathrm{Ni}$ & & 1.12 & $24 \%$ & & 0.336 & $26 \%$ \\
$\mathrm{Zn}$ & $167 \pm 8$ & 155 & $3 \%$ & $93 \%$ & 197 & $2 \%$ \\
$\mathrm{As}$ & & 0.137 & $11 \%$ & & 0.0584 & $28 \%$ \\
$\mathrm{Se}$ & $1 \pm 0.2$ & 2.68 & $61 \%$ & $268 \%$ & 1.50 & $38 \%$ \\
$\mathrm{Mo}$ & & 0.0621 & $16 \%$ & & 0.0231 & $20 \%$ \\
$\mathrm{Cd}$ & & 0.1785 & $23 \%$ & & $\mathrm{~N} / \mathrm{A}$ & $\mathrm{N} / \mathrm{A}$ \\
$\mathrm{Pb}$ & & 9.79 & $3 \%$ & & 2.55 & $11 \%$ \\
\hline
\end{tabular}


Table 4.4: Correlation coefficient, LOD and LOQ of elements (ppb)

\begin{tabular}{lccc}
\hline & $r$ & LOD & LOQ \\
\hline $\mathrm{Al}$ & 0.9998 & 0.60 & 2.0 \\
$\mathrm{Ti}$ & 1.000 & 0.17 & 0.56 \\
$\mathrm{Cr}$ & 1.000 & 0.11 & 0.36 \\
$\mathrm{Mn}$ & 1.000 & 0.017 & 0.056 \\
$\mathrm{Fe}$ & 1.000 & 1.4 & 4.7 \\
$\mathrm{Co}$ & 1.000 & 0.0015 & 0.0051 \\
$\mathrm{Ni}$ & 1.000 & 0.019 & 0.063 \\
$\mathrm{Zn}$ & 0.9996 & 0.084 & 0.28 \\
$\mathrm{As}$ & 1.000 & 0.0058 & 0.019 \\
$\mathrm{Se}$ & 1.000 & 0.056 & 0.19 \\
$\mathrm{Mo}$ & 0.9999 & 0.0040 & 0.013 \\
$\mathrm{Cd}$ & 1.000 & 0.030 & 0.099 \\
$\mathrm{~Pb}$ & 1.000 & 0.0017 & 0.0057 \\
\hline
\end{tabular}


Table 4.4 summarizes the LOD and LOQ values for the 13 elements for study. LOD and LOQ values were calculated the same manner as described in Section 2.3.1. As mentioned earlier, the sampling size is rather small for most samples. Digestion time was re-evaluated due to the reduced sample size. Eighteen IAEA-086 samples were weighed and were digested at $140{ }^{\circ} \mathrm{C}$ for 10 min, $20 \mathrm{~min}$, and $30 \mathrm{~min}$, six each for different time. The results are shown in Table 4.5. For most of the elements, as digestion time increases, mean concentration increases and \%RSD decreases. Therefore, 30 min was chosen for the digestion of samples. 
Table 4.5: Digestion time study $(\mathrm{ppm}, \mathrm{n}=6)$

\begin{tabular}{lcccccc}
\hline & \multicolumn{2}{c}{10 min } & \multicolumn{2}{c}{20 min } & \multicolumn{2}{c}{30 min } \\
& Mean & $\% R S D$ & Mean & $\% R S D$ & Mean & $\% R S D$ \\
\hline $\mathrm{Al}$ & 32 & $6 \%$ & 37 & $9 \%$ & 41 & $10 \%$ \\
$\mathrm{Ti}$ & 4.3 & $8 \%$ & 4.1 & $5 \%$ & 4.4 & $6 \%$ \\
$\mathrm{Cr}$ & 1.1 & $23 \%$ & 1.3 & $33 \%$ & 1.3 & $12 \%$ \\
$\mathrm{Mn}$ & 9.7 & $5 \%$ & 9.6 & $3 \%$ & 9.8 & $2 \%$ \\
$\mathrm{Fe}$ & 87 & $8 \%$ & 91 & $6 \%$ & 94 & $6 \%$ \\
$\mathrm{Co}$ & 0.066 & $17 \%$ & 0.077 & $5 \%$ & 0.082 & $3 \%$ \\
$\mathrm{Ni}$ & 0.99 & $39 \%$ & 1.1 & $9 \%$ & 1.2 & $9 \%$ \\
$\mathrm{Zn}$ & 160 & $8 \%$ & 160 & $3 \%$ & 160 & $3 \%$ \\
$\mathrm{As}$ & 0.10 & $17 \%$ & 0.12 & $4 \%$ & 0.13 & $7 \%$ \\
$\mathrm{Se}$ & 3.8 & $39 \%$ & 2.9 & $7 \%$ & 2.9 & $20 \%$ \\
$\mathrm{Mo}$ & 0.078 & $10 \%$ & 0.080 & $6 \%$ & 0.083 & $7 \%$ \\
$\mathrm{Cd}$ & 0.51 & $52 \%$ & 0.30 & $12 \%$ & 0.30 & $34 \%$ \\
$\mathrm{~Pb}$ & 10. & $5 \%$ & 10 & $3 \%$ & 10. & $1 \%$ \\
\hline
\end{tabular}


Since the sample size varies, with some being as low as sub milligram, sample size test was performed by weighing different masses (ranging from 0.6 $\mathrm{mg}$ to $82.7 \mathrm{mg}$ ) and digesting the reference material using the same conditions. The results show that if the sample volume is too small $(<10 \mathrm{mg})$, most of the elements fall below LOQ and therefore unreliable concentrations will be generated. Table 4.6 shows the details of the study. The left two columns are mean and \%RSD calculated based on all the masses studied, and the right two columns are the mean and \%RSD calculated for the rest of the masses $(11.5 \mathrm{mg}$ and up) after removing the lowest mass $(0.6 \mathrm{mg})$. The \%RSD decreased dramatically after the remove. As mentioned earlier, more than one fourth samples are below $10 \mathrm{mg}$, this is a great challenge since the lowest sample size found in previous studies is at least $25 \mathrm{mg}$ [84]. 
Table 4.6: Sample size study (ppm)

\begin{tabular}{lcccc}
\hline & \multicolumn{2}{c}{ All masses } & \multicolumn{2}{c}{ Lowest mass excluded $^{* *}$} \\
& Mean & $\% R S D$ & Mean & \%RSD \\
\hline $\mathrm{Al}$ & 43.1 & $25 \%$ & 39.3 & $9 \%$ \\
$\mathrm{Ti}$ & 4.45 & $38 \%$ & 3.82 & $10 \%$ \\
$\mathrm{Cr}$ & 1.81 & $53 \%$ & 1.48 & $28 \%$ \\
$\mathrm{Mn}$ & 10.6 & $16 \%$ & 10.0 & $7 \%$ \\
$\mathrm{Fe}$ & 105 & $36 \%$ & 91.3 & $11 \%$ \\
$\mathrm{Co}$ & 0.0866 & $11 \%$ & 0.0887 & $10 \%$ \\
$\mathrm{Ni}$ & 1.08 & $14 \%$ & 1.14 & $7 \%$ \\
$\mathrm{Zn}$ & 182 & $20 \%$ & 168 & $5 \%$ \\
$\mathrm{As}$ & 0.120 & $48 \%$ & 0.140 & $17 \%$ \\
$\mathrm{Se}$ & 5.81 & $132 \%$ & 2.92 & $8 \%$ \\
$\mathrm{Mo}$ & 0.0622 & $45 \%$ & 0.0726 & $10 \%$ \\
$\mathrm{Cd}$ & 0.828 & $204 \%$ & 0.0679 & $100 \%$ \\
$\mathrm{~Pb}$ & 10.9 & $24 \%$ & 9.96 & $12 \%$ \\
\hline $\mathrm{All}$ & & & &
\end{tabular}

${ }^{*}$ All masses studied.

${ }^{*}$ Lowest mass $(0.6 \mathrm{mg})$ was excluded in the mean and \%RSD calculation. 
As expected, some elements of certain samples fall below the LOQ. However, for comparison purposes, these values were retained for this discussion. The value below zero due to blank correction was assigned to zero. The results were plotted into mean plots shown in Figures 4.1 and 4.2. Figure 4.1 shows the mean difference of elements between mining and control area, while Figure 4.2 shows the mean difference between cancer and non-cancer cases. The mean concentrations can be found in Table 4.7.

$\mathrm{Al}, \mathrm{Zn}, \mathrm{As}$, Se, and Mo in mining area have higher mean concentration than that of the control area. $\mathrm{Zn,} \mathrm{Ni}$, and $\mathrm{Se}$ are higher in cancer cases than non -cancer ones. By comparing Figures 4.1 and 4.2, a similar pattern was found between the two compared categories. The enrichment of these elements requires attention in the public health study.

From Table 4.7, it is interesting to notice that mean concentration of $\mathrm{Cr}$ in control area is almost 20 times higher than that in the mining area. Similarly, $\mathrm{Cr}$ in non-cancer population is also significantly higher than cancer population. $\mathrm{Mn}$ and Fe show the same trend based on the mean concentration. The depletion of these essential elements could be a health concern for the population in the mining area. 
Figure 4.1: Mean plot of normalized mean of mining area vs. control area.

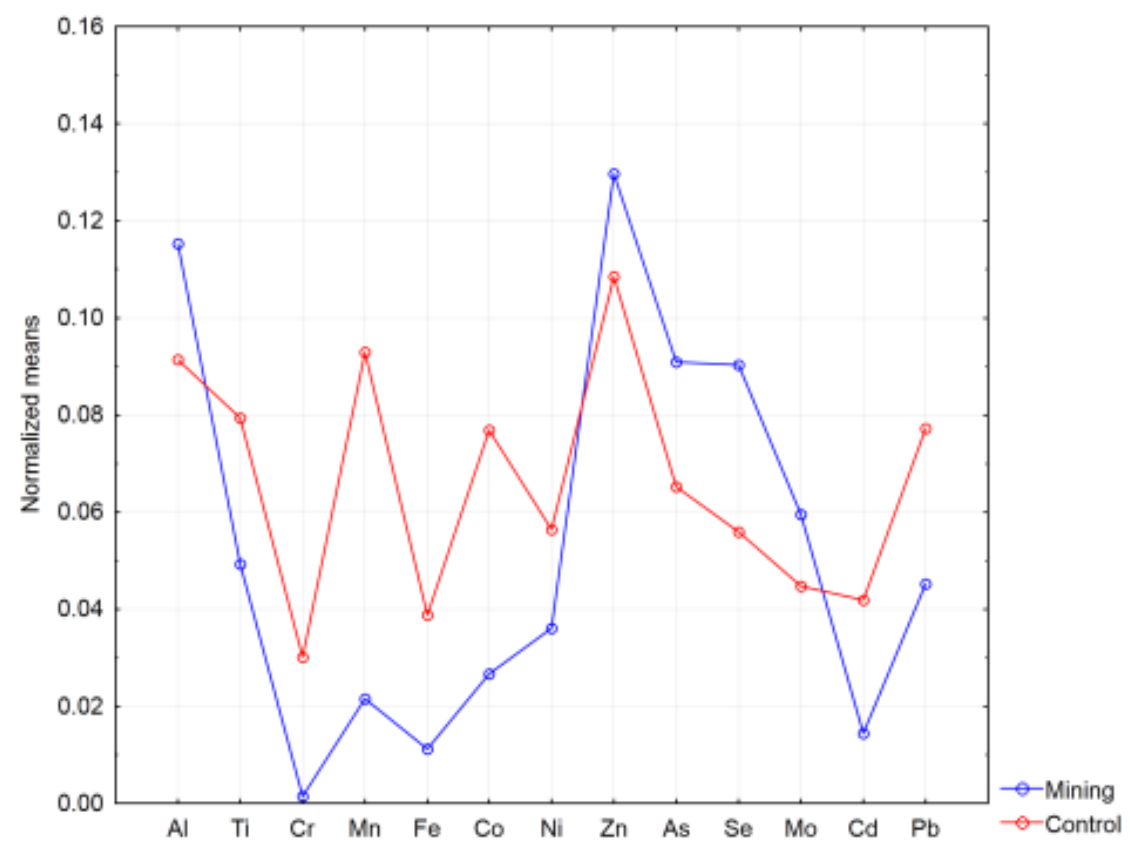

Figure 4.2: Mean plot of normalized mean of cancer cases vs. non-cancer cases.

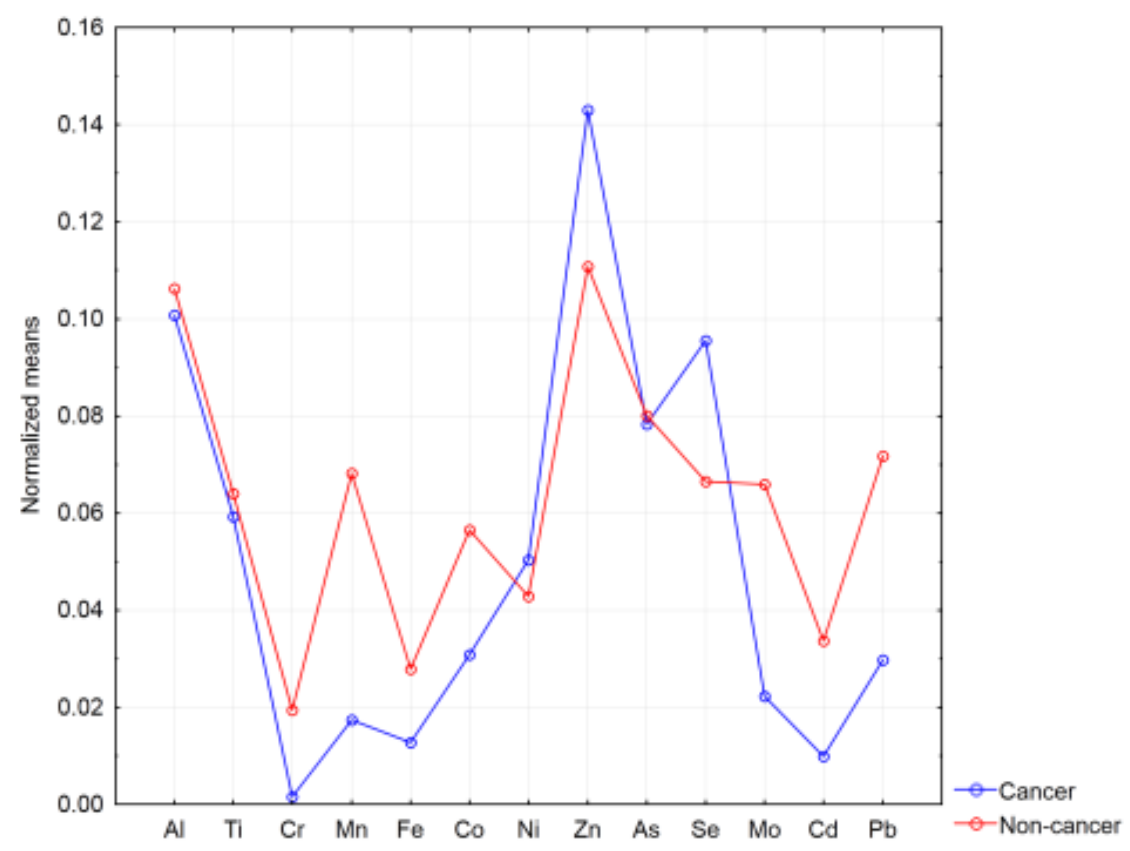


Table 4.7: Mean concentration of different groups (ppm)

\begin{tabular}{rccccccccccccc}
\hline & $\mathrm{Al}$ & $\mathrm{Ti}$ & $\mathrm{Cr}$ & $\mathrm{Mn}$ & $\mathrm{Fe}$ & $\mathrm{Co}$ & $\mathrm{Ni}$ & $\mathrm{Zn}$ & $\mathrm{As}$ & $\mathrm{Se}$ & $\mathrm{Mo}$ & $\mathrm{Cd}$ & $\mathrm{Pb}$ \\
\hline Mining & 5.74 & 2.55 & 0.0499 & 0.335 & 4.51 & 0.0133 & 0.297 & 210 & 0.0350 & 2.27 & 0.0207 & 0.0728 & 0.408 \\
Control & 4.55 & 3.68 & 1.00 & 1.44 & 15.6 & 0.0385 & 0.465 & 176 & 0.0251 & 1.41 & 0.0156 & 0.211 & 0.697 \\
& & & & & & & & & & & & & \\
$\begin{array}{r}\text { Cancer } \\
\begin{array}{r}\text { Non- } \\
\text { cancer }\end{array}\end{array}$ & 5.02 & 2.93 & 0.0531 & 0.270 & 5.14 & 0.0154 & 0.415 & 232 & 0.0302 & 2.40 & 0.00774 & 0.0497 & 0.269 \\
\hline
\end{tabular}


Although a difference can be observed in the mean concentration, there is a large variation within group associated with the difference of mean concentrations between groups, making the unambiguous separation difficult. The variance could because of the gender, smoking status or other interferences mentioned earlier. Therefore, more samples from the survey are needed in order to make a meaningful comparison. Nonetheless, this work established the analytical method for the determination of elements in hair.

\subsection{Conclusion}

The primary innovation of this project was the development of a method to work with microsamples of hair for elemental characterization. The results showed a large variation within groups of mining and control areas. This is probably due to the sample size. Also, the samples analyzed are only part of the complete survey. Therefore, it is difficult to draw a conclusion for the comparison. However, since the method is established, more samples can be analyzed in the future. Meaningful comparison may be accomplished if more data is obtained. And if more hair samples can be collected from individuals, it is possible to perform replicates of analysis on each sample. The comparison will be more accurate. 


\section{Summary}

ICP-MS as a powerful instrument in trace elemental analysis has been explored in archaeological, forensic, and health studies. The application of ICPMS has been explored in these areas based on the reference materials and the use of multivariate statistical methods. For different sample matrices, corresponding sample digestion methods were evaluated. The simple acid digestion method used in pottery samples provided an alternative to the other complicated sample digestion methods and eventually offered comparable results to NAA. Although the concentration obtained is not comparable to bulk analysis, the results with good precision can serve as discrimination tool. Statistical tools bivariate plot, PCA, and cluster analysis were applied to the resulting dataset and similar groups were revealed compared to previous study.

Both the concentrations of $\mathrm{Sb}, \mathrm{Ba}$, and $\mathrm{Pb}$ and the pattern of distribution allowed the differentiation between shooters from non-shooters. The addition of lead isotope ratio analysis provided a possible differentiation between brands of ammunitions. Although quadrupole analyzer is not ideal for the isotope analysis purpose, a reasonable precise and accurate result can be obtained through optimized parameters.

The size of the sample became the main hindrance for the hair analysis. However, precise results were obtained if enough samples are available. The method developed here can be used in the future for more samples and meaningful comparison may be able to accomplish. 


\section{Future Work}

In the future, more pottery samples and clay or ash samples can be analyzed using the method developed here. When a larger database is generated, multivariate statistical methods discussed in the text can be used to reveal the relationship between clays, ashes and pottery. When it is possible, the clay and ashes can be mixed and fired to mimic the pottery making process and the products can be analyzed accordingly. This probably will generate more comparable matrix to the pottery and facilitate the provenience.

For the GSR project, non-shooters from different occupations can be explored in order to create a database for the non-shooters' profile. Other ammunitions can be analyzed based on the isotope method. The method then can be combined with the organic GSR study and standard procedure for casework can be generated after full method validation.

More hair samples are needed in the hair project to make a comparison between the mining area and the control area. However, this project forms groundwork that can be applied to more samples in this study. 


\section{References}

1. Hasenaka, T.; Carmichael, I. S. E., The Cinder Cones of Michoacan Guanajuato, Central Mexico - Petrology and Chemistry. J. Petrol. 1987, 28 (2), 241-269.

2. Pollard, H., Tariácuri's Legacy: The Prehispanic Tarascan State. . University of Oklahoma Press: Norman, OK, 1993.

3. Hirshman, A. J. A Case Study in the Relationship between Social Complexity and the Organization of Ceramic Production from the Lake Patzcuraro Basin, Michoacan, Mexico. Michigan State University, East Lansing, MI, 2003.

4. Hirshman, A. J.; Ferguson, J. R., Temper Mixture Models and Assessing Ceramic Complexity in the Emerging Tarascan State. J. Archaeol. Sci. 2012.

5. Rice, P. M., Pottery Analysis: A Sourcebook. The University of Chicago Press: Chicago, USA, 1987; p 584.

6. Heron, C., Archaeological Science as Forensic Science. In Studies in Crime: An Introduction to Forensic Archaeology, Hunter, J., Ed.

Routledge: New York, NY, 1997; pp 156-168.

7. Glascock, M. D., Characterization of Archaeological Ceramics at Murr by Neutron Activation Ananlysis and Multivariate Statistics. In Chemical Characterization of Ceramic Pastes in Archaeology, Neff, H., Ed. Prehistory Press: Madison, Wis., 1992; pp 11-26.

8. Bishop, R. L.; Canouts, V.; Crown, P. L.; Deatley, S. P., Sensitivity, Precision, and Accuracy - Their Roles in Ceramic Compositional DataBases. Amer Antiq 1990, 55 (3), 537-546.

9. Emeleus, V. M., The Technique of Neutron-Activation Analysis as Applied to Trace-Element Deteremination in Pottery and Coins. Archaeometry 1958, 1 (6).

10. Tsolakidou, A.; Kilikoglou, V., Comparative Analysis of Ancient Ceramics by Neutron Activation Analysis, Inductively Coupled Plasma-OpticalEmission Spectrometry, Inductively Coupled Plasma-Mass Spectrometry, and X-Ray Fluorescence. Anal. Bioanal. Chem. 2002, 374 (3), 566-572.

11. Hirshman, A. J., Tarascan Ceramic Production and Implications for Ceramic Distribution. Ancient Mesoamer 2008, 19 (2), 299-310.

12. Meloni, S.; Oddone, M.; Genova, N.; Cairo, A., The Production of Ceramic Materials in Roman Pavia: An Archaeometric Naa Investigation of Clay Sources and Archaeological Artifacts. J. Radioanal. Nucl. Chem. 2000, 244 (3), 553-558.

13. Munita, C. S., Provenance Study of Archaeological Ceramic. Journal of Trace \& Microprobe Techniques 2003, 21 (4), 697-706.

14. Little, N. C.; Kosakowsky, L. J.; Speakman, R. J.; Glascock, M. D.; Lohse, J. C., Characterization of Maya Pottery by Inaa and Icp-Ms. J. Radioanal. Nucl. Chem. 2004, 262 (1), 103-110.

15. Kennett, D. J.; Sakai, S.; Neff, H.; Gossett, R.; Larson, D. O., Compositional Characterization of Prehistoric Ceramics: A New Approach. J. Archaeol. Sci. 2002, 29 (5), 443-455. 
16. Mallory-Greenough, L. M.; Greenough, J. D.; Owen, J. V., New Data for Old Pots: Trace-Element Characterization of Ancient Egyptian Pottery Using Icp-Ms. J. Archaeol. Sci. 1998, 25 (1), 85-97.

17. Navarro, M. S.; Andrade, S.; Ulbrich, H.; Gomes, C. B.; Girardi, V. A. V., The Direct Determination of Rare Earth Elements in Basaltic and Related Rocks Using Icp-Ms: Testing the Efficiency of Microwave Oven Sample Decomposition Procedures. Geostandards and Geoanalytical Research 2008, 32 (2), 167-180.

18. FBI, Uniform Crime Reports. Justice, D. o., Ed. 2010.

19. Dalby, O.; Butler, D.; Birkett, J. W., Analysis of Gunshot Residue and Associated Materials-a Review. J. Forensic Sci. 2010, 55 (4), 924-943.

20. Romolo, F. S.; Margot, P., Identification of Gunshot Residue: A Critical Review. Forensic Sci. Int. 2001, 119 (2), 195-211.

21. Basu, S., Formation of Gunshot Residues. J. Forensic Sci. 1982, 27 (1), 72-91.

22. Schwoeble, A. J.; Exline, D. L., Current Methods in Forensic Gunshot Residue Analysis. CRC Press LLC: Boca Raton, Florida, 2000.

23. Zeichner, A., Recent Developments in Methods of Chemical Analysis in Investigations of Firearm-Related Events. Anal. Bioanal. Chem. 2003, 376 (8), 1178-1191.

24. Kempson, I. M.; Lombi, E., Hair Analysis as a Biomonitor for Toxicology, Disease and Health Status. Chem. Soc. Rev. 2011, 40 (7), 3915-3940.

25. Park, H.-S.; Shin, K.-O.; Kim, J.-S., Assessment of Reference Values for Hair Minerals of Korean Preschool Children. Biol. Trace Elem. Res. 2007, 116 (2), 119-130.

26. Rao, K. S.; Balaji, T.; Rao, T. P.; Babu, Y.; Naidu, G. R. K., Determination of Iron, Cobalt, Nickel, Manganese, Zinc, Copper, Cadmium and Lead in Human Hair by Inductively Coupled Plasma-Atomic Emission Spectrometry. Spectrochimica Acta Part B-Atomic Spectroscopy 2002, 57 (8), 1333-1338.

27. Afridi, H. I.; Kazi, T. G.; Kazi, G. H.; Jamali, M. K.; Shar, G. Q., Essential Trace and Toxic Element Distribution in the Scalp Hair of Pakistani Myocardial Infarction Patients and Controls. Biol. Trace Elem. Res. 2006, 113 (1), 19-34.

28. Batzevich, V. A., Hair Trace-Element Analysis in Human-Ecology Studies. Sci. Total Environ. 1995, 164 (2), 89-98.

29. Bencko, V., Use of Human Hair as a Biomarker in the Assessment of Exposure to Pollutants in Occupational and Environmental Settings. Toxicology 1995, 101 (1-2), 29-39.

30. Ahern, M. M.; Hendryx, M.; Conley, J.; Fedorko, E.; Ducatman, A.; Zullig, K. J., The Association between Mountaintop Mining and Birth Defects among Live Births in Central Appalachia, 1996-2003. Environ. Res. 2011, 111 (6), 838-846.

31. Hendryx, M. W., L.; Luo, J.; Webb, B., Self-Reported Cancer Rates in Two Rural Areas of West Virginia with and without Mountaintop Coal Mining. J. Community Health 2011. 
32. Houk, R. S.; Fassel, V. A.; Flesch, G. D.; Svec, H. J.; Gray, A. L.; Taylor, C. E., Inductively Coupled Argon Plasma as an lon-Source for MassSpectrometric Determination of Trace-Elements. Anal. Chem. 1980, 52 (14), 2283-2289.

33. Falkner, K. K.; Klinkhammer, G. P.; Ungerer, C. A.; Christie, D. M., Inductively-Coupled Plasma-Mass Spectrometry in Geochemistry. Annual Review of Earth and Planetary Sciences 1995, 23, 409-449.

34. Riddle, C.; Vandervoet, A.; Doherty, W., Rock Analysis Using Inductively Coupled Plasma Mass-Spectrometry - a Review. Geostandards Newsletter 1988, 12 (1), 203-234.

35. Gilbert, E. N.; Shabanova, L. N., The Modern Multielements Methods for Analysis of the Environmental-Samples. Sibirskii Khimicheskii Zhurnal 1992, (3), 5-14.

36. Huang, J. Q.; Hu, X.; Zhang, J. R.; Li, K. X.; Yan, Y.; Xu, X. B., The Application of Inductively Coupled Plasma Mass Spectrometry in Pharmaceutical and Biomedical Analysis. J. Pharm. Biomed. Anal. 2006, 40 (2), 227-234.

37. Linge, K. L.; Jarvis, K. E., Quadrupole Icp-Ms: Introduction to Instrumentation, Measurement Techniques and Analytical Capabilities. Geostandards and Geoanalytical Research 2009, 33 (4), 445-467.

38. Koppenaal, D. W.; Eiden, G. C.; Barinaga, C. J., Collision and Reaction Cells in Atomic Mass Spectrometry: Development, Status, and Applications. J. Anal. At. Spectrom. 2004, 19 (5), 561-570.

39. Neff, H., Analysis of Mesoamerican Plumbate Pottery Surfaces by Laser Ablation-Inductively Coupled Plasma-Mass Spectrometry (La-Icp-Ms). J. Archaeol. Sci. 2003, 30 (1), 21-35.

40. Cochrane, E. E.; Neff, H., Investigating Compositional Diversity among Fijian Ceramics with Laser Ablation-Inductively Coupled Plasma-Mass Spectrometry (La-Icp-Ms): Implications for Interaction Studies on Geologically Similar Islands. J. Archaeol. Sci. 2006, 33 (3), 378-390.

41. Li, B. P.; Zhao, J. X.; Collerson, K. D.; Greig, A., Application of Icp-Ms Trace Element Analysis in Study of Ancient Chinese Ceramics. Chin. Sci. Bull. 2003, 48 (12), 1219-1224.

42. Kennett, D. J.; Anderson, A. J.; Cruz, M. J.; Clark, G. R.; Summerhayes, G. R., Geochemical Characterization of Lapita Pottery Via Inductively Coupled Plasma-Mass Spectrometry (Icp-Ms). Archaeometry 2004, 46, 35-46.

43. Klein, M.; Jesse, F.; Kasper, H. U.; Golden, A., Chemical Characterization of Ancient Pottery from Sudan by X-Ray Fluorescence Spectrometry (Xrf), Electron Microprobe Analyses (Empa) and Inductively Coupled Plasma Mass Spectrometry (Icp-Ms). Archaeometry 2004, 46, 339-356.

44. Marengo, E.; Aceto, M.; Robotti, E.; Liparota, M. C.; Bobba, M.; Panto, G., Archaeometric Characterisation of Ancient Pottery Belonging to the Archaeological Site of Novalesa Abbey (Piedmont, Italy) by Icp-Ms and Spectroscopic Techniques Coupled to Multivariate Statistical Tools. Anal. Chim. Acta 2005, 537 (1-2), 359-375. 
45. Longerich, H. P.; Jenner, G. A.; Fryer, B. J.; Jackson, S. E., Inductively Coupled Plasma-Mass Spectrometric Analysis of Geological Samples - a Critical-Evaluation Based on Case-Studies. Chem. Geol. 1990, 83 (1-2), 105-118.

46. Burton, J. H.; Simon, A. W., Acid-Extraction as a Simple and Inexpensive Method for Compositional Characterization of Archaeological Ceramics. Amer Antiq 1993, 58 (1), 45-59.

47. Burton, J. H.; Simon, A. W., A Pot Is Not a Rock: A Reply to Neff, Glascock, Bishop, and Blackman. Amer Antiq 1996, 61 (2), 405-413.

48. Pillay, A.; Punyadeera, C., A Sudy, by Fire-Assay and Icp-Ms, of the Distribution of Rhodium, Platinum, and Gold in Iron-Age Pottery. Journal of Trace \& Microprobe Techniques 2001, 19 (2), 243.

49. De Muynck, D.; Cloquet, C.; Vanhaecke, F., Development of a New Method for Pb Isotopic Analysis of Archaeological Artefacts Using SingleCollector Icp-Dynamic Reaction Cell-Ms. J. Anal. At. Spectrom. 2008, 23 (1), 62-71.

50. Cook, D. E.; Kovacevich, B.; Beach, T.; Bishop, R., Deciphering the Inorganic Chemical Record of Ancient Human Activity Using Icp-Ms: A Reconnaissance Study of Late Classic Soil Floors at Cancuen, Guatemala. J. Archaeol. Sci. 2006, 33 (5), 628-640.

51. Arnold, D. E.; Neff, H.; Glascock, M. D.; Speakman, R. J., Sourcing the Palygorskite Used in Maya Blue: A Pilot Study Comparing the Results of Inaa and La-Icp-Ms. Latin Amer Antiq 2007, 18 (1), 44-58.

52. Giussani, B.; Monticelli, D.; Rampazzi, L., Role of Laser AblationInductively Coupled Plasma-Mass Spectrometry in Cultural Heritage Research: A Review. Anal. Chim. Acta 2009, 635 (1), 6-21.

53. EPA, Method 3050b Acid Digestion of Sediments, Sludges, and Soils. In 3000 Series Methods, United States Environmental Protection Agency: Washington, D.C., 1996.

54. Neff, H.; Glascock, M. D.; Bishop, R. L.; Blackman, M. J., An Assessment of the Acid-Extraction Approach to Compositional Characterization of Archaeological Ceramics. Amer Antiq 1996, 61 (2), 389-404.

55. Miller, J. N.; Miller, J. C., Statistics and Chemometrics for Analytical Chemistry. Pearson Education Limited: Harlow, England, 2005; p 268.

56. Otto, M., Chemometrics: Statistics and Computer Application in Analytical Chemistry. second ed.; WILEY-VCH Verlag GmbH \& Co. KGaA: Weinheim, 2007; p 328.

57. Giacomino, A.; Abollino, O.; Malandrino, M.; Mentasti, E., The Role of Chemometrics in Single and Sequential Extraction Assays: A Review. Part li. Cluster Analysis, Multiple Linear Regression, Mixture Resolution, Experimental Design and Other Techniques. Anal. Chim. Acta 2011, 688 (2), 122-139.

58. Baxter, M. J., A Review of Supervised and Unsupervised Pattern Recognition in Archaeometry. Archaeometry 2006, 48, 671-694. 
59. Michelaki, K.; Hancock, R. G. V., Chemistry Versus Data Dispersion: Is There a Better Way to Assess and Interpret Archaeometric Data? Archaeometry 2011, 53, 1259-1279.

60. Reis, E. L. T.; Sarkis, J. E. D.; Rodrigues, C.; Neto, O. N.; Viebig, S., Identification of Gunshot Residues by High Resolution Inductively Coupled Plasma Mass Spectrometry. Quim. Nova 2004, 27 (3), 409-413.

61. Steffen, S.; Otto, M.; Niewoehner, L.; Barth, M.; Brozek-Mucha, Z.; Blegstraaten, J.; Horvath, R., Chemometric Classification of Gunshot Residues Based on Energy Dispersive X-Ray Microanalysis and Inductively Coupled Plasma Analysis with Mass-Spectrometric Detection. Spectrochimica Acta Part B-Atomic Spectroscopy 2007, 62 (9), 10281036.

62. Mejia, R., Why We Cannot Rely on Firearm Forensics. New Sci. 23 November 2005, 2005.

63. Koons, R. D.; Havekost, D. G.; Peters, C. A., Analysis of Gunshot Primer Residue Collection Swabs Using Flameless Atomic-Absorption Spectrophotometry - a Reexamination of Extraction and Instrument Procedures. J. Forensic Sci. 1987, 32 (4), 846-865.

64. Koons, R. D.; Havekost, D. G.; Peters, C. A., Determination of Barium in Gunshot Residue Collection Swabs Using Inductively Coupled PlasmaAtomic Emission-Spectrometry. J. Forensic Sci. 1988, 33 (1), 35-41.

65. Koons, R. D., Analysis of Gunshot Primer Residue Collection Swabs by Inductively Coupled Plasma-Mass Spectrometry. J. Forensic Sci. 1998, 43 (4), 748-754.

66. Zeichner, A.; Ehrlich, S.; Shoshani, E.; Halicz, L., Application of Lead Isotope Analysis in Shooting Incident Investigations. Forensic Sci. Int. 2006, 158 (1), 52-64.

67. Wunnapuk, K.; Minami, T.; Durongkadech, P.; Tohno, S.; Ruangyuttikarn, W.; Moriwake, Y.; Vichairat, K.; Sribanditmongkol, P.; Tohno, Y., Discrimination of Bullet Types Using Analysis of Lead Isotopes Deposited in Gunshot Entry Wounds. Biol. Trace Elem. Res. 2009, 129 (1-3), 278289.

68. Udey, R. N.; Hunter, B. C.; Smith, R. W., Differentiation of Bullet Type Based on the Analysis of Gunshot Residue Using Inductively Coupled Plasma Mass Spectrometry. J. Forensic Sci. 2011, 56 (5), 1268-1276.

69. Santos, A.; Magalhaes, T.; Vieira, D. N.; Almeida, A. A.; Sousa, A. V., Firing Distance Estimation through the Analysis of the Gunshot Residue Deposit Pattern around the Bullet Entrance Hole by Inductively Coupled Plasma-Mass Spectrometry - an Experimental Study. Am. J. Forensic Med. Pathol. 2007, 28 (1), 24-30.

70. Sarkis, J. E. S.; Neto, O. N.; Viebig, S.; Durrant, S. F., Measurements of Gunshot Residues by Sector Field Inductively Coupled Plasma Mass Spectrometry - Further Studies with Pistols. Forensic Sci. Int. 2007, 172 (1), 63-66.

71. Yanez, J.; Farias, M. P.; Zuniga, V.; Soto, C.; Contreras, D.; Pereira, E.; Mansilla, H. D.; Saavedra, R.; Castillo, R.; Saez, P., Differentiation of Two 
Main Ammunition Brands in Chile by Regularized Discriminant Analysis (Rda) of Metals in Gunshot Residues. Microchem. J. 2012, 101, 43-48.

72. Abrego, Z.; Ugarte, A.; Unceta, N.; Fernandez-Isla, A.; Aranzazu Goicolea, M.; Barrio, R. J., Unambiguous Characterization of Gunshot Residue Particles Using Scanning Laser Ablation and Inductively Coupled Plasma-Mass Spectrometry. Anal. Chem. 2012, 84 (5), 2402-2409.

73. Russell, R.; Farquhar, R., Lead Isotope in Geology. Interscience: New York, 1960.

74. Keisch, B.; Callahan, R. C., Lead Isotope Ratios in Artists Lead White Progress Report. Archaeometry 1976, 18 (JUL), 181-193.

75. Keisch, B.; Callahan, R. C., Potential Uses of Lead Isotope Ratios in Gunshot Cases. Journal of the Association of Official Analytical Chemists 1978, 61 (3), 520-525.

76. Andrasko, J.; Kopp, I.; Abrink, A.; Skiold, T., Lead-Isotope Ratios in Lead Smears and Bullet Fragments and Application in Firearm Investigations. J. Forensic Sci. 1993, 38 (5), 1161-1171.

77. Dufosse, T.; Touron, P., Comparison of Bullet Alloys by Chemical Analysis: Use of Icp-Ms Method. Forensic Sci. Int. 1998, 91 (3), 197-206.

78. Reis, E. L. T.; Sarkis, J. E. S.; Neto, O. N.; Rodrigues, C.; Kakazu, M. H.; Viebig, S., A New Method for Collection and Identification of Gunshot Residues from the Hands of Shooters. J. Forensic Sci. 2003, 48 (6), 12691274.

79. Havakost, D. G.; Peters, C. A.; Koons, R. D., Barium and Antimony Distributions on the Hands of Nonshooters. J. Forensic Sci. 1990, 35 (5), 1096-114.

80. Rodriguez-Salazar, M. T.; Bermea, O. M.; Hernandez-Alvarez, E.; GarciaArreola, M. E.; Ortuno-Arzate, M. T., Development and Validation of an Analytical Method for the Determination of Lead Isotopic Composition Using Icp-Qms. Geofis. Int. 2010, 49 (3), 113-117.

81. Boffetta, P.; Nyberg, F., Contribution of Environmental Factors to Cancer Risk. Br. Med. Bull. 2003, 68, 71-94.

82. Il'yasova, D.; Schwartz, G. G., Cadmium and Renal Cancer. Toxicol. Appl. Pharmacol. 2005, 207 (2), 179-186.

83. Rodushkin, I.; Axelsson, M. D., Application of Double Focusing Sector Field Icp-Ms for Multielemental Characterization of Human Hair and Nails. Part I. Analytical Methodology. Sci. Total Environ. 2000, 250 (1-3), 83-100.

84. Goulle, J. P.; Mahieu, L.; Castermant, J.; Neveu, N.; Bonneau, L.; Laine, G.; Bouige, D.; Lacroix, C., Metal and Metalloid Multi-Elementary Icp-Ms Validation in Whole Blood, Plasma, Urine and Hair - Reference Values. Forensic Sci. Int. 2005, 153 (1), 39-44.

85. Assarian, G. S.; Oberleas, D., Effect of Washing Procedures on TraceElement Content of Hair. Clin. Chem. 1977, 23 (9), 1771-1772.

86. Toro, E. C.; Degoeij, J. J. M.; Bacso, J.; Cheng, Y. D.; Kinova, L.; Matsubara, J.; Niese, S.; Sato, T.; Wesenberg, G. R.; Muramatsu, Y.; Parr, R. M., The Significance of Hair Mineral Analysis as a Means for Assessing Internal Body Burdens of Environmental-Pollutants - Results 
from an laea Coordinated Research-Program. Journal of Radioanalytical and Nuclear Chemistry-Articles 1993, 167 (2), 413-421. 